Ramom Rachide Nunes

\title{
DINÂMICA DE HERBICIDAS SULFONILUREIA NO AMBIENTE
}

\begin{abstract}
Dissertação apresentada ao Instituto de Química de São Carlos, da Universidade de São Paulo para obtenção de título de mestre em Ciências (Química Analítica e Inorgânica)
\end{abstract}

Área de Concentração: Química Analítica

Orientadora: Profa. Dra. Maria Olímpia de Oliveira Rezende

São Carlos

2012 


\section{Exemplar Revisado}

O exemplar original encontra-se em acervo registrado na Biblioteca do IQSC-USP

Ficha Catalográfica elaborada pela Seção de Referência e Atendimento ao Usuário do SBI/IQSC

Nunes, Ramom Rachide

Dinâmica de herbicidas sulfonilureia no ambiente. / Ramom Rachide Nunes. -- São Carlos, 2012. $158 \mathrm{p}$.

Dissertação (Mestrado) - Instituto de Química de São Carlos / Universidade de São Paulo, 2012.

Edição revisada

Orientadora: Profa. Dra. Maria Olímpia de Oliveira Rezende

1. Dinâmica de herbicidas. 2. Sulfonilureias. 3. Etilclorimuron. I Título. 


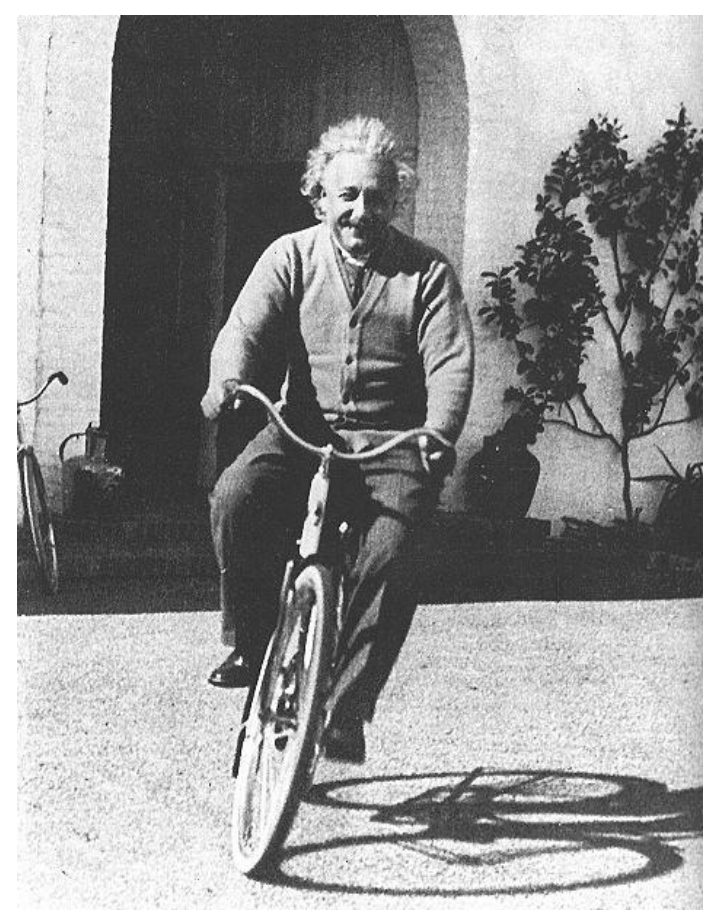

A vida é como andar de bicicleta. Para manter seu equilíbrio você deve continuar em movimento

Albert Einsten 


\section{AGRADECIMENTOS}

À Deus, pelas bênçãos e graças recebidas durante todos os dias de meu mestrado.

Aos meus pais: João e Leide, por serem os meus exemplos, meu incentivo e motivo de muito orgulho. Mais que um agradecimento, esta dissertação é a concretização de um sonho, meu e de vocês, fruto da educação e valores que recebo e recebi. Minha eterna gratidão.

Aos meus irmãos: Rôney e Renata, pela amizade e incentivo.

Aos meus demais familiares pelo carinho e zelo, sempre acreditando na concretização de meus objetivos.

À minha orientadora: Marió, pela orientação e amizade, sua presença e atenção dentro e fora do laboratório.

Aos amigos e colegas de trabalho do LQA: em especial a Lívia, Leandro, Dani, Fernanda e Tulio pelo companheirismo e paciência.

Aos técnicos e funcionários do IQSC, em especial a Verô, Andréia, Silvia, Gustavo e André, pela competência e qualidade de seus serviços prestados.

À querida Divininha, pelo amor e simplicidade que tanto contribuiu para o desenvolvimento deste trabalho.

Aos meus amigos: Alysson, Fran, Yvan, Dani, Virgínia, Kaka, Rodrigo, entre outros, que fizeram o fardo do mestrado mais leve. Meu obrigado pelos dias felizes e momentos especiais.

À Universidade de São Paulo e ao Instituto de Química de São Carlos, pela estrutura, oportunidades e experiências aqui vividas.

Aos professores pelo conhecimento adquirido e construído ao longo deste curso.

À CAPES, pela concessão da bolsa e auxílios financeiros.

A todos aqueles que diretamente ou indiretamente contribuíram para a realização deste trabalho

Dedicado à glória de Deus e ao progresso humano 


\section{RESUMO}

No limiar do ano de 2012 a população humana chegou a 7 bilhões de pessoas. Há apenas 12 anos atrás, 6 bilhões de seres humanos habitavam nosso planeta. 0 crescente e acentuado aumento da população tem exigido um uso exacerbado de bens naturais, principalmente do recurso solo, principal via para produção de alimentos. Para aumentar a produção de alimentos, sem aumentar a área cultivada, frequentemente faz-se o uso de pesticidas. Hoje, os herbicidas são os pesticidas mais comercializados, correspondendo à metade do mercado. Dentre seus grupos químicos mais comuns, há um destaque para as sulfonilureias, segunda classe de herbicida mais consumida em todo o mundo, contudo pouco investigada no âmbito da química analítica e ambiental. Uma vez no ambiente, o princípio ativo das sulfonilureias pode se tornar um risco para todo o ecossistema. Nos sedimentos, a sorção dos herbicidas determina quanto destes ficarão retidos na matriz e quanto estará disponível na solução do solo, contaminando os recursos hídricos. Neste sentido, o presente trabalho teve como objetivo realizar estudos que visam a determinar a dinâmica do herbicida etilclorimuron (exemplar da família das sulfonilureias) no ambiente. Estes estudos foram realizados via cinética e isotermas de adsorção em sedimentos. Compararam-se sedimentos com diferentes características em função do uso dado à terra (amostras Zona Agrícola, Zona Pecuária e Estação Ecológica). Para as três amostras, o modelo cinético obtido foi de pseudosegunda-ordem. A amostra Zona Pecuária foi a que apresentou maior retenção $\left(37,97.10^{2}\right.$ ug $\mathrm{kg}^{-1}$ ), logo uma dinâmica mais lenta. As demais amostras não apresentaram diferenças significativas para o processo sortivo (retenção de $29,07.10^{2}$ e $31,67.10^{2}$ ug $\mathrm{kg}^{-1}$ para as amostras Zona Agrícola e Estação Ecológica). Todos os sedimentos adsorveram de acordo com o modelo de Freundlich e suas isotermas foram classificadas como sendo do tipo C. A adsorção ocorreu com a formação de multicamadas e interações de natureza física (fisiossorção). O herbicida foi determinado via HPLC-UV. O método analítico foi validado de acordo com os documentos do INMETRO e da ANVISA e quando cabível de valores orientativos, os resultados obtidos se encontram em concordância. 


\section{ABSTRACT}

On the threshold of 2012 the human population reached 7 billion of people. Only 12 years ago, 6 billion of human beings inhabited our planet. The growing and accentuated increase of the population has required an overuse of natural resources, especially the soil, main via for food production. Intending to increase the food production, without increasing the area under cultivation, pesticides are often used as an alternative. Nowadays herbicides are the pesticides most commonly traded, corresponding to a half of its market. Among the most common chemical groups, sulphonylureas have a noteworthy, the second most used class of herbicides throughout the world, however little studied in the context of analytical and environment chemistry. Once in the environment, the active principles of sulphonylureas may become a risk to the entire ecosystem. The sorption of herbicides in sediments determines how these will be retained in the matrix and how much will be available in soil solution, contaminating water resources. In this sense, this study aimed to realize studies for determinate the dynamics of chlorimuron ethyl (example of sulphonylurea herbicide family) in the environment. These studies were performed via kinetic and isotherm of absorptions in sediments. Sediments were compared with different characteristics depending of the use of earth (samples: Agricultural Zone, Farming Zone and Ecological Station). For all three samples, the obtained kinetic model was pseudo-second order. The farming Zone showed highest retention $\left(37.97 \times 10^{2} \mathrm{ug} \mathrm{kg}^{-1}\right)$, therefore a slower dynamic. The remaining samples didn't showed significant differences for the sorption process (retention of $29.07 \times 10^{2}$ and $31.67 \times 10^{2} \mathrm{ug} \mathrm{\textrm {kg } ^ { - 1 }}$ for Agricultural Zones and Ecological Stations). All sediments adsorbed according to Freundich's model and their isotherms were classified as C type. Adsorption occurred with the formation of multilayer and interactions were of physical type (physisorption). The herbicide was determined by HPLC-UV. The analytical method was validated in according with the INMETRO and ANVISA documents and, when appropriated of references values, the results have been in agreement. 


\section{LISTA DE ILUSTRAÇÕES}

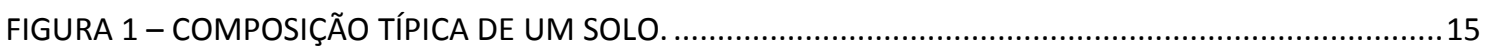

FIGURA 2 - INTERAÇÕES ENTRE A SOLUÇÃO DO SOLO E OS DEMAIS ELEMENTOS DO AMBIENTE............18

FIGURA 3 - PRINCIPAIS VIAS PARA A FORMAÇÃO DAS SUBSTÂNCIAS HÚMICAS. ....................................22

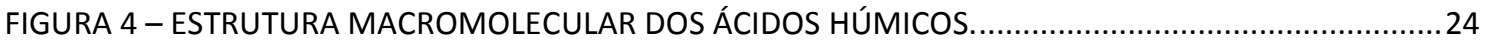

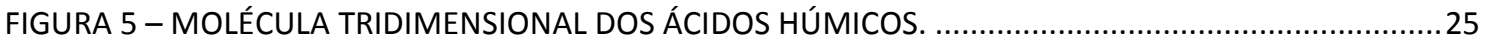

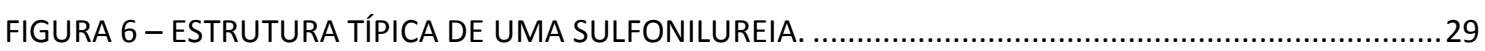

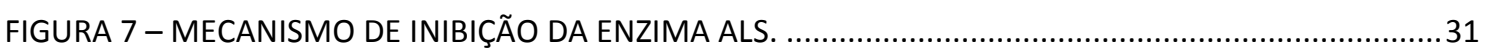

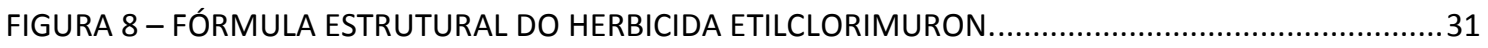

FIGURA 9 - ESQUEMA REPRESENTATIVO DAS ISOTERMAS DE ADSORÇÃO ..........................................40

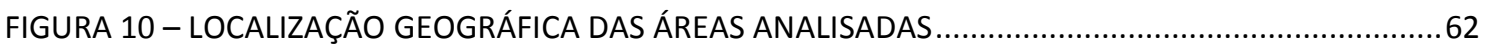

FIGURA 11 - TRIÂNGULO PARA DETERMINAÇÃO DE CLASSES TEXTURAIS............................................69

FIGURA 12 - FRACIONAMENTO E PURIFICAÇÃO DOS ÁCIDOS HÚMICOS...............................................72

FIGURA 13 - ESPECTROS DE FTIR DOS ÁCIDOS HÚMICOS ANALISADOS..............................................93

FIGURA 14 - ESPECTROS NA REGIÃO DO VISÍVEL DOS ÁCIDOS HÚMICOS ANALISADOS..........................95

FIGURA 15 - ESPECTROS DE FLUORESCÊNCIA OBTIDOS PELO MÉTODO MILORI. ...................................97

FIGURA 16 - ESPECTROS DE FLUORESCÊNCIA OBTIDOS PELO MÉTODO KALBITZ. ................................97

FIGURA 17 - GRAU DE HUMIFICAÇÃO DOS SEDIMENTOS ANALISADOS. ..............................................99

FIGURA 18 - ESPECTRO NA REGIÃO DO ULTRAVIOLETA PARA O HERBICIDA ETILCLORIMURON.............101

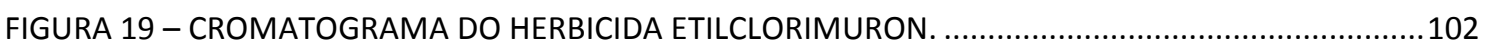

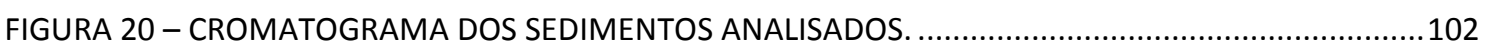

FIGURA 21 - CURVAS ANALÍTICAS DO HERBICIDA ETILCLORIMURON. ...............................................104

FIGURA 22 - EFEITOS SOBRE A ROBUSTEZ DO MÉTODO ANALÍTICO..................................................114

FIGURA 23 - CINÉTICA DE ADSORÇÃO DO HERBICIDA ETILCLORIMURON EM SEDIMENTOS. ..................116

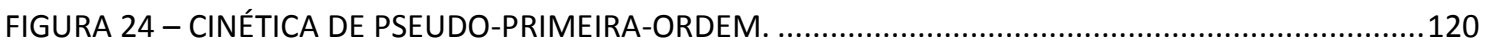

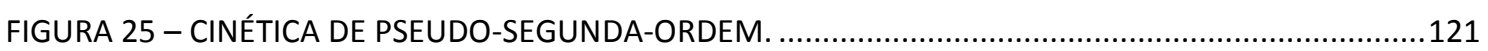

FIGURA 26 - ISOTERMAS DE ADSORÇÃO LINEARIZADAS SEGUNDO MODELO DE FREUNDLICH. .............124

FIGURA 27 - ISOTERMAS DE ADSORÇÃO LINEARIZADAS SEGUNDO MODELO DE LANGMUIR................125

FIGURA 28 - ISOTERMAS DE ADSORÇÃO SEGUNDO MODELO DE FREUNDLICH ................................128 


\section{LISTA DE TABELAS}

TABELA 1 - SOLUBILIDADE DO HERBICIDA ETILCLORIMURON EM SOLVENTES ORGÂNICOS A $25^{\circ} \mathrm{C} \ldots \ldots . . . .32$

TABELA 2 - SOLUBILIDADE DO HERBICIDA ETILCLORIMURON EM SOLUÇÃO COM PH CONTROLADO.......32

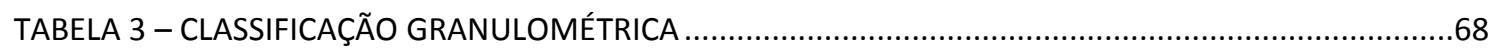

TABELA 4 - VOLUMES NECESSÁRIOS PARA PREPARO DAS SOLUÇÕES ANALÍTICAS....................................75

TABELA 5 - COMBINAÇÕES ENSAIADAS PARA TESTE ESTATÍSTICO DE YOUDEN …………………….......82

TABELA 6 - CARACTERÍSTICAS FÍSICAS E QUÍMICAS DAS AMOSTRAS DOS SEDIMENTOS ANALISADAS ....89

TABELA 7 - ÍNDICES DE HUMIFICAÇÃO DAS AMOSTRAS DE SEDIMENTO ANALISADAS .............................98

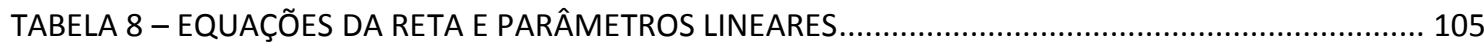

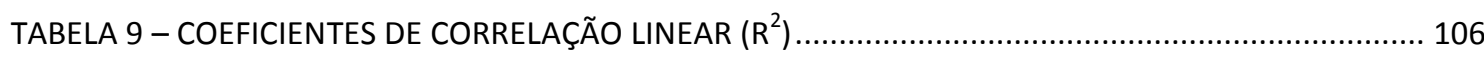

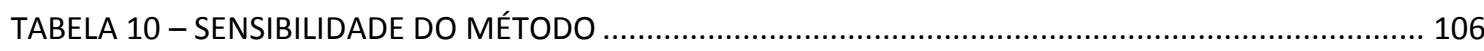

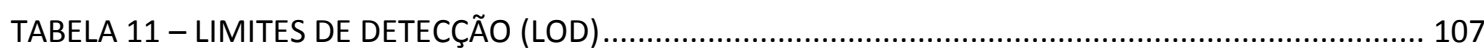

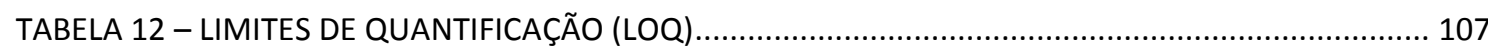

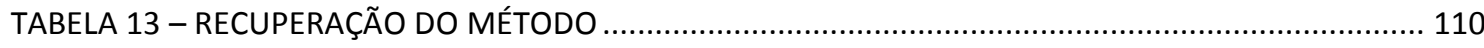

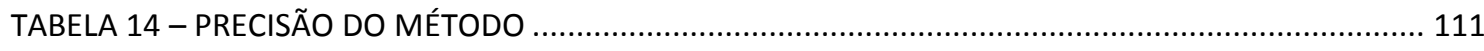

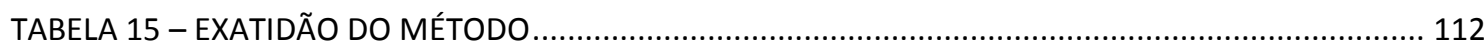

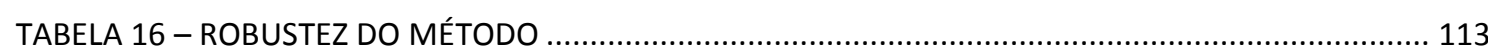

TABELA 17 - RESUMO DOS RESULTADOS OBTIDOS NA VALIDAÇÃO DA METODOLOGIA ANALÍTICA ..... 115

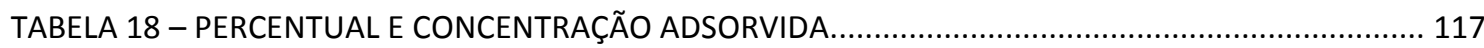

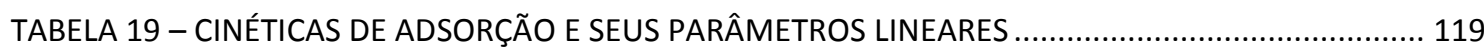

TABELA 20 - MODELOS DAS ISOTERMAS DE ADSORÇÃO E SEUS PARÂMETROS LINEARES ....................... 126

TABELA 21 - RESUMO DOS RESULTADOS OBTIDOS PARA A DINÂMICA DO ETILCLORIMURON .............. 129 


\title{
LISTA DE ABREVIAÇÕES
}

\author{
A \\ Acidez trocável \\ ALS Acetolactato sintase \\ ANVISA Agência Nacional de Vigilância Sanitária \\ BET Brunauer, Emmett e Teller \\ CAS Serviço de Resumo para Substâncias Químicas \\ Chemical Abstracts Service \\ CETESB Companhia Ambiental do Estado de São Paulo \\ CGC Coordenação Geral de Creditação \\ CONAMA Conselho Nacional do Meio Ambiente \\ CRM Materiais certificados de referência \\ Certified reference material \\ CTC Capacidade de troca catiônica \\ CV Coeficiente de variação \\ DDT Dicloro-difenil-tricloroetano \\ DOU Diário Oficial da União \\ EACH Escola de Artes, Ciências e Humanidades \\ EE Estação Ecológica \\ EESC Escola de Engenharia de São Carlos \\ EF Espectroscopia de fluorescência \\ EMBRAPA Empresa Brasileira de Pesquisa Agropecuária \\ EPA Agência Americana de Proteção Ambiental \\ United States Environmental Protection Agency \\ FAO Organização para Agricultura e Alimentação \\ Food and Agriculture Organization \\ FTIR Espectroscopia na região do infravermelho com transformada de Fourier \\ Fourier transform infrared spectroscopy \\ HPLC-UV Cromatografia líquida de alta eficiência com detector de ultravioleta \\ High performance liquid chromatography - Ultraviolet detector \\ IAC Instituto Agronômico de Campinas \\ IHSS Sociedade Internacional de Substâncias Húmicas \\ International Humic Substances Society \\ INMETRO Instituto Nacional de Metrologia, Normalização e Qualidade Industrial \\ IRIS Sistema de Informação Integrado de Perigos \\ Integrated Risk Information System
}


ISO

LMR Limites Máximos de Resíduos

LOD Limite de detecção

Limit of detection

LOQ Limite de quantificação

Limit of quantification

MO Matéria orgânica

OMS Organização Mundial de Saúde

PMEP Programa Educacional para Gestão de Pesticidas

Pesticide Management Education Program

RBC Rede Brasileira de Calibração

RC Celulose regenerada

Regenerated cellulose

$\mathrm{RP}$

Fase reversa

Reverse phase

RSD Desvio-padrão relativo

Relative standard deviation

S

SH Substâncias húmicas

SHS Laboratório de Saneamento e Hidráulica

TOC Carbono orgânico total

Total organic carbon

UNESCO Organização das Nações Unidas para a Educação e Cultura

United Nations Educational, Scientific and Cultural Organization

USP Universidade de São Paulo

UV Espectroscopia na região do ultravioleta

VMP Valor Máximo Permitido

Vis Espectroscopia na região do visível

ZA Zona Agrícola

ZP

Zona pecuária 


\section{SUMÁRIO}

Fase sólida do solo

Fase gasosa do solo

Estabilização da Matéria Orgânica

Substâncias húmicas $\quad 23$

Reatividade das substâncias húmicas $\quad 25$

Sedimentos $\quad 26$

Contaminação dos solos e sedimentos $\quad 28$

Mecanismo de ação das sulfonilureias $\quad 30$

Isotermas de adsorção

Isoterma de Langmuir

Isotermas de Freundlich

Classificação das Isotermas

Isotermas do tipo $\mathrm{S}$

Isotermas do tipo L

Isotermas do tipo $\mathrm{H}$

Isotermas do tipo $\mathrm{C}$

Cinética de adsorção

Análise quantitativa

Documentos orientativos - Legislações

$\begin{array}{ll}\text { Seletividade } & 46\end{array}$

$\begin{array}{ll}\text { Linearidade } & 47\end{array}$

Faixa de trabalho e faixas lineares $\quad 47$

Limite de detecção $\quad 48$

Limite de quantificação $\quad 49$

Sensibilidade $\quad 50$

Recuperação $\quad 50$

Exatidão $\quad 51$

Precisão $\quad 52$ 
Sólidos totais - Humidade

Potencial de hidrogênio $(\mathrm{pH})$

Teor de matéria orgânica

Teor de carbono orgânico total

Capacidade de troca catiônica (CTC)

Classe textural

Fracionamento das substâncias húmicas

Purificação dos ácidos húmicos

Preparo da solução estoque e soluções iniciais $\quad 74$

Preparo das soluções analíticas

Parâmetros Cromatográficos

Seletividade $\quad 76$

4.7 .5

4.7.6

Linearidade

Faixa de Trabalho e Faixa Linear $\quad 78$

Limite de detecção e de quantificação

4.7.9

4.7.10

Sensibilidade

$\begin{array}{ll}\text { Recuperação } & 79\end{array}$

4.7.11

Exatidão

Precisão $\quad 81$

4.7.12

Robustez

DINÂMICA DO HERBICIDA $\quad 83$

Preparo da solução estoque $\quad 83$

Preparo das soluções analíticas $\quad 84$

Construção da isoterma de adsorção

$\begin{array}{lll}\text { 4.8.5 Isoterma de Langmuir } & 86\end{array}$

$\begin{array}{lll}\text { 4.8.6 Correlação entre os modelos de isoterma } & 87\end{array}$

$\begin{array}{lll}\text { 4.8.7 Cinética de adsorção } & 87\end{array}$

$5 \quad$ RESULTADOS E DISCUSSÃO $\quad 89$

$\begin{array}{llr}5.1 & \text { CARACTERIZAÇÃo dOS SEDIMENTOS } & 89\end{array}$

5.1.1 Caracterização física e química dos sedimentos $\quad 89$

5.1.2 Espectroscopia na região do infravermelho (FTIR) dos ácidos húmicos 93

$\begin{array}{ll}\text { 5.1.3 Determinação do grau de humificação } & 95\end{array}$

5.2 VALIDAÇÃo do MÉtodo AnaLítICO $\quad 100$

$\begin{array}{lll}5.2 .1 & \text { Seletividade } & 100\end{array}$

$\begin{array}{ll}\text { 5.2.2 Linearidade - Faixa de Trabalho e Faixa Linear } & 103\end{array}$

$\begin{array}{lll}5.2 .3 & \text { Sensibilidade } & 106\end{array}$

5.2.4 Limite de detecção (LOD) e limite de quantificação (LOQ) 107

$\begin{array}{llr}5.2 .5 & \text { Recuperação do método } & 109\end{array}$

$\begin{array}{llr}\text { 5.2.6 Precisão } & 110\end{array}$

$\begin{array}{ll}5.2 .7 & 111\end{array}$

$\begin{array}{llr}5.2 .8 & \text { Robustez } & 112\end{array}$

\begin{tabular}{ll} 
5.2.9 & RESUMO - Validação do Método Analítico \\
\hline
\end{tabular}

$\begin{array}{llr}5.3 & \text { DINÂMICA DO HERBICIDA NO AMBIENTE } & 116\end{array}$

$\begin{array}{ll}\text { 5.3.1 Cinética de Adsorção } & 116\end{array}$

$\begin{array}{lll}\text { 5.3.2 Isoterma de Adsorção } & 123\end{array}$

5.3.3 RESUMO - Estudo da dinâmica dos herbicidas sulfonilureia em sedimentos $\quad 129$

$\begin{array}{lll}\text { 5.3.4 Efeito dos sedimentos na dinâmica dos herbicidas } & 130\end{array}$

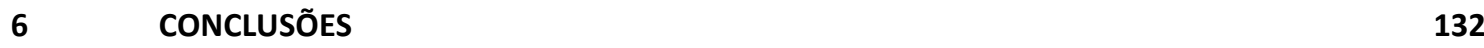

$\begin{array}{lr}\text { REFERENCIAS BIBLIOGRÁFICAS } & 134\end{array}$ 


\section{INTRODUÇÃO}

Em uma perspectiva histórica, é evidente que o legado ambiental que nos chegou até hoje é produto das relações de populações passadas com o meio ambiente. Assim, em termos de paisagem, o que temos hoje por natural pode se tratar de um sistema manejado durante séculos.

Entre os elementos naturais pertencentes a um ecossistema, os corpos d'água e seus sedimentos estão entre os mais suscetíveis à ação antrópica. A agricultura, a pecuária, entre outras formas de uso da terra, podem atuar sobre as características físicas e químicas destes compartimentos ambientais, proporcionando significativas modificações no fluxo de nutrientes e energia de seus ciclos naturais.

Dentre os usos incorretos dos recursos naturais destaca-se o emprego do solo como depósito de resíduos ou materiais em sua cobertura, o que leva à incorporação de elementos não naturais ao meio ambiente. Além disso, as práticas incorretas ou abusivas na agricultura, como a aplicação de pesticidas e insumos agrícolas em excesso, possui ação direta sobre a qualidade e fertilidade do solo. Neste sentido, é mandatório conhecer o solo como um organismo importante na manutenção da vida sobre a Terra, sua composição e elementos fundamentais. Mediante a presença de substâncias nocivas ao ambiente, deve-se investigar a resposta dada pelo solo e sedimentos a este estímulo. No caso dos pesticidas, é importante um estudo da dinâmica destas moléculas, pois pode nos predizer sobre as possíveis contaminações de corpos d'água superficiais ou subterrâneos, afetando toda biodiversidade que vive concomitantemente, compartilhando o mesmo ambiente.

Atualmente, as sulfonilureias estão entre os pesticidas mais comercializados em todo mundo e, ao passo que aumenta seu uso e aplicação nas práticas agrícolas, o número de publicações científicas não acompanha o mesmo ritmo de crescimento, se restringindo a revistas e periódicos da área de agronomia e demais ciências agrárias.

No Brasil, há um destaque para o etilclorimuron, herbicida seletivo do grupo químico das sulfonilureias, largamente empregado no controle de plantas daninhas em plantações de soja. Considera-se que o comportamento deste herbicida no ambiente seja semelhante ao que seria observado para as demais sulfonilureias. Neste sentido, é 
desnecessário investigar várias formulações, levando em conta que suas características químicas e físicas são bastante semelhantes.

Neste trabalho, optou-se pela análise dos herbicidas sulfonilureias em sedimentos. Este compartimento ambiental constitui uma camada sólida divisora entre o recurso solo e os corpos d'água superficiais. Uma vez presente no solo, o herbicida necessita transpor esta divisão para chegar ao recurso hídrico, contaminando-o. Neste processo, parte do composto orgânico certamente será retido. Esta propriedade acumulativa e de redisposição são características importantes no estudo e análise de áreas de degradação ambiental.

Neste sentido, o presente trabalho não teve como objetivo realizar um monitoramento ambiental em áreas contaminadas por herbicidas sulfonilureia, mas sim, no âmbito da química analítica e ambiental, investigou-se a dinâmica destes compostos orgânicos no ambiente via estudos cinéticos e isotermas de adsorção. Os sedimentos pertenceram a regiões manejadas para diferentes finalidades e uso da terra: atividade agrícola, pecuária e área de proteção ambiental. A detecção e quantificação do herbicida foram realizadas via cromatografia líquida de alta eficiência (HPLC). O método analítico e cromatográfico foi validado de acordo com os documentos e critérios da ANVISA e INMETRO, agregando valor aos resultados obtidos. 


\section{REVISÃO BIBLIOGRÁFICA}

\section{$2.1 \quad$ O Solo}

O solo é um tecido tridimensional biológico, de constituição física expressa pelo arranjo espacial das partículas sólidas e dos vazios a ele associados (poros), recobrindo a superfície terrestre emersa, entre a litosfera, hidrosfera, atmosfera, além da biosfera e da ação antrópica. ${ }^{1-2}$

O solo tem importância fundamental nos ciclos da natureza, participando da maioria das atividades que ocorrem no planeta. Além de ser o principal substrato para a agricultura, o solo também é suporte para estradas e para construções civis, sendo muitas vezes utilizado indevidamente como depósito de resíduos. ${ }^{1}$

Quanto a sua origem, os solos são formados a partir do processo de intemperismo aos quais as rochas são submetidas. Estas rochas são o material de origem do solo, cuja transformação se desenvolve em um determinado relevo, clima, bioma e ao longo do tempo. ${ }^{3}$

No tocante à sua composição, o solo é um sistema composto por três fases: sólida, líquida e gasosa. Um solo típico possui aproximadamente o seguinte percentual de seus constituintes: $45 \%$ de minerais (fração inorgânica), 5\% de substâncias orgânicas, 25\% de ar e $25 \%$ de água, como mostra a Figura $1 .^{1}$

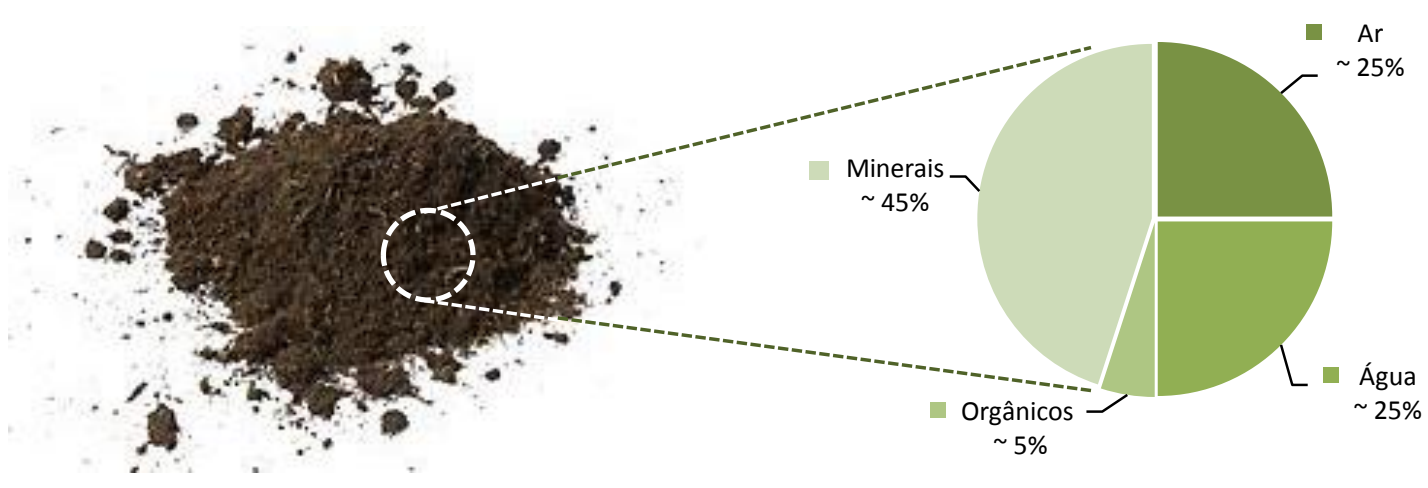

Figura 1 - Composição típica de um solo. 


\subsubsection{Fase sólida do solo}

A fase sólida do solo é uma mistura de minerais e matéria orgânica, os quais fornecerão a forma estrutural do solo. Esta estrutura é repleta de poros, os quais, por sua vez, são partilhados pelas fases gasosa e líquida (esta última conhecida como solução do solo). ${ }^{2}$

Aproximadamente $50 \%$ do volume do solo é constituído por material sólido. Desse percentual, aproximadamente, $90 \%$ são compostos de natureza inorgânica. ${ }^{2}$

Quanto à composição da fração inorgânica, a maioria dos minerais que compõe o solo são silicatos, visto que os elementos silício e oxigênio são os mais abundantes na crosta terrestre. ${ }^{2,4-5}$ Além dos silicatos, óxidos metálicos são facilmente encontrados em solos tropicais, principalmente na fração argila. ${ }^{5}$

Os arranjos espaciais das partículas sólidas e seus poros implicarão em uma textura característica para o solo. Esta textura dependerá da forma e da disposição dos minerais, além de incluir a presença de água e compostos orgânicos. As partículas que constituem o solo compreendem diferentes frações granulométricas, sendo facilmente classificadas em função de seu diâmetro. Os componentes de textura grossa possuem diâmetro acima de 2 um. Estes componentes podem ser divididos em partículas inorgânicas (por exemplo, os minerais primários) e orgânicas (por exemplo, fragmentos de raízes mortas e outros organismos). Por outro lado, os materiais finos possuem diâmetro abaixo de 2 um, incluem a fração inorgânica (a argila, por exemplo) e a fração orgânica (substâncias húmicas, microrganismos, entre outros). ${ }^{2}$

Os componentes de textura grossa são considerados relativamente imóveis, portanto, não são facilmente transportados. Já os de textura fina constituem uma parte móvel e quimicamente ativa do solo, sendo facilmente carreados pela água e pelo ar. ${ }^{2}$

\subsubsection{Fase gasosa do solo}

Conforme citado anteriormente, os poros são preenchidos com ar e água. A composição química e o comportamento dos gases são determinados pela interação entre as fases gasosa e sólida. ${ }^{2}$ 
Os constituintes da fase gasosa são semelhantes àqueles encontrados na atmosfera. $\mathrm{O}$ ar atmosférico contém aproximadamente, em volume, $20 \%$ de $\mathrm{O}_{2}, 0,03 \% \mathrm{CO}_{2} \mathrm{e}$ $78 \%$ de $\mathrm{N}_{2}{ }^{2}$

No solo, estes valores tendem a se diferenciar. Em geral, os volumes dos gases oxigênio e nitrogênio são menores em comparação com o ar atmosférico, estes valores variam dentre os diversos tipos de solos existentes. Já os teores de $\mathrm{CO}_{2}$ são significativamente maiores, resultado da atividade dos microrganismos presentes no solo. ${ }^{2}$

Sob aeração restrita, ocorre a fermentação anaeróbia da matéria orgânica causada pela atividade microbiana, o que eleva os valores de $\mathrm{CO}_{2}$, além de se produzirem outros gases como o metano $\left(\mathrm{CH}_{4}\right)$, sulfeto de hidrogênio $\left(\mathrm{H}_{2} \mathrm{~S}\right){ }^{2}$

\subsubsection{Solução do solo}

A fase aquosa do solo constitui uma solução que permeia entre os poros, interagindo com as fases sólida e gasosa. Quase todas as reações químicas que ocorrem no solo são mediadas ou ocorrem em sua solução, dentre as quais se podem citar as reações de hidrólise, ácido-base, oxirredução e complexação. Devido a essa característica, a solução do solo atua como mediadora de reações que controlam a retenção de substâncias pela fase sólida do solo, como precipitação-dissolução, adsorção-dessorção e troca iônica. Essas reações determinarão o comportamento das diversas substâncias presentes no solo por meio de sua solução. ${ }^{6}$

O conceito de solução do solo e seu papel nas inter-relações com o solo, as plantas e os organismos remontam há mais de um século. Atualmente, considerando a atual preocupação com o meio ambiente, principalmente com a qualidade da água, muitos autores têm enfatizado a participação da solução do solo como meio de transporte de contaminantes orgânicos (geralmente os pesticidas e derivados de petróleo) e inorgânicos (elementos tóxicos, por exemplo) do solo para grandes mananciais de água potável, com sérios efeitos ecotoxicológicos. ${ }^{2,7}$

Os elementos químicos contidos na solução do solo são governados por uma série de mecanismos ilustrados na Figura 2. O sentido das setas indica a direção da relação da solução do solo com os demais componentes do sistema. ${ }^{7}$ 


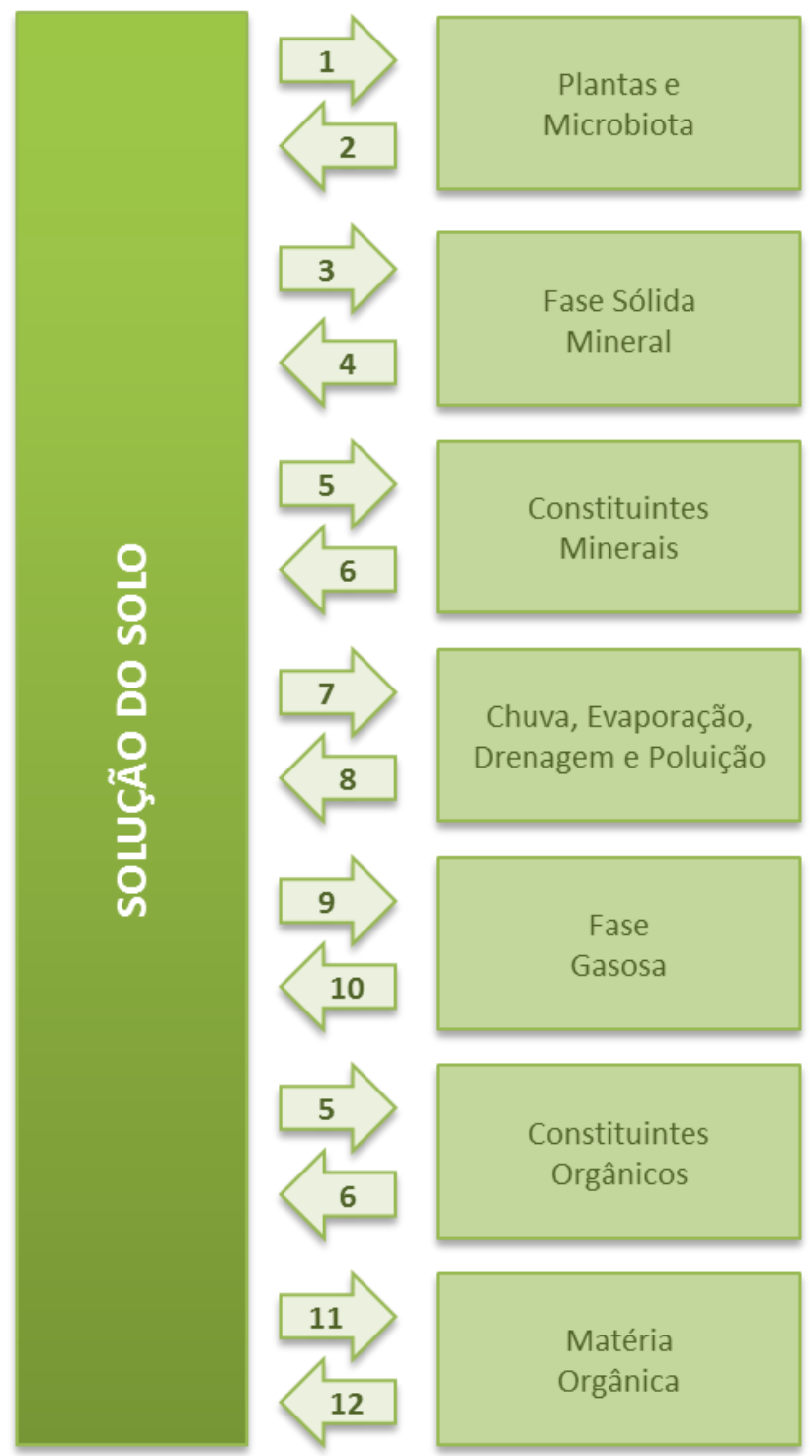

FONTE: Adaptado de Pérez e Campos (2003) ${ }^{7}$

Figura 2 - Interações entre a solução do solo e os demais elementos do ambiente 
De acordo com Figura 2, os mecanismos identificados nas setas são: ${ }^{7}$

1 - Absorção de nutrientes pela nutrição das plantas e microbiota;

2 - Exsudação e excreção de substâncias orgânicas pelas raízes e microrganismos, além da decomposição dos organismos;

3 - Precipitação derivada da supersaturação e nucleação na solução do solo;

4 - $\quad$ Dissolução via intemperismo;

5 - Adsorção por causa de vários tipos de interação intermoleculares, tais como, força de Van der Waals, ligação de hidrogênio, ligações hidrofóbicas, troca de íons, entre outras;

6 - Dessorção e troca iônica;

7 - Drenagem de constituintes para fora do solo, ocorrendo transporte para outros sistemas (rios e lagos, por exemplo);

8 - Adição de metais e ligantes à solução do solo por fertilizantes e contaminantes, formando novos minerais;

9 - $\quad$ Liberação de gases para a fase gasosa;

10 - Dissolução de gases na água;

11 - Formação de compostos orgânicos via polimerização,

12 - Decomposição da matéria orgânica via ação microbiana.

Neste trabalho foi investigada a ação do herbicida etilclorimuron presente em uma solução que, em termos analíticos, reproduziu (mimetizou) a solução do solo. Foi analisada a ação deste xenobiótico sobre a fase sólida mineral, os constituintes minerais e orgânicos do solo.

\subsubsection{Matéria orgânica do solo (MO)}

A fração orgânica é o componente mais complexo do solo. Formada por um grande número de compostos orgânicos, muitos ainda são desconhecidos, sendo objetos de pesquisa e investigação cientifica. ${ }^{7}$ 
O termo matéria orgânica do solo é utilizado na designação dos constituintes orgânicos do solo, incluindo aqueles provenientes da decomposição de vegetais e animais, seus produtos de decomposição parcial e a biomassa do solo. ${ }^{1}$

A matéria orgânica existente nos solos consiste em uma mistura de produtos animais e vegetais em vários estágios de decomposição, resultantes da degradação química, biológica e da atividade sintética dos micro-organismos. A matéria orgânica é uma fonte de energia e nutrientes para os organismos que participam de seu ciclo biológico, mantendo o solo em estado dinâmico, exercendo importante papel em sua fertilidade. ${ }^{1}$

Pode-se classificar a matéria orgânica $(\mathrm{MO})$ em duas classes distintas: ${ }^{1-7}$

(i ) MO não-humificada: é constituída, principalmente, pelos compostos liberados nos processos de decomposição da matéria orgânica recente, na forma original ou pouco modificada. A despeito da grande variedade de moléculas envolvidas nesse processo, somente algumas poucas estruturas orgânicas são detectáveis no solo, tais como alguns carboidratos, aminoácidos, proteínas, lipídeos, ácidos nucléicos, ligninas e ácidos orgânicos.

(ii ) MO humificada: inclui os ácidos húmicos, ácidos fúlvicos, ácidos himatomelânicos e huminas, cuja origem deriva principalmente da interpolimerização de compostos fenólicos, peptídeos, aminoácidos e carboidratos.

Uma das propriedades da matéria orgânica humificada e das argilas é a capacidade de formação de coloides, fato devido à presença de carga elétrica em suas superfícies. Por isso, esses dois componentes da fração sólida são considerados os principais sítios de atividade do solo, sendo, portanto, os responsáveis por sua reatividade. ${ }^{7-8}$

Dentre as várias funções da matéria orgânica no solo, destaca-se sua capacidade de reter cátions via complexação de elementos tóxicos e de micronutrientes, além de adsorver compostos orgânicos de ação tóxica. ${ }^{9-10}$ 


\subsubsection{Estabilização da Matéria Orgânica}

Sendo a Terra um sistema dinâmico em evolução, o movimento e a estocagem de seus materiais afetam todos os processos físicos, químicos e biológicos. A matéria orgânica do solo rege vários processos pedogenéticos e interfere nos processos geoquímicos e nas propriedades físico-químicas do solo. Em condições naturais, há equilíbrio entre o solo, a vegetação e os animais que fornecem os resíduos orgânicos. ${ }^{1}$

A estabilização da matéria é o processo em que os compostos orgânicos ali presentes são parcialmente transformados em substâncias húmicas.

As substâncias húmicas são moléculas relativamente estáveis e importantes para a manutenção e melhoria na fertilidade e qualidade do solo. As substâncias húmicas são subdivididas em ácido húmico, ácido fúlvico e humina, classificadas em função da solubilidade destas espécies em solução aquosa. ${ }^{1}$

Aproximadamente $50 \%$ da matéria orgânica estabiliza-se completamente devido à degradação de compostos mais facilmente degradáveis, por exemplo, as proteínas, celulose e hemicelulose, que são utilizados pelos microrganismos como fonte de carbono e nitrogênio. A matéria orgânica residual contem macromoléculas recentemente formadas e matéria orgânica não degradada que, juntamente, formam as substâncias húmicas. ${ }^{11-12}$

Um aumento no nível dos ácidos húmicos em uma amostra de solo indica a diminuição no teor de matéria orgânica. Este processo indica o grau de humificação e a maturidade do solo. Em geral, solos com grande quantidade de compostos orgânicos frescos, contêm baixos níveis de ácido húmico e altos níveis de ácido fúlvico. Com o aumento do grau de humificação os níveis de ácido húmico aumentam e os de ácido fúlvico diminuem significativamente. ${ }^{12}$

A Figura 3 esquematiza pelo menos quatro vias principais de formação das substâncias húmicas durante a decomposição de resíduos no solo. ${ }^{13}$ 


\section{Resíduos Vegetais e Animais}

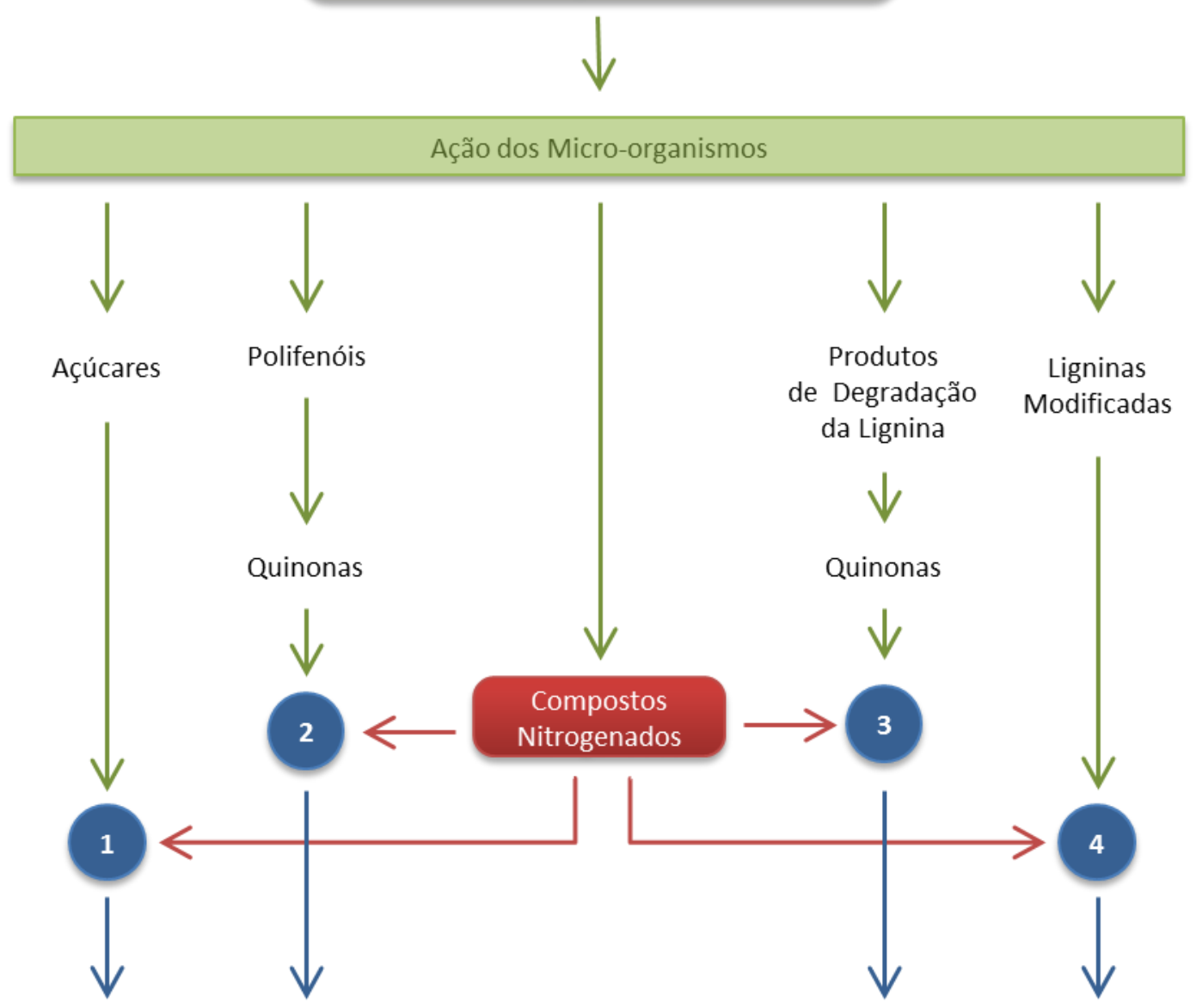

Substâncias Húmicas

FONTE: Adaptado de Stevenson (1994) ${ }^{14}$

Figura 3 - Principais vias para a formação das substâncias húmicas.

As quatro vias podem ocorrer simultaneamente no solo, porém não com a mesma extensão e importância. Em geral, o principal processo para a formação das substâncias húmicas ocorre por meio da oxidação de substratos hidrolisados monoméricos. Estas moléculas conduzem a formação de polímeros macromoleculares de coloração mais escura e massa molecular elevada. ${ }^{13}$

O mecanismo 1 propõe a formação das substâncias húmicas a partir da polimerização não enzimática por condensação entre aminoácidos e açúcares formados como subprodutos da atividade microbiana. Os mecanismos 2 e 3 envolvem a participação de quinonas e 
representam a teoria clássica. No mecanismo 4 as substâncias húmicas seriam derivadas de ligninas modificadas. ${ }^{13}$

A via da lignina pode se processar predominantemente em solos mal drenados e em áreas hidromórficas, enquanto a síntese a partir de polifenóis pode ser de considerável importância para certos solos sob florestas. Em razão da rápida assimilação biológica dos açúcares, o mecanismo 1 é válido para meios de baixa atividade biológica. ${ }^{13}$

Os mecanismos baseados na condensação polimérica de polifenóis e quinonas têm sido os mais aceitos por pesquisadores e pela Sociedade Internacional de Substâncias Húmicas (IHSS). ${ }^{13}$

\subsubsection{Substâncias húmicas}

As substâncias húmicas (SH) são componentes importantes do solo, constituídas de uma mistura heterogênea de compostos em que cada fração (ácidos húmicos, ácidos fúlvicos e humina) deve ser considerada como uma série de moléculas de tamanhos diferentes, cuja maioria não apresenta a mesma configuração estrutural ou grupos reativos na mesma posição. Os ácidos húmicos constituem a fração das substâncias húmicas solúveis em meio alcalino e que precipita após acidificação. Os ácidos fúlvicos permanecem em solução quando o meio é acidificado e a humina é a fração insolúvel tanto em meio ácido quanto em álcali diluídos. ${ }^{1}$

As substâncias húmicas são amorfas, escuras e com grande conteúdo de grupos orgânicos, tais como, carboxílicos, fenólicos, enólicos, alcoólicos, quinonas entre outros. Possuem massa molar que varia de centenas a milhares de unidade de massa atômica e são bastante resistentes à degradação química e biológica. ${ }^{14-16}$ São onipresentes no ambiente, sendo encontradas em solos, sedimentos e sistemas aquáticos. ${ }^{1}$

A química do solo, área que estuda a estrutura das substâncias húmicas, tem obtido relevantes avanços nas últimas décadas na elucidação de uma fórmula estrutural das substâncias húmicas, em especial dos ácidos húmicos. Ainda hoje não existe um modelo que contemple totalmente a composição química, a estrutura, a forma e o tamanho de suas moléculas constituintes, o que gera controvérsias e discussões no tocante aos estudos recentes publicados. ${ }^{17-19}$ 
A composição das SH depende da natureza química dos resíduos, dos microorganismos envolvidos e das condições em que se realiza a decomposição. Embora de natureza essencialmente orgânica, as SH apresentam vários elementos inorgânicos que são parte integrante do sistema, tais como: $\mathrm{P}, \mathrm{S}, \mathrm{Ca}, \mathrm{Mg}, \mathrm{K}, \mathrm{Al}$, entre outros. ${ }^{1}$

Em 1993, os pesquisadores Schulten e Schnitzer, a partir de técnicas analíticas como pirólise, espectroscopia e microscopia eletrônica, entre outras, sugeriram a estrutura

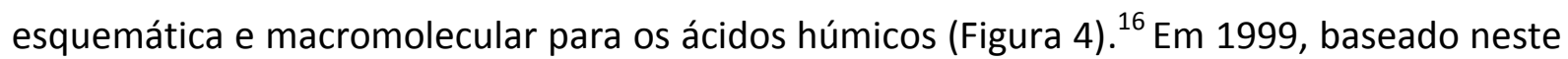
modelo, Sein Jr. e colaboradores sugeriram o modelo conformacional apresentado na Figura 5. Nesse modelo as variações conformacionais são similares àquelas observadas nas macromoléculas biológicas similares às proteínas, polissacarídeos, ácidos nucléicos, ligninas entre outros. Esse modelo propõe a existência de "vazios" hidrofóbicos no interior das moléculas. Nessas regiões pode ocorrer a adsorção de íons metálicos ou moléculas orgânicas. $^{20}$

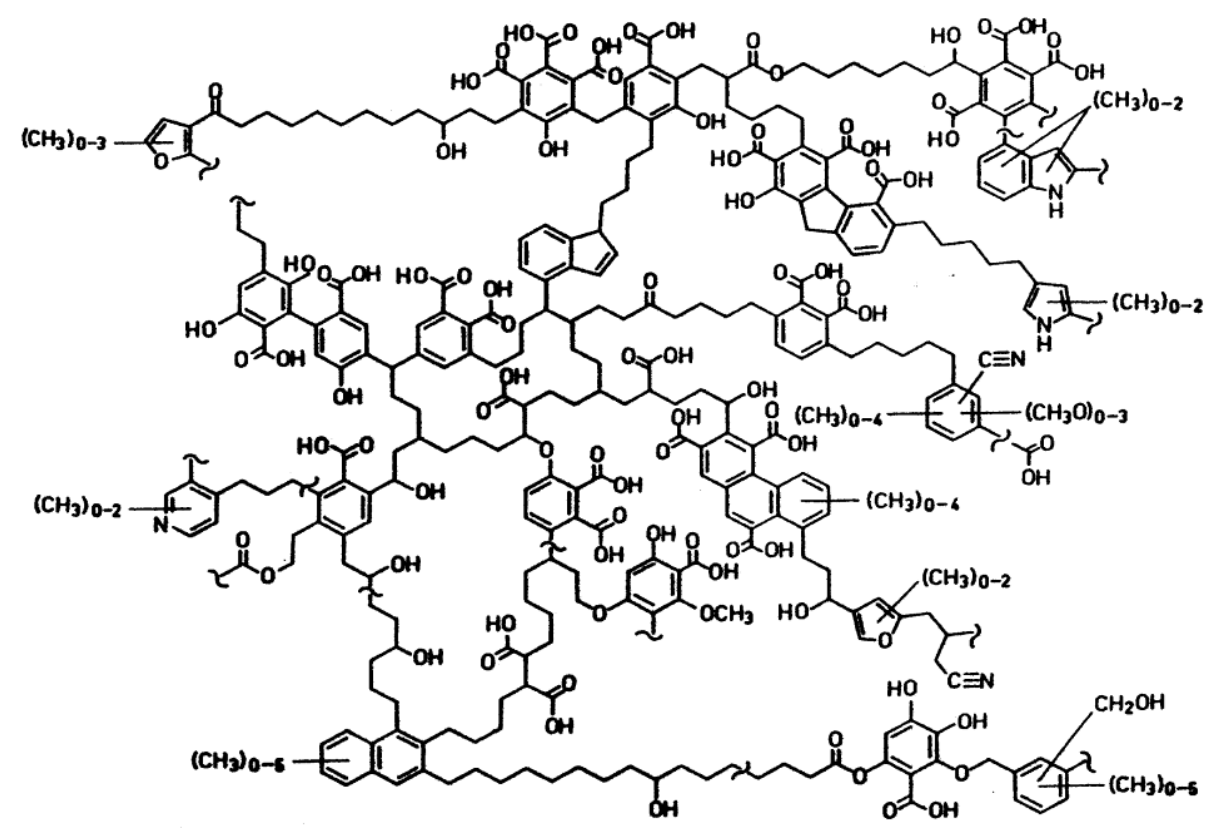

FONTE: Schulten e Schnitzer (1993) ${ }^{16}$

Figura 4 - Estrutura macromolecular dos ácidos húmicos. 


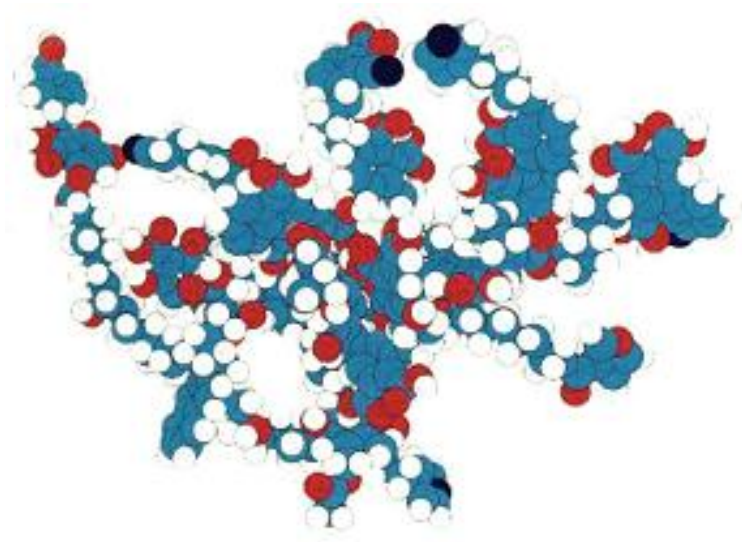

FONTE: Schulten e Schnitzer (1997) ${ }^{22}$

Figura 5 - Molécula tridimensional dos ácidos húmicos.

Os átomos de carbono estão representados em azul, os átomos de nitrogênio em preto, átomos de oxigênio em vermelho e os átomos de hidrogênio em branco.

\subsubsection{Reatividade das substâncias húmicas}

A reatividade das substâncias húmicas é decorrente, principalmente, de quatro características estruturais: $^{1}$

(i) Polifuncionalidade: presença de vários grupos funcionais, com reatividades diferentes, representativos de uma mistura heterogênea de polímeros que interagem entre si;

(ii) Carga macromolecular: caráter aniônico do arranjo molecular cujos efeitos refletem na reatividade dos grupos funcionais e na conformação molecular;

(iii) Hidrofilicidade: esta propriedade reflete-se na tendência das substâncias húmicas em formarem ligações de hidrogênio com as moléculas da água do meio, solvatando, desta maneira, grupos funcionais como $\mathrm{COOH}$ e $\mathrm{OH}$; 
(iv) Labilidade estrutural: decorrente da capacidade de associações intermoleculares e de mudanças conformacionais em resposta a mudanças de $\mathrm{pH}$, condições redox, concentração iônica e ligações químicas.

Todas as propriedades citadas são semelhantes às propriedades de outros biopolímeros. Contudo, no caso das substâncias húmicas, essas propriedades refletem o comportamento de uma mistura heterogênea de moléculas interagindo entre si, em vez de o comportamento de um único tipo de macromolécula estruturalmente bem definida. ${ }^{1}$

\subsubsection{Sedimentos}

Sedimentos são camadas de partículas minerais e orgânicas, frequentemente de granulometria fina, que são encontradas em contato com os corpos de águas naturais como lagos, rios e oceanos. Nos sedimentos, a proporção entre minerais e matéria orgânica varia substancialmente, dependendo da localização. ${ }^{21}$

$\mathrm{Na}$ análise de impactos ambientais os sedimentos são de relevante importância, pois atuam como depósitos de muitas substâncias químicas, especialmente os elementos tóxicos e compostos orgânicos, tais como os pesticidas, sendo possível a transferência destes para os organismos que habitam essa região. ${ }^{21}$

Em termos de gênese, os sedimentos são os detritos rochosos resultantes da erosão seguida pela precipitação química de suas partículas. Os sedimentos tendem a se depositar na superfície da Terra dando origem às rochas sedimentares. A palavra sedimentar ilustra a natureza destas rochas, uma vez que significa o resultado do processo de deposição dos sedimentos em suspensão ou transportados por um fluido, normalmente a água. Os geólogos estimam que as rochas sedimentares constituam apenas $5 \%$ da camada exterior de $16 \mathrm{~km}$ de espessura da Terra. No entanto, a importância deste grupo de rochas é muito maior do que esta percentagem poderia indicar. A maioria das formações rochosas à superfície são de natureza sedimentar (cerca de 75\%) o que se relaciona ao fato dos sedimentos se acumularem à superfície da terra. ${ }^{22}$ 
Os sedimentos constituem um depósito de constituintes químicos e mineralógicos determinantes para a qualidade dos sistemas onde se formam, incluindo os corpos d'água como rios e lagos. ${ }^{3}$

Suas características dependem da composição da rocha erosionada (erodida), do agente de transporte, da duração do transporte e das condições físicas da bacia de sedimentação. ${ }^{3}$

Um sedimento é geralmente formado por fases sólidas, compostas por elementos químicos diversos, os quais podem estar presentes originalmente em altas concentrações ou terem sido adicionados ao meio a partir de fontes antropogênicas. Em águas naturais, os sedimentos consistem predominantemente de detritos orgânicos, material coloidal, células vivas (bactérias e algas) e sólidos inorgânicos, tais como óxidos e hidróxidos de ferro e manganês, carbonatos, sulfetos e argilas. ${ }^{23-34}$

Solos e sedimentos são fatores essenciais de numerosos processos e bens essenciais à vida humana e ao desenvolvimento sustentável, incluindo a produção agrícola e a qualidade da água para consumo. Por apresentarem características visivelmente semelhantes, geralmente os solos e sedimentos são tratados como matrizes ambientais de mesma natureza, porém sob o prisma da química e da física, existem diferenças significativas entre estes. A diferença básica entre ambos dá-se em seus processos de formação. O solo é o perfil que sofreu alterações estruturais de forma vertical a partir de uma rocha, representando as alterações intempéricas, in situ. Já os sedimentos são o produto de alteração de uma rocha preexistente que sofreu transporte e posterior deposição ou precipitação. ${ }^{22}$

Nos sedimentos, as propriedades acumulativas e de redisposição os qualificam como de extrema importância em estudos de impactos ambientais, registrando em caráter mais permanente os efeitos da contaminação. Em geral, as partículas de sedimentos possuem elevada área superficial se comparadas às partículas do solo. Além disso, a superfície destas partículas são quimicamente mais ativas, com presença de um maior número de grupos químicos expostos, favorecendo os processos de sorção dos contaminantes e xenobióticos. ${ }^{25}$ Neste sentido, o uso de sedimentos como matriz ambiental é uma alternativa para o monitoramento e avaliação da qualidade do meio ambiente em áreas de paisagem degradada. 
No tocante às legislações ambientais, autarquias ambientais como a CETESB (Companhia Ambiental do Estado de São Paulo), a americana EPA (Agência de Proteção Ambiental), ou o Ministério do Meio Ambiente, via CONAMA (Conselho Nacional do Meio Ambiente) regulamentam os limites máximos permitidos para deteç̧ão de pesticidas em água e, raramente, para solo. Porém, quanto aos sedimentos não existem legislações no âmbito nacional.

\subsubsection{Contaminação dos solos e sedimentos}

A contaminação do solo por resíduos não é somente um fenômeno dos tempos modernos. Na época de Roma, jazidas de metais eram exploradas e o minério era fundido, poluindo os arredores da zona rural com resíduos das minas. A produção de materiais e produtos químicos na Europa, mesmo no início da Revolução Industrial, produziu uma poluição substancial. No entanto, a extensão da contaminação e o risco dos materiais descartados se expandiram muito no último século, particularmente no período após a Segunda Guerra Mundial. ${ }^{21}$

Existem várias indicações de que excedemos a capacidade de carga do solo, que é a habilidade deste em converter nosso resíduo de volta aos seus recursos tão rapidamente quanto nós consumimos os bens naturais. ${ }^{21}$

Por ser um tecido exposto e em confluência com a hidrosfera, atmosfera, litosfera e biosfera, o solo é facilmente susceptível à ação de patógenos e contaminantes. ${ }^{1}$ Dentre estes, destaca-se a ação danosa causada pelo uso irregular e exacerbado dos pesticidas, seus impactos sobre solo e o meio ambiente.

\section{$2.2 \quad$ Pesticidas}

O aumento crescente na demanda por alimentos e insumos agrícolas tem impulsionado, nas últimas décadas, a utilização cada vez maior de pesticidas. Os pesticidas são substâncias que podem matar diretamente um organismo indesejável presente em uma produção agrícola ou controlá-lo. Todos os pesticidas têm a propriedade comum de bloquear o processo metabólico vital dos organismos para os quais são tóxicos. ${ }^{21}$

Segundo a EPA, um pesticida é qualquer substância ou mistura de substâncias destinadas a prevenir ou destruir, repelindo ou mitigando qualquer praga no ambiente 
agrícola. Os pesticidas são divididos em classes. Cada classe tende a atuar sobre um conjunto de organismos específicos. São exemplos de classes: os acaricidas, fungicidas, pesticidas, herbicidas, entre outros. ${ }^{26}$

No Brasil o uso de pesticidas organossintéticos teve inicio na década de $40 \mathrm{com}$ a chegada das primeiras amostras de dicloro-difenil-tricloroetano (DDT) utilizadas no combate a insetos. ${ }^{27} \mathrm{~A}$ partir de então, o consumo desses compostos teve um aumento progressivo no país. Recentemente, o Brasil ultrapassou os Estados Unidos, tornando-se o maior mercado mundial de agrotóxicos, embora não seja o campeão mundial de produção agrícola. $^{28}$

Dentre as classes de pesticidas, destacam-se os herbicidas. Trata-se de um grupo de agentes químicos que atuam sobre as plantas, controlando-as. Frequentemente são empregados na destruição de ervas daninhas sem causar prejuízo à vegetação de interesse. ${ }^{21}$ Atualmente, o setor de herbicidas é responsável por $45 \%$ do total do mercado mundial de pesticidas. ${ }^{21-29}$

\subsubsection{Sulfonilureias}

Do total de herbicidas comercializados em todo o mundo, $12,2 \%$ do mercado pertence ao grupo químico das sulfonilureias, que hoje ocupa o segundo lugar no setor. Nos Estados Unidos, as sulfonilureias são empregadas em mais de 150 milhões de hectares cultivados, totalizando US\$ 1,5 bilhões em vendas ao ano. No Brasil, não existem dados sobre esse consumo. ${ }^{29}$

A Figura 6 apresenta a estrutura típica de uma sulfonilureia. ${ }^{31}$

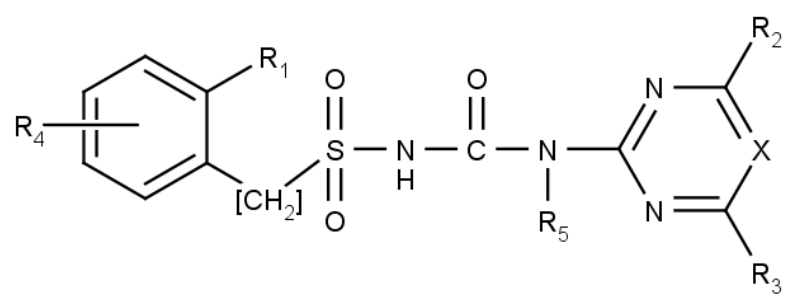

Figura 6 - Estrutura típica de uma sulfonilureia.

A estrutura das sulfonilureias é caracterizada pela presença de uma "ponte" sulfonil-uréia conectando duas ramificações laterais. A primeira ramificação pode ser 
constituída por compostos alifáticos, aromáticos ou grupamentos heterocíclicos. A segunda ramificação pode ser uma triazina substituída ou um sistema pirimidina. ${ }^{31}$ Os grupos $X$ podem apresentar-se como átomos de nitrogênio, enxofre ou de carbono, dependendo da formulação. Já o $\left[\mathrm{CH}_{2}\right]$ é comum apenas na estrutura de algumas sulfonilureias. Os radicais $\mathrm{R}$ são cadeias alifáticas, mas também podem ser grupos ésteres ou amidas. ${ }^{32}$

As Sulfonilureias são compostos não voláteis que possuem um próton ionizável no grupo amino adjacente ao grupo sulfonil. Isso faz com que, em solução, as sulfonilureias se comportem como ácidos fracos, com $\mathrm{pK}_{\mathrm{a}}$ na faixa de 3 a $5 .^{31-32}$

O grupo químico das sulfonilureias foi desenvolvido na década de setenta pela Companhia DuPont ${ }^{\circledR}$ e, desde 1982, é comercializado. Por controlar espécies de difícil manejo, além causar baixo dano ao ambiente e baixa toxicidade aos mamíferos, as sulfonilureias foram rapidamente aceitas em muitos países. ${ }^{30}$

\subsubsection{Mecanismo de ação das sulfonilureias}

Nas plantas susceptíveis, as sulfonilureias inibem a enzima acetolactato sintase (ALS). A enzima ALS é responsável pela síntese destes aminoácidos ramificados essenciais para as plantas: leucina, isoleucina e valina. Essa inibição impede a síntese proteica que, por sua vez, interfere na síntese do DNA e no crescimento celular dos vegetais. Após a aplicação de herbicidas sulfonilureias, as plantas susceptíveis tendem a definhar e morrem no prazo de 7 a 14 dias. $^{29,33}$

Os inibidores da ALS têm sido intensivamente utilizados em função da alta eficiência em doses muito baixas, baixa toxicidade para mamíferos e boa seletividade para várias das culturas de grande importância econômica. Além das sulfonilureias, as imidazolinonas, pirimidinil(tio)benzoatos, sulfonilaminocarbonitriazolinonas e as triazolopirimidinas também são classes de herbicidas inibidores da enzima ALS. ${ }^{33}$

Na Figura 7 está esquematizado o mecanismo pelo qual as sulfonilureias inibem a enzima ALS. 


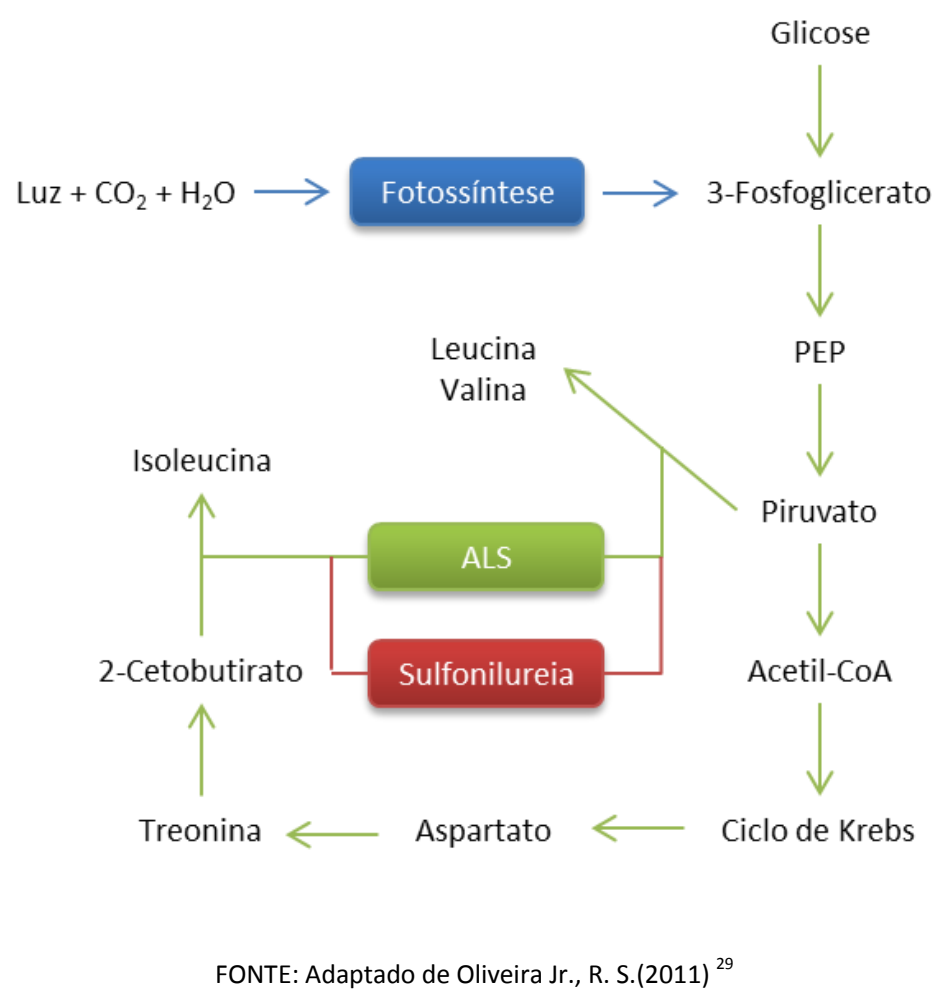

Figura 7 - Mecanismo de inibição da enzima ALS.

\subsubsection{Etilclorimuron}

Entre as sulfonilureias destaca-se o etilclorimuron (CAS 90982-32-4), herbicida largamente utilizado no controle de ervas daninhas em plantações de soja.

No Brasil, o herbicida etilclorimuron foi licenciado pelo governo federal há 24 anos, conforme registrado no Diário Oficial da União, aos 22 dias do mês de julho de 1987, passando a ser de uso permitido em atividades agropecuárias, classificado como herbicida seletivo do grupo químico das sulfonilureias com ação danosa a seres humanos. ${ }^{34}$ A fórmula estrutural do herbicida etilclorimuron está apresentada na Figura 8.

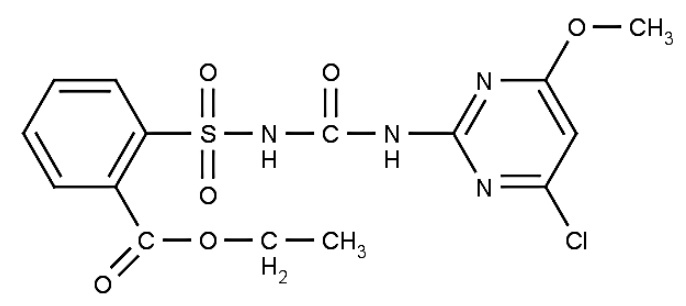

Figura 8 - Fórmula estrutural do herbicida etilclorimuron. 
Segundo o PMEP (Pesticide Management Education Program) e dados técnicos do IRIS (Integrated Risk Information System) da EPA, o herbicida etilclorimuron possui as seguintes características: estado físico sólido, não apresenta odor, ponto de fusão igual a $181^{\circ} \mathrm{C}$ e densidade de $1,51 \mathrm{~g} \mathrm{cc}^{-1} .^{35-36}$

Nas tabelas 1 e 2 constam as solubilidades do herbicida em diferentes solventes e em soluções aquosas com diferentes $\mathrm{pH}^{35-36}$

Tabela 1 - Solubilidade do herbicida etilclorimuron em solventes orgânicos a $25^{\circ} \mathrm{C}$

\begin{tabular}{lc}
\hline Solvente & Solubilidade / $\mathrm{g} 100 \mathrm{~mL}^{-1}$ \\
\hline Acetonitrila & 3,10 \\
Benzeno & 0,82 \\
Etanol & 0,39 \\
Hexano & 0,01 \\
Metanol & 0,74 \\
Diclorometano & 15,3 \\
Xileno & 0,28 \\
\hline
\end{tabular}

Tabela 2 - Solubilidade do herbicida etilclorimuron em solução com $\mathrm{pH}$ controlado

\begin{tabular}{lc}
\hline $\mathbf{p H}$ & Solubilidade $/ \mathrm{mg} \mathrm{mL}^{-1}$ \\
\hline 1,3 & 1,5 \\
1,9 & 1,5 \\
4,2 & 4,1 \\
5,0 & 9,0 \\
5,8 & 99,0 \\
6,5 & 450,0 \\
7,0 & 1200,0 \\
\hline
\end{tabular}


No tocante à toxicologia do etilclorimuron em seres humanos, de acordo com a bula do produto comercial utilizado neste estudo, as vias de exposição são: oral, inalatória, ocular e dérmica. Estudos com animais de laboratórios (ratos) constam que sua excreção na urina e fezes é rápida e em quantidades aproximadamente iguais, com uma meia-vida biológica de aproximadamente 50 horas. $^{37}$

\subsection{Dinâmica dos herbicidas no ambiente}

Após a aplicação de um herbicida em determinada cultura agrícola, vários processos físicos, químicos, físico-químicos e biológicos determinam seu comportamento no meio ambiente. A dinâmica dos herbicidas é governada por processos relacionados ao movimento destas moléculas nas águas (rios, lagos, entre outros), solos e sedimentos. Esse movimento dá-se pelos processos de retenção (sorção: adsorção, absorção), de transformação (decomposição, degradação) e de transporte (deriva, volatilização, lixiviação, escoamento superficial), e por interações desses processos. Além da variedade de processos envolvidos na determinação do destino ambiental de herbicidas, diferenças nas estruturas e propriedades das substâncias químicas e nas características e condições ambientais podem afetar esses processos. As condições meteorológicas, a composição das populações de micro-organismos no solo, a presença ou ausência de plantas, a localização do solo na topografia e as práticas de manejo podem também afetar o destino de herbicidas no ambiente. Além disso, a taxa e a quantidade de água movendo-se na superfície e através do perfil do solo têm um grande impacto na dinâmica dos herbicidas. ${ }^{38-39}$

Um entendimento dos processos de retenção, transformação e transporte de herbicidas no ambiente, particularmente nas condições dos solos brasileiros, é essencial para direcionar os trabalhos de monitoramento e avaliação de impactos ambientais, nos quais é imprescindível que os atributos e indicadores ambientais de alteração e de impacto sejam conhecidos para que a avaliação seja possível. ${ }^{38}$

Os tipos de interações dos herbicidas com os diferentes componentes do meio ambiente são enormes. Considerando os processos de transporte entre compartimentos ambientais, a lixiviação e o escoamento superficial merecem destaque. O escoamento superficial favorece a contaminação das águas superficiais, pois o herbicida é carreado adsorvido às partículas do solo erodido ou em sedimentos. A lixiviação dos herbicidas 
através do solo tende a resultar em contaminação das águas subterrâneas e, neste caso, as substâncias químicas são carreadas em solução juntamente com a água que alimenta os aquíferos. A permanência dos herbicidas no solo agrícola é inversamente dependente da taxa de ocorrência dos processos de transporte. ${ }^{38}$

O comportamento dos herbicidas no solo e em sedimentos é bastante complexo e é resultante de vários fatores, sendo um deles a interação com os constituintes das diferentes frações contidas no solo (ácido húmico, ácido fúlvico, humina, argila, óxidos, entre outros). ${ }^{40}$

O processo predominante na retenção dos herbicidas nos solos e sedimentos é a sorção, que envolve a adsorção e a dessorção. A adsorção é a interação do soluto (herbicida) presente na solução do solo com a superfície das partículas da fase sólida do solo ou sedimento. É um processo determinante para se entender o comportamento dos herbicidas, influenciando diretamente na disponibilidade dos produtos para as plantas e na ação seletiva dos herbicidas pela interferência no seu deslocamento. ${ }^{40}$

$\mathrm{Na}$ adsorção há uma diminuição da energia livre superficial do sistema sendo, portanto, um processo espontâneo, isto é, o $\Delta G$ é menor do que zero. Entretanto, há uma diminuição do número de graus de liberdade do sistema, pois as moléculas do adsorbato só podem deslocar-se sobre a superfície do adsorvente. Neste sentido, o $\Delta S$ é menor do que zero. De acordo com a Equação 1, pode-se deduzir que o $\Delta \mathrm{H}$ (variação da entalpia) será negativo, mostrando que a adsorção é também um processo exotérmico. ${ }^{41}$

$$
\Delta \mathrm{G}=\Delta \mathrm{H}-\mathrm{T} \Delta \mathrm{S}
$$

Onde: $\quad \Delta G$ é a variação da energia livre de Gibbs (J)

$\Delta \mathrm{H}$ é a variação da entalpia (J)

T é a temperatura $(K)$

$\Delta S$ é a variação da entropia $\left(\mathrm{J} \mathrm{K}^{-1}\right)$

Existem basicamente dois tipos de adsorção: a adsorção física ou fisiossorção e a adsorção química ou quimiossorção. No entanto, em certas ocasiões os dois tipos podem ocorrer simultaneamente. ${ }^{42}$ 
$\mathrm{Na}$ fisiossorção há uma interação de van der Waals entre o adsorbato e o adsorvente. Estas interações são de longo alcance, mas fracas. Esta energia pode ser absorvida como vibrações da rede do adsorvente e dissipada como movimento térmico. Uma molécula que se desloque sobre a superfície perde gradualmente energia e termina por ser adsorvida. Pequenas variações de entalpia são insuficientes para romper as ligações químicas e, por isso, uma molécula fisicamente adsorvida retém a sua identidade, embora possa ser deformada pela presença dos campos de força da superfície. ${ }^{43}$

$\mathrm{Na}$ quimiossorção, as moléculas unem-se à superfície do adsorvente por ligações químicas (usualmente covalentes) e tendem a acomodar-se em sítios que propiciem o número de coordenação máximo como substrato. A entalpia da adsorção química é muito maior do que a da adsorção física, os valores são aproximadamente 10 vezes maiores. A distância entre a superfície do adsorvente e o átomo mais próximo do adsorbato é menor na adsorção química comparada à física. Uma molécula quimicamente ligada pode ser decomposta em virtude de forças de valência dos átomos da superfície e é a existência de fragmentos moleculares adsorvidos que corresponde, em parte, ao efeito catalítico das superfícies sólidas. ${ }^{43}$

A principal forma de avaliar a eficiência de um processo sortivo é por meio das isotermas de adsorção.

\subsubsection{Isotermas de adsorção}

A distribuição do adsorbato entre as fases fluída e adsorvida envolve um equilíbrio que é governado pelos princípios da termodinâmica. Os dados deste equilíbrio são geralmente representados na forma de isotermas. Isotermas de adsorção são gráficos que apresentam a variação da concentração de equilíbrio no sólido adsorvente com a pressão parcial ou concentração da fase fluida, em uma temperatura específica. ${ }^{44-45}$

A determinação experimental das isotermas é o primeiro passo no estudo de um novo sistema de sorção. A informação obtida por meio dessa análise é importante na determinação da quantidade de adsorvente necessária para um determinado processo e, consequentemente, no dimensionamento dos equipamentos a serem utilizados. ${ }^{44-45}$

Após determinação experimental, os resultados e dados obtidos são aplicados a modelos matemáticos para construção das isotermas de adsorção. Os modelos mais utilizados são aqueles desenvolvidos por Langmuir e Freundlich. No entanto, outras 
equações são encontradas na literatura, como a isoterma de Peterson, de Temkin, BET (Brunauer, Emmett e Teller), entre outras. Neste trabalho, apenas as isotermas de Freundlich e Langmuir serão investigadas. ${ }^{43-45}$

\subsubsection{Isoterma de Langmuir}

A isoterma de Langmuir é o modelo mais simples de isoterma e está baseada principalmente em três hipóteses: ${ }^{43,46-47}$

(i ) A adsorção não pode ir além do recobrimento de uma monocamada;

(ii ) Todos os sítios de adsorção são equivalentes uns aos outros e a superfície é uniforme (isto é, a superfície é perfeitamente plana em escala microscópica);

( iii ) A capacidade de uma molécula ser adsorvida em certo sítio é independente da ocupação dos sítios vizinhos (não existem interações entre as moléculas adsorvidas).

No modelo matemático proposto por Langmuir, utiliza-se a Equação 2 para os cálculos pertinentes ao processo sortivo relacionado a este tipo de isoterma.

$$
\frac{X}{M}=\frac{K_{L} \cdot C_{S} \cdot Q}{1+K_{L} \cdot C_{S}}
$$

Onde: $\frac{X}{M}$ é a quantidade adsorvida por grama de sedimento $\left(\mathrm{mg} \mathrm{kg}^{-1}\right)$

$\mathrm{K}_{\mathrm{L}}$ é a constante de Langmuir $\left(\mathrm{L} \mathrm{kg}^{-1}\right)$

Q é a quantidade máxima adsorvida $\left(\mathrm{mg} \mathrm{kg}^{-1}\right)$

$C_{S}$ é a concentração do herbicida em solução $\left(\mathrm{mg} \mathrm{L}^{-1}\right)$ 
A constante de Langmuir $\left(K_{L}\right)$ possui a mesma conotação de uma constante de equilíbrio e está relacionada com a energia livre de adsorção. Esta energia corresponde à afinidade entre a superfície do adsorvente e o soluto. $O$ valor de $Q$ apresenta a máxima quantidade possível de se adsorver, ou seja, nos fornece informações sobre a cobertura do adsorbato em uma monocamada. ${ }^{48}$

$\mathrm{O}$ valor do produto de $\mathrm{K}_{\mathrm{L}}$ e $\mathrm{C}_{S}$ nos indica a afinidade entre o adsorbato e o sítio de adsorção. A adsorção será favorável quando este valor for muito maior que 1 . Se o produto estiver no intervalo entre 0 e 1 , a isoterma tenderá à linearidade, sendo pouco significante a adsorção. $^{48}$

\subsubsection{Isotermas de Freundlich}

Analisando a isoterma de Langmuir e suas hipóteses, é possui concluir que este modelo coexiste em um sistema reacional ideal: as moléculas não interagem entre si e a superfície de adsorção é homogênea, não apresentando falhas. ${ }^{49}$

Neste sentido, o modelo de Freundlich adiciona elementos reais de um sistema reacional, considerando interações químicas e físicas entre as moléculas do adsorbato e entre os sítios de adsorção. ${ }^{41,49}$

A equação de Freundlich (Equação 3) foi originalmente introduzida como uma correlação empírica de dados experimentais, sendo mais tarde derivada matematicamente em 1973 pelo matemático Appel. Nesta equação, considera-se que o processo de adsorção apresenta uma distribuição exponencial dos calores de adsorção a partir da monocamada adsorvida Appel. ${ }^{48-49}$

$$
\frac{X}{M}=K_{f} \cdot C_{e^{\frac{1}{n}}}
$$

Onde: $\frac{X}{M}$ é a quantidade adsorvida por grama de sedimento $\left(\mathrm{mg} \mathrm{k}^{-1}\right)$

$\mathrm{K}_{\mathrm{f}}$ é a constante de Freundlich $\left(\mathrm{Lg}^{-1}\right)$

$\frac{1}{n}$ é a intensidade da adsorção

$C_{e}$ é a concentração de equilíbrio $\left(\mathrm{mg} \mathrm{L}^{-1}\right)$ 
O valor de $K_{f}$ indica a capacidade de adsorção e, quanto maior este valor, maior será a capacidade de adsorção. A constante $1 / \mathrm{n}$ possui valor entre 0 e 1 e está relacionado à heterogeneidade da superfície e à composição química do adsorbato e do sítio de adsorção. Estes fatores interferem diretamente na intensidade da adsorção. Quanto maior o valor de n, mais intensa será a adsorção. Este valor deve ser sempre maior do que 1. Quando $\mathrm{n}$ está em um intervalo entre 2 e 10 considera-se que o processo de adsorção é favorável. ${ }^{41,49}$ Os resultados dessa equação nos mostra que, para baixas concentrações ou altas temperaturas, a constante $\mathrm{n}$ se aproxima de 1 e a quantidade adsorvida tende a ser proporcional à concentração da solução. ${ }^{41}$

Embora a isoterma de Freundlich seja de grande aplicabilidade, principalmente onde ocorre a formação de multicamadas, e de ter sido alvo de inúmeras derivações, esta isoterma apresenta algumas limitações e falhas nos seguintes aspectos: ${ }^{41}$

(i) A quantidade adsorvida cresce indefinidamente com o aumento da concentração;

(ii ) Em soluções diluídas a equação não se reduz a uma isoterma linear, mostrando não obediência à Lei de Henry.

Pela Lei de Henry tem-se que, para a adsorção física em uma superfície homogênea e em baixas concentrações, a isoterma toma uma forma linear, seguindo a relação expressa pela Equação $4 .{ }^{41}$ Esta lei é adequada para casos em que a concentração do sistema é média. Em soluções muito diluídas ou muito concentradas pode não apresentar um bom ajuste. $O$ aumento gradual da concentração causa uma saturação gradual dos sítios de adsorção e um aumento nas interações entre as moléculas adsorvidas. ${ }^{41}$

$$
\mathrm{q}=\mathrm{K} \cdot \mathrm{c}
$$

Onde: q é a quantidade adsorvida, a temperatura constante $\left(\mathrm{mg}^{-1}\right)$

K é a constante de adsorção empírica c é a concentração de equilíbrio (mg t $\left.{ }^{-1}\right)$ 


\subsubsection{Classificação das Isotermas}

Um marco no estudo da sorção de compostos orgânicos e inorgânicos, presentes em solução, foi a publicação dos estudos realizados por Giles e colaboradores em 1960, intitulado: "Estudos em adsorção: um sistema de classificação de isotermas de adsorção de soluções e seu uso no diagnóstico de mecanismos de adsorção e na medição de áreas superficiais específicas dos sólidos". ${ }^{50}$ Este trabalho é um estudo da relação entre os mecanismos de adsorção de soluto em superfícies sólidas e os tipos de isoterma de adsorção obtidos.

Por meio de discussões baseadas em diversos trabalhos de divulgação científica, os sistemas de classificação de todas as isotermas de adsorção em solução, que são conhecidos, são assim descritos. Além disso, este trabalho sugere como a forma da isoterma pode ser utilizada para diagnosticar o mecanismo de adsorção e para obtenção de informações sobre a natureza física do soluto e da superfície do substrato. ${ }^{50} \mathrm{O}$ sistema de classificação proposto (Figura 9) divide as isotermas de adsorção em quatro classes principais, de acordo com a inclinação inicial da curva. As quatro classes foram assim nomeadas: $:^{50-51}$

(i) Isoterma do tipo S (Spherical)

(ii ) Isoterma do tipo L (Langmuir)

( iii ) Isoterma do tipo $\mathrm{H}$ (High Affinity)

(iv) Isoterma do tipo C (Constant Partition). 


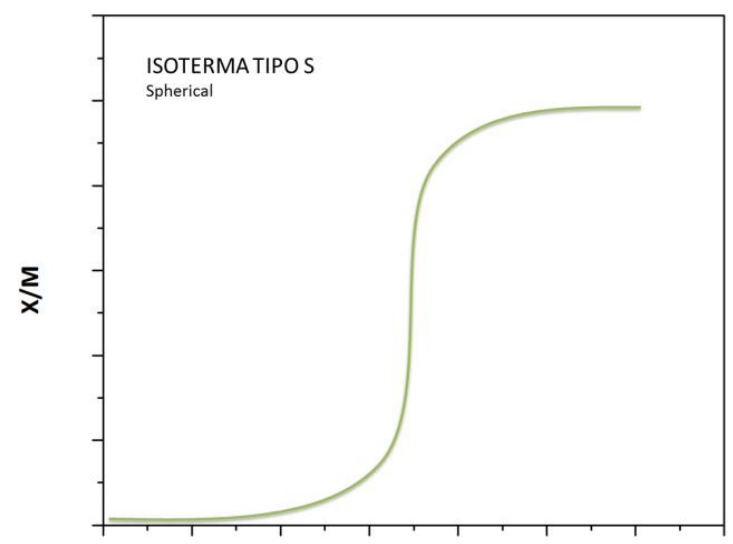

c.

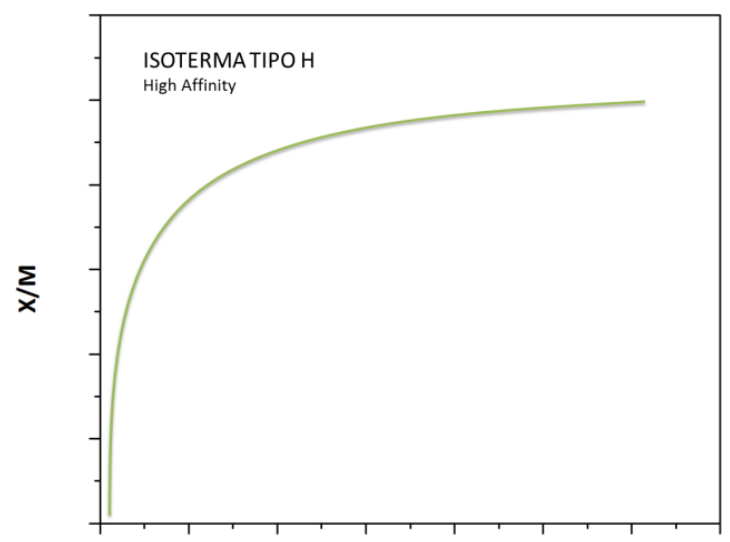

c.

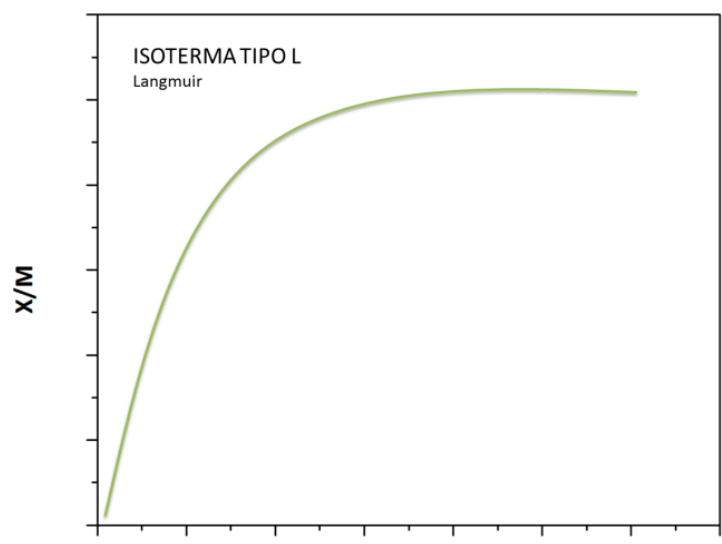

$c_{\text {e }}$

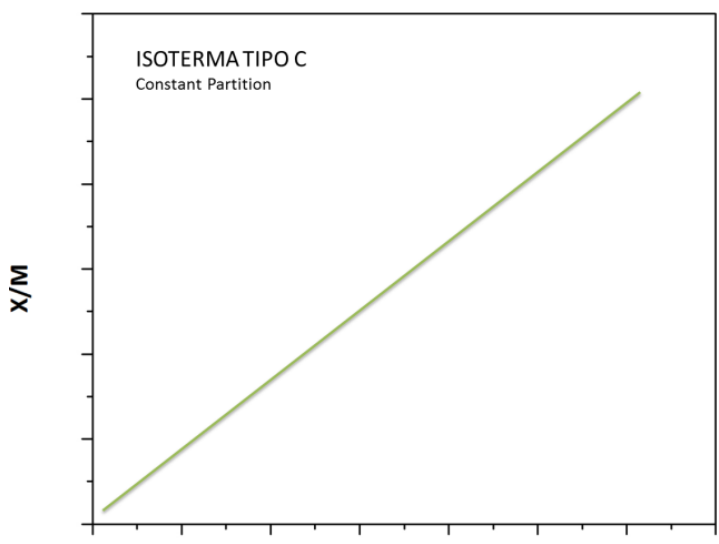

c

FONTE: Adaptado de Giles et al. (1960) ${ }^{50}$

Figura 9 - Esquema representativo das Isotermas de adsorção 


\subsubsection{Isotermas do tipo $S$}

A direção inicial da curvatura das isotermas de tipo $\mathrm{S}$ nos mostra que a adsorção se torna mais eficiente com o aumento da concentração do analito em solução. A adsorção inicial é baixa e aumenta à medida que o número de moléculas adsorvidas aumenta. ${ }^{51} \mathrm{Na}$ prática, estas isotermas são mais bem obtidas diante de três condições: ${ }^{50}$

(i) as moléculas adsorvidas precisam ser monofuncionais;

(ii ) precisam possuir atração intermolecular moderada, causando um empacotamento vertical com disposição regular das camadas;

( iii ) necessitam competir fortemente pelos sítios do substrato com as moléculas do solvente ou outras espécies adsorvidas.

A definição de molécula monofuncional, neste contexto, indica a presença de regiões com polaridades distintas na estrutura molecular do adsorbato. Parte desta estrutura deve apresentar uma região com caráter hidrofóbico, e outra, com acentuada atuação das forças intermoleculares. Isso favorece a adsorção de moléculas em unidades individuais, dificultando a adsorção de micelas. ${ }^{50}$

\subsubsection{Isotermas do tipo L}

A forma das isotermas de tipo L possui inclinação não linear e côncava em relação à abcissa. ${ }^{51}$ Neste caso, a curvatura inicial indica que, quanto mais sítios no substrato forem preenchidos, mais difícil será para uma molécula encontrar um sítio disponível para se adsorver. ${ }^{50}$ Neste sentido, há uma diminuição na disponibilidade dos sítios de adsorção quando a concentração da solução aumenta. ${ }^{51}$

Nesse tipo de isoterma as moléculas adsorvidas são menos susceptíveis à competição entre o solvente e os sítios de adsorção, permanecendo mais fortemente ligada ao adsorvente. Uma situação em que isto ocorre seria em sistemas onde o soluto e o substrato são altamente polares. Nesses casos, os íons adsorvidos podem se associar em aglomerados muito grandes antes da ocorrência da adsorção. ${ }^{50}$ 


\subsubsection{Isotermas do tipo $\mathrm{H}$}

Este é um caso especial da isoterma de tipo L em que o soluto tem uma elevada afinidade de tal forma que, em as soluções diluídas, o adsorbato se encontrará completamente adsorvido ou em quantidades muito pequenas, não sendo passivo de quantificação. ${ }^{51}$

Nesse tipo de isoterma as espécies adsorvidas são moléculas grandes, por exemplo, micelas iônicas ou moléculas poliméricas. Às vezes, o adsorbato são íons pequenos que participam de reações de simples troca com outros íons com afinidade muito menor pela superfície do adsorvente. ${ }^{50}$

\subsubsection{Isotermas do tipo C}

As isotermas do tipo C são caracterizadas pelo processo de partição constante do soluto entre solução e o sítio de adsorção, até a adsorção máxima possível. ${ }^{50}$

As condições que favorecem as isotermas de tipo $C$ são: ${ }^{50}$

(i) presença de substratos porosos com moléculas flexíveis e regiões de diferentes graus de cristalinidade;

( ii ) grande afinidade entre o adsorvente e o adsorbato;

(iii) melhor poder de penetração da espécie adsorvida nos poros do adsorvente.

A linearidade das isotermas de tipo $C$ nos mostra que o número de sítios de adsorção permanece constante durante o processo sortivo. À medida que mais moléculas são adsorvidas mais sítios de adsorção são criados. Tal situação pode surgir quando o adsorbato tem uma maior atração pelo adsorvente do que pelo solvente em si. ${ }^{50}$

\subsubsection{Cinética de adsorção}

A cinética do processo de adsorção é um estudo importante, pois avalia a eficiência da sorção em função do tempo de contato do analito na superfície do adsorvente. ${ }^{45}$ 
O estudo da velocidade da adsorção é feito por meio de modelos cinéticos aplicados aos dados experimentais. Neste trabalho, os cálculos cinéticos serão baseados no método do isolamento. Para resolução de cálculos aplicados a este método, considera-se que as concentrações de todos os reagentes, exceto a de um deles, estaria em grande excesso. Por exemplo, se uma espécie B estiver bastante concentrada na solução, saturando o sistema reacional, é uma boa aproximação considerar esta concentração como constante durante o avanço da reação. Neste caso, a lei de velocidade seria escrita em função de uma pseudo ordem, uma vez que a concentração de B estaria sendo multiplicada pela constante de equilíbrio real.

Entre os modelos cinéticos mais utilizados destacam-se a equação de pseudoprimeira ordem (Equação 5), ${ }^{52}$ também conhecida como a equação de Lagergren, e a equação de pseudo segunda ordem (Equação 6). ${ }^{53}$

$$
\begin{aligned}
& \frac{d C_{a d s}}{d t}=k_{1} \cdot\left(C_{e}-C_{a d s}\right) \\
& \frac{d C_{a d s}}{d t}=k_{2} \cdot\left(C_{e}-C_{a d s}\right)^{2}
\end{aligned}
$$

Onde: t é o tempo de contato $(h)$

$\mathrm{C}_{\mathrm{ads}}$ é a concentração adsorvida em certo $\mathrm{t}\left(\mathrm{mg} \mathrm{L}^{-1}\right)$

$C_{e}$ é a concentração do analito no equilíbrio $\left(\mathrm{mg} \mathrm{L}^{-1}\right)$

$k_{1}$ e $k_{2}$ são as constantes de velocidade da adsorção

\subsubsection{Análise quantitativa}

Nas últimas décadas, diversas técnicas analíticas e instrumentais vêm sendo utilizadas no isolamento e quantificação de xenobióticos, isto é, moléculas estranhas ao ambiente tido como natural. Dentre estas, a cromatografia vem sendo empregada na determinação de pesticidas, seus metabólitos e produtos de transformação em matrizes ambientais, como solo, água e sedimentos. ${ }^{54}$ 
Tais métodos permitem a identificação simultânea de mais de uma centena de princípios ativos a partir da extração com solventes orgânicos e procedimentos para retirada de impurezas, conhecidos como clean-up. ${ }^{55}$

Separações difíceis são, geralmente, alcançadas mais facilmente pela cromatografia líquida de alta eficiência (HPLC). Mesmo apresentando limitações como alto custo de instrumentação e operação, a cromatografia líquida tem sido cada vez mais usada em análises de resíduos de pesticidas devido a sua versatilidade. Pode ser aplicada para compostos orgânicos e inorgânicos, iônicos ou covalentes. ${ }^{55}$

Quando se trabalha com cromatografia e se pensa em verificar se um determinado resultado é confiável ao analito, todo sistema ao redor dessa metodologia deve ter, também, algum sentido de confiabilidade. Na Química Analítica, a amostra definirá sempre os rumos a serem tomados para a determinação qualitativa ou quantitativa de uma ou várias espécies presentes. $\mathrm{O}$ analista lida com a relação amostra/sinal analítico e, para isso, a sua perspicácia e os meios à sua disposição tornarão possível a resolução analítica. Ter um método enquadrado em um nível de validação significa agregar confiança e credibilidade aos dados obtidos. $^{56}$

\subsection{Validação de metodologia analítica}

Validar uma metodologia analítica é dar à mesma validade, credibilidade, confiança. No caso de um sistema de análise de substâncias químicas, a validação objetiva, principalmente, assegurar que o sistema funcione adequadamente dentro das condições de análise para as quais foi validado. Todo sistema apresenta limitações. O importante na validação é conhecer essas limitações e assegurar que o sistema analítico apresente o desempenho esperado, dentro dos limites determinados no processo de validação. ${ }^{57}$

Em uma análise química, ter certeza sobre os dados obtidos pode ser perigoso, pois a certeza dá uma sensação de confiança, criando, portanto, um estado de espírito que, para a emissão de um resultado, pode ter baixa confiabilidade. A clareza sim, como sinônimo de compreensão, permite ao analista apresentar resultados de alta confiabilidade para emissão e para discussões técnicas. ${ }^{56}$

O processo de validação de um método deve estar descrito em um procedimento e 
equipamentos e instrumentos dentro das especificações, funcionando corretamente e adequadamente calibrados. Do mesmo modo, o responsável pela realização dos estudos deve ser competente na área e precisa ter conhecimento suficiente sobre o trabalho, sendo capaz de tomar as decisões apropriadas durante a realização do mesmo. ${ }^{58}$

\subsubsection{Documentos orientativos - Legislações}

Existem razões legais, técnicas e comerciais que justificam a implantação da validação de métodos analíticos, apesar de não haver uma norma estabelecida de âmbito nacional ou internacional. Atualmente, para mostrar competência técnica, os laboratórios que executam as análises devem submeter-se a um credenciamento de um órgão vigente de âmbito nacional ou internacional. ${ }^{59}$

Neste trabalho, os critérios de validação serão discutidos em conformidade a dois documentos ligados a órgãos federais do governo brasileiro: o INMETRO (Instituto Nacional de Metrologia, Normalização e Qualidade Industrial) e a ANVISA (Agência Nacional de Vigilância Sanitária).

O INMETRO é uma autarquia federal brasileira, no formato de uma agência executiva, vinculada ao Ministério do Desenvolvimento, Indústria e Comércio Exterior. Já a ANVISA é uma agência reguladora vinculada ao Ministério da Saúde do Brasil.

O documento do INMETRO é intitulado "Orientação Sobre Validação de Métodos Analíticos: Documento de Caráter Orientativo", código DOQ-CGCRE-008, da Coordenação Geral de Creditação (CGC), está em sua terceira revisão e é datado de fevereiro de $2011 .^{58}$

O documento da ANVISA é a Resolução RE no 899 de 29 de maio de 2003, criado pelo Adjunto da Diretoria Colegiada da Agência Nacional de Vigilância Sanitária, intitulado "Guia para Validação de Métodos Analíticos e Bioanalíticos". 60

Ambos os documentos têm como objetivo auxiliar os laboratórios na tarefa de demonstrar que um método analítico, nas condições em que é praticado, tem as características necessárias para a obtenção de resultados com a qualidade exigida. ${ }^{59}$ 
Os parâmetros de validação devem estar claramente declarados no procedimento documentado e incluir, quando aplicável:

(i ) Seletividade
(ii ) Linearidade
( iii ) Sensibilidade
( iv ) $\quad$ Faixa de trabalho e faixa linear
(v) Limite de detecção
( vi ) Limite de quantificação
( vii ) Recuperação
( viii ) Precisão
( ix ) Exatidão
(x) Robustez

O conceito para cada parâmetro de validação pode variar de acordo com o documento orientativo. Neste sentido, buscou-se comparar as diferentes definições e cálculos para cada parâmetro analisado. Além disso, verificou-se se os valores obtidos contemplam ou não os documentos orientativos, se estão ou não validados.

Nos itens seguintes têm-se a designação de cada conceito. A forma de se determinar cada parâmetro encontra-se na parte experimental deste trabalho.

\subsubsection{Seletividade}

A seletividade, em termos químicos, tem como objetivo garantir a identidade do analito que se deseja determinar. ${ }^{56}$ Este parâmetro corresponde à capacidade de um método em determinar o analito de maneira inequívoca na presença de outras substancias susceptíveis de interferência na determinação. ${ }^{57}$ 
Trata-se de um parâmetro de grande importância na análise de amostras complexas. Neste caso devem-se analisar várias alíquotas diferentes da mesma matriz de forma a determinar, inequivocamente, os componentes da matriz que interferem na determinação do analito de interesse. ${ }^{57}$

Analisando cromatograficamente, caso a matriz possua picos cromatográficos com o mesmo tempo de retenção do herbicida em estudo, será necessária uma revisão da metodologia adotada. Se a seletividade não for assegurada, a linearidade, a recuperação e a precisão estarão seriamente comprometidas. ${ }^{58}$

\subsubsection{Linearidade}

Linearidade é a resposta obtida em função da concentração do analito, a qual deve ser estudada em um intervalo de concentração apropriado. ${ }^{57}$

A correlação entre o sinal medido (área ou altura do pico) e a massa ou concentração da espécie a ser quantificada muito raramente é conhecida a priori. Na maior parte dos casos, a relação matemática entre o sinal e a concentração ou massa da espécie de interesse deve ser determinada empiricamente, a partir de sinais medidos para massas ou concentrações conhecidas dessa espécie. Essa relação matemática, muitas vezes, pode ser expressa como uma equação de reta chamada de "curva analítica". Embora somente dois pontos definam uma reta, na prática as linhas devem ser definidas por, no mínimo, cinco pontos que não incluam o ponto zero na curva, devido aos possíveis erros associados. $^{59}$

Na prática, a linearidade é determinada por intermédio de gráficos, seguidos de um tratamento estatístico. Esses gráficos devem ser construídos relacionando a resposta do equipamento em função de várias concentrações do analito em estudo. ${ }^{57}$

\subsubsection{Faixa de trabalho e faixas lineares}

Para qualquer método quantitativo existe uma faixa de concentrações do analito no qual o método pode ser aplicado. ${ }^{58}$

Todo experimento de determinação da faixa de trabalho é iniciado pela escolha de uma faixa preliminar. A faixa de trabalho deve cobrir a faixa de aplicação para a qual o ensaio vai ser usado. A concentração mais esperada da amostra deve, sempre que possível, situar-se no centro da faixa de trabalho. ${ }^{58,60}$ 
No limite inferior da faixa de concentração, o fator limitante é o valor do limite de quantificação. No limite superior, os fatores limitantes dependem do sistema de resposta do equipamento de medição. ${ }^{58}$

Dentro da faixa de trabalho podem existir as faixas lineares e, dentro destas, a resposta do sinal terá uma relação linear com o analito ou valor da propriedade. A extensão dessa faixa pode ser estabelecida durante a avaliação da faixa de trabalho. ${ }^{58}$

\subsubsection{Limite de detecção}

O limite de detecção (LOD, do inglês limit of detection) corresponde à menor quantidade de um analito que pode ser detectada, não necessariamente quantificada como um valor exato. ${ }^{57}$

$\mathrm{Na}$ prática, o LOD é determinado como a menor quantidade que pode ser diferenciada do ruído do sistema com segurança. O ruído é a amplitude esperada em volts, amperes ou unidades de absorbância do envelope da linha de base, a qual inclui todas as variações randômicas do sinal do detector cuja frequência esteja na ordem de um ou mais ciclos por minuto. ${ }^{57}$

O LOD pode ser calculado de três maneiras diferentes: método visual, método relação sinal-ruído e o método baseado nos parâmetros da curva analítica: ${ }^{59}$

(i) Método visual: é utilizado para determinar o limite de deteç̧ão utilizando a matriz com adição de concentrações conhecidas da substância de interesse, de tal modo que se possa distinguir entre ruído e sinal analítico pela visualização da menor concentração visível (detectável). Este procedimento também pode ser feito pelo instrumento utilizando parâmetros de deteç̧ão no método de integração.

(ii ) Método da relação sinal-ruído: este método pode ser aplicado somente em procedimentos analíticos que mostram o ruído da linha de base. Para determinar a relação sinal-ruído, é feita a comparação entre a medição dos sinais de amostras em baixas concentrações conhecidas do composto de interesse na matriz e um branco (matriz 
isenta do composto de interesse) dessas amostras. Assim, é estabelecida uma concentração mínima na qual a substância pode ser facilmente detectada. A relação sinal-ruído pode ser de 3:1 ou 2:1, proporções geralmente aceitas como estimativas do limite de deteç̧ão.

(iii ) Método baseado em parâmetros da curva analítica: este é o método utilizado neste trabalho. O limite de detecção pode ser calculado em função de dois parâmetros da curva analítica. Um deles é desviopadrão da resposta, que pode ser a estimativa do desvio-padrão do branco, da equação da linha de regressão ou do coeficiente linear da equação. O outro parâmetro é a inclinação ou coeficiente angular da curva analítica. Para calcular estes dados, uma curva analítica deverá ser feita utilizando a matriz contendo o composto de interesse na faixa de concentração próxima ao LOD.

\subsubsection{Limite de quantificação}

O limite de quantificação (LOQ, do inglês limit of quantitaion) corresponde à menor quantidade de um analito que pode ser quantificada com exatidão e com uma fidelidade determinada. ${ }^{57}$

Assim como o LOD, o LOQ é expresso como uma concentração, sendo que a precisão e a exatidão das determinações também devem ser registradas. Esse critério é uma boa regra a ser seguida, porém, a determinação do LOQ representa um compromisso entre a concentração, a precisão e a exatidão exigidas. Isto significa que, quando decresce o nível de concentração do LOQ, as medições tornam-se menos precisas. Se houver necessidade de maior precisão, uma concentração maior deve ser registrada para o LOQ. O método analítico e seu respectivo uso ditam esse compromisso. ${ }^{59}$

O LOQ pode ser calculado utilizando o método visual, a relação sinal-ruído ou a relação entre a estimativa do desvio-padrão da resposta e a inclinação da curva analítica, assim como ocorre para o LOD. ${ }^{59}$ 
O melhor caminho para resolver o problema do cálculo dos LOQ e LOD é utilizar o método baseado nos parâmetros da curva analítica, que é estatisticamente mais confiável. ${ }^{59}$

\subsubsection{Sensibilidade}

Existe uma discordância entre os conceitos que tangem o que seria e como se determinar a sensibilidade de um método analítico.

Segundo o INMETRO, o método é mais sensível quando pequenas variações de concentração resultam em maior variação na resposta, ou seja, maior inclinação da curva analítica. ${ }^{58}$ Sendo assim, a sensibilidade pode ser determinada por intermédio do valor de $a$ da equação da reta. No caso da curva analítica, quanto maior o ângulo de inclinação, mais sensível será o método. ${ }^{57}$

Para a ANVISA, a sensibilidade tem o mesmo significado do LOD. Quanto menor a quantidade passível de detecção, mais sensível será o método. ${ }^{60}$ Contudo, tratam-se de conceitos diferentes, tanto em suas definições, quanto nos cálculos pertinentes para determiná-los. ${ }^{57}$

\subsubsection{Recuperação}

Toda amostra que recebe tratamento de análise indireta (diluição, extração, concentração, derivação, mudança de especiação, entre outras), assim como de forma direta (baixa solubilidade, possibilidade de cristalização, entre outras) deve ter calculado experimentalmente o erro ou a perda da espécie em análise. À porcentagem de erro ou a perda da espécie em análise denomina-se recuperação. ${ }^{56}$

Em outras palavras, a recuperação é uma medida da eficiência do processo de isolamento do analito de interesse da matriz na qual se encontra presente. ${ }^{57}$

Para o INMETRO a recuperação também recebe o nome de tendência. A tendência, quando aplicada a uma série de resultados de ensaios, implica numa combinação de componentes de erros aleatórios e sistemáticos. Seu cálculo pode ser expresso como a recuperação analítica do composto de interesse na matriz, definida como a razão entre o valor observado e o valor esperado. A partir dos valores da recuperação são calculadas a exatidão e a precisão do método. ${ }^{58}$

Para a ANVISA, a recuperação é o valor obtido nos cálculos da exatidão, não apresentando fórmulas com as indicações e procedimentos para realização dos cálculos. ${ }^{60}$ 
Em geral, estes estudos são efetuados adicionando-se soluções do padrão analítico de interesse de concentração conhecida à matriz isenta do analito. Efetuam-se as operações necessárias à recuperação do analito adicionado, e o valor do analito é, então, determinado. Realizando os cálculos pertinentes, encontra-se a quantidade recuperada pelo método. ${ }^{57}$

\subsubsection{Exatidão}

A exatidão expressa a concordância entre o valor encontrado e o valor aceito como verdadeiro ou aceito como referência. ${ }^{57}$

A exatidão é sempre analisada dentro de certos limites, a um dado nível de confiança (ou seja, aparece sempre associada a valores de precisão). Estes limites podem ser estreitos em níveis de concentrações elevadas e mais amplos em níveis de traço. ${ }^{59}$

O número de ensaios varia segundo a legislação ou diretriz adotada e também com as características da pesquisa. Os métodos mais utilizados para avaliar a exatidão de um método são: o uso de materiais de referência certificados, a comparação de métodos, realização de ensaios de recuperação e a adição padrão. ${ }^{59}$ Neste trabalho a exatidão será calculada via ensaios de recuperação. Os itens abaixo apresentam uma descrição de cada método mencionado. ${ }^{59}$

(i) Materiais certificados de referência (CRM): os CRM são materiais de referência acompanhados de um certificado que possui o valor de concentração de uma dada substância, ou outra grandeza para cada parâmetro e uma incerteza associada. Os valores obtidos pelo laboratório (a média e a estimativa do desvio-padrão de uma série de replicatas) da mesma amostra padrão devem ser comparados com os valores certificados do material de referência, para verificar a exatidão do método.

(ii ) Comparação de métodos: consiste na comparação entre resultados obtidos empregando-se o método em desenvolvimento e os resultados conseguidos via um método de referência, avaliando o grau de proximidade entre os resultados obtidos pelos dois métodos, ou seja, o grau de exatidão do método testado em relação ao de 
referência. Esta abordagem assume que a incerteza do método de referência é conhecida. As análises são efetuadas em replicata, utilizando os dois métodos em separado (o método em desenvolvimento e o método de referência), sobre as mesmas amostras, em uma faixa de concentrações em que se pretende validar o método.

(iii ) Ensaios de recuperação: a recuperação é definida como a proporção da quantidade da substância de interesse, presente ou adicionada na porção analítica do material teste, que é extraída e passível de ser quantificada. O conceito de recuperação foi apresentado no item anterior (2.4.8).

(iv ) Adição padrão: este método é usado quando for difícil ou impossível preparar um branco da matriz. No método de adição padrão, quantidades conhecidas da substância são adicionadas à matriz, antes do procedimento de preparo da amostra. A concentração da substância de interesse na amostra original pode ser determinada pelo método gráfico ou matematicamente.

Fazendo uma comparação entre os conceitos apresentados pela ANVISA e pelo INMETRO no tocante à exatidão: para o INMETRO a exatidão deve ser avaliada numericamente de acordo com a tendência (recuperação do método), porém não é tratada como sendo um parâmetro para se validar. Já a ANVISA tem a exatidão como parâmetro de validação e o calcula como sendo a recuperação do método. ${ }^{58,60}$

\subsubsection{Precisão}

A precisão é a expressão da concordância entre vários resultados analíticos obtidos para uma mesma amostra. ${ }^{57}$ Representa a dispersão de resultados entre ensaios independentes, repetidos de uma mesma amostra, amostras semelhantes ou padrões, sob condições definidas. ${ }^{59}$ 
A precisão é avaliada pelo desvio-padrão absoluto $(\sigma)$, que utiliza um número significativo de medições, normalmente maior que 20. Outra expressão da precisão é pela estimativa do desvio-padrão relativo (RSD), também conhecido como coeficiente de variação (CV). ${ }^{59}$

Normalmente, métodos que quantificam compostos em macro quantidades requerem um CV de 1 a 2\%. Em métodos de análise de traços ou impurezas, são aceitos os valores de CV de até $20 \%$, dependendo da complexidade da amostra. Uma maneira simples de melhorar a precisão é aumentar o número de replicatas. ${ }^{59}$

A precisão pode ser determinada em condições de repetibilidade ou em condições de reprodutibilidade. Condições de repetibilidade são aquelas em que resultados independentes são obtidos utilizando: ${ }^{57}$

(i) o mesmo método,

(ii ) o mesmo laboratório,

(iii ) os mesmos operadores,

(iv ) o mesmo equipamento,

(v) em um curto intervalo de tempo

As condições de reprodutibilidade são aquelas em que resultados são obtidos usando: ${ }^{57}$

(i) o mesmo método,

(ii ) diferentes laboratórios,

(iii ) diferentes operadores,

(iv) diferentes equipamentos,

(v) em um longo intervalo de tempo. 


\subsubsection{Robustez}

A robustez é uma medida da capacidade que um método tem de não sofrer alterações em decorrência de pequenas variações, deliberadamente introduzidas nos parâmetros desse método. ${ }^{57}$ Embora não faça parte de alguns procedimentos de validação, a robustez deve ser incluída em um procedimento completo de validação, uma vez que ela mede a confiabilidade do método em condições anormais de operação. A influência dos fatores na resposta da análise pode ser verificada individual ou simultaneament. ${ }^{57}$

Este parâmetro consta em ambos os documentos de validação, complementando mutualmente a carência de informações que existe tanto para a ANVISA quanto para o INMETRO. O documento do INMETRO orienta os procedimentos para o cálculo da robustez. Tal procedimento é mais bem descrito no documento anterior ao utilizado neste trabalho, trata-se da 1a revisão realizada em março de $2003 .{ }^{61} \mathrm{O}$ texto apresenta exemplos, cálculos e fórmulas que auxiliam a resolução do problema via teste estatístico de Youden. Trata-se de um teste que permite não só avaliar a robustez do método, mas também ordenar a influência de cada uma das variações nos resultados finais, indicando qual é a influência de cada variável na robustez do método. Convém salientar que quanto maior for a robustez, maior será a confiança desse relacionamento à sua precisão. ${ }^{58}$ Este documento é falho por não orientar quanto aos parâmetros necessários para realização dos ensaios de robustez. Já o documento da ANVISA apresenta de forma clara esses parâmetros, mas não orienta quanto aos cálculos necessários para resolução da análise.

A ANVISA recomenda os parâmetros necessários para realização dos ensaios da robustez para diferentes técnicas analíticas. Para cromatografia líquida da alta eficiência (HPLC), os parâmetros para determinação da robustez são: ${ }^{60}$

(i) variação do $\mathrm{pH}$ da fase móvel,

(ii ) variação na composição da fase móvel,

( iii ) colunas de diferentes lotes e fabricantes,

(iv) temperatura e

(v) fluxo da fase móvel. 


\section{OBJETIVO}

O presente trabalho tem como objetivo realizar estudos que visam a determinar a dinâmica do herbicida etilclorimuron no ambiente via sua adsorção em sedimentos. Além disso, têm-se como objetivos específicos:

(i) Caracterizar amostras de sedimentos de localidades distribuídas ao longo de um gradiente de degradação ambiental em uma paisagem agrícola;

(ii ) Validar um método para determinação do herbicida etilclorimuron em sedimentos utilizando cromatografia líquida de alta eficiência (HPLC) com detector de ultravioleta (UV);

(iii ) Determinar a dinâmica do herbicida etilclorimuron nos sedimentos caracterizados. Estes estudos serão realizados via cinética e isotermas de adsorção. 


\section{METODOLOGIA}

\subsection{Materiais e Reagentes}

\subsubsection{Equipamentos e Materiais}

Os equipamentos e materiais utilizados na realização deste trabalho encontram-se listados abaixo:

(i) Cromatógrafo líquido de alta eficiência (HPLC) Shimadzu, modelo SCL-10A com: detector UV-Vis SPD-20A, desgaseificador DGU-20A5, bomba LC-20AT, sistema de controle CBM-20A, monitor MPSV1410SL e software Shimadzu Class-VP (Kyoto, 26 - Japão)

(ii) Coluna cromatográfica Agilent Zorbax RP-18 5 um, 150 x 4,6 mm (Saint Louis, MO - Estados Unidos)

(iii) Filtro de seringa Sartorius Stedin, Minisart RC $25 \mathrm{~mm}, 0,45$ um (Aubagne, 13 - França)

(iv ) Balança analítica Scientech SA-210 (Bradford, MA - Estados Unidos)

( v ) Sistema de destilação de água Tecnal TE-180 (Piracicaba, SP - Brasil)

( vi ) Sistema de filtração de água ultrapura (tipo Milli-Q) Millipore (Billerica, MA - Estados Unidos)

( vii ) Estufa de secagem e esterificação Fanem 315-SE (São Paulo, SP - Brasil)

( viii ) Forno de mufla EDG EDGCOM-1P (São Paulo, SP - Brasil)

( ix ) Mesa agitadora Tecnal TE-140 (Piracicaba, SP - Brasil)

( x ) Centrífuga Hitachi Himac CR20B2 (Chiyoda, 13 - Japão)

( xi ) pHmetro digital Tecnal modelo pH Meter TEC-2 (Piracicaba, SP - Brasil) 
(xii ) Espectrofotômetro TOC-V CPH Shimadzu, acoplado ao módulo para amostras sólidas SSM-5000A Shimadzu (Kyoto, 26 - Japão)

( xiii ) Espectrofluorímetro Hitachi F-4500 (Chiyoda, 13- Japão)

(xiv) Espectrofotômetro de infravermelho com transformada de Fourier (FTIR) Bomem MB-102 (Quebec, QC - Canadá)

( xv ) Espectrofotometro de UV-Vis Jasco V 630 (Oklahoma, OK - Estados Unidos)

( xvi ) Absorção Atômica Varian 240FS (São Francisco, CA - Estados Unidos)

( xvii ) Liofilizador Liotop L202 (São Carlos, SP - Brasil)

\subsection{2 $\quad$ Reagentes}

Os reagentes e solventes utilizados na realização deste trabalho encontram-se listados abaixo:

(i) Acetonitrila $\left(\mathrm{CH}_{3} \mathrm{CN}\right)$ grau HPLC Tedia

(ii) Acetona $\left(\mathrm{CH}_{3} \mathrm{COCH}_{3}\right)$ grau HPLC Tedia

( iii ) Metanol $\left(\mathrm{CH}_{3} \mathrm{OH}\right)$ grau HPLC Tedia

(iv) Ácido fosfórico $\left(\mathrm{H}_{3} \mathrm{PO}_{4}\right)$ Qhemis

(v) Ácido fluorídrico (HF) Qhemis

(vi ) Ácido clorídrico $(\mathrm{HCl})$ Tedia

( vii ) Hidróxido de sódio $(\mathrm{NaOH})$ Qhemis

( viii ) Hidróxido de potássio $(\mathrm{KOH})$ Merck

(ix ) Cloreto de cálcio $\left(\mathrm{CaCl}_{2}\right) \mathrm{QM}$

(x) Cloreto de potássio $(\mathrm{KCl})$ Merck 


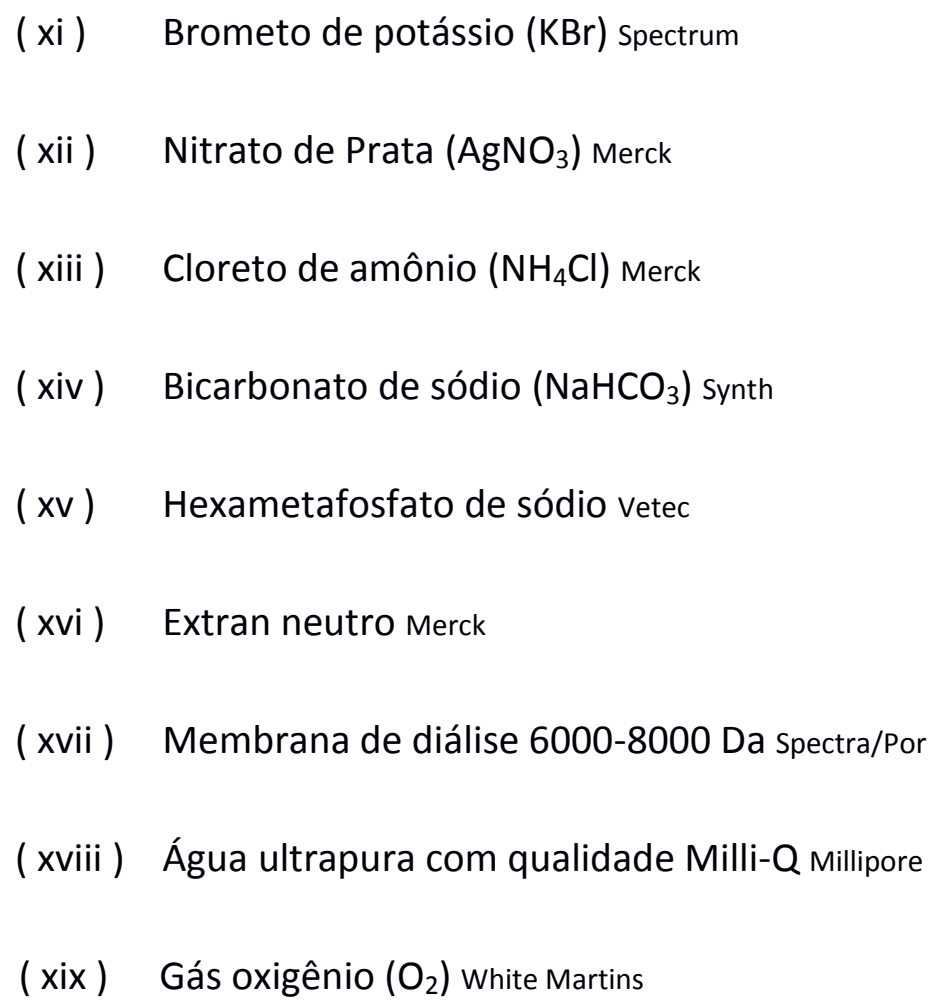

\subsection{Vidrarias e acessórios}

Para o preparo das soluções, foram utilizadas vidrarias e acessórios volumétricos Classe A calibrados conforme critérios da norma ISO 17.025 por empresa competente credenciada pelo INMETRO e acreditada pela RBC (Rede Brasileira de Calibração). ${ }^{62}$ As calibrações foram realizadas pela empresa Ellus Instrumentação ${ }^{\circledR}$.

\subsection{Padrão analítico}

O padrão analítico do pesticida etilclorimurom (CAS 90982-32-4) foi adquirido da empresa Sigma-Aldrich ${ }^{\circledR}$ (Munich, BY - Alemanha), no estado sólido e com 97,1\% de pureza. O padrão foi utilizado na validação do método analítico.

\subsection{Procedimentos comuns}

\subsubsection{Limpeza das vidrarias e utensílios}

Toda vidraria e demais utensílios utilizados foram, antes de sua utilização, imersos em solução de detergente Extran ${ }^{\circledR}$ neutro por 24 horas. Em seguida, o material foi enxaguado exaustivamente: seis vezes em água corrente, três vezes em água destilada, uma 
vez com água ultrapura (Milli- ${ }^{\circledR}$ ) e uma vez com acetona. A secagem foi feita em estufa a $60^{\circ} \mathrm{C}$ com exceção dos materiais volumétricos, os quais secaram a temperatura ambiente. Quando secos, antes de sua utilização, realizaram-se mais duas lavagens utilizando acetona.

\subsubsection{Determinações cromatográficas}

O herbicida etilclorimuron foi determinado cromatograficamente via HPLC-UV. Em cada procedimento descrito ao longo deste trabalho, utilizaram-se diferentes parâmetros como: temperatura, fluxo da fase móvel, pH da fase móvel, origem do analito, entre outros, quando necessário. As determinações cromatográficas foram realizadas nas seguintes etapas:

(i) Purga: o sistema foi purgado com metanol e água ultrapura (50:50) de acordo com os parâmetros pré-configurados do cromatógrafo;

(ii ) Estabilização do sistema e condicionamento da coluna cromatográfica: inicialmente a coluna foi condicionada com metanol e água ultrapura (50:50 V/V) a um fluxo de $0,2 \mathrm{~mL} \mathrm{~min}^{-1}$ durante 20 minutos, elevado gradualmente em unidades de $0,2 \mathrm{~mL} \mathrm{~min}^{-1}$ até o fluxo que foi utilizado na determinação cromatográfica. Utilizou-se neste processo o mesmo tempo de análise e composição da fase móvel.

(iii ) Injeção da amostra: utilizando uma seringa devidamente calibrada e verificada, injetaram-se $50 \mathrm{uL}$ da amostra no injetor do cromatógrafo. O sistema já estava configurado para coletar 20 uL (volume da alça do injetor de 6 pórticos). O excedente deste montante foi descartado.

(iv) Limpeza da coluna: a cada três determinações cromatográficas injetou-se apenas a fase móvel para evitar o saturamento do leito cromatogáfico. Ao término das análises injetou-se metanol e água ultrapura (50:50) a fluxo de $0,5 \mathrm{~mL} \mathrm{~min}^{-1}$ durante 20 minutos. 


\subsubsection{Purificação do analito em solução}

O analito em solução foi purificado via filtração em papel seguida por purificação em filtro de seringa - disco de material sorbente RC (celulose regenerada).

Em um frasco de $200 \mathrm{~mL}$ com tampa, adicionou-se $1 \mathrm{~g}$ do sedimento e $10 \mathrm{~mL}$ de solvente (acetonitrila ou a solução do herbicida, dependendo da análise). O frasco foi mantido em agitação orbital em tempos determinados. Nas análises para a validação do método analítico (seletividade, recuperação, exatidão e precisão), o tempo de contato foi de 15 minutos. Para construção das isotermas de adsorção manteve-se o contato por um tempo de 24 horas. Na determinação da cinética de adsorção o tempo variou dentro do intervalo de 5 minutos a 48 horas.

A suspensão foi filtrada em papel utilizando um funil como suporte. O tempo de filtração foi de 15 minutos. O produto obtido foi coletado em vials de $40 \mathrm{~mL}$. Para diminuição do efeito da matriz, purificou-se o filtrado em discos de material sorbente RC. Os discos foram condicionados com $5 \mathrm{~mL}$ de metanol, seguido por $5 \mathrm{~mL}$ de acetonitrila. Após purificação, o mesmo procedimento foi utilizado na limpeza dos discos. O material coletado foi armazenado em vials de $10 \mathrm{~mL}$ e armazenados em refrigerador com temperatura entre 2 e $4^{\circ} \mathrm{C}$ para posterior determinação em HPLC-UV.

\subsection{Análise estatística}

Todas as análises, testes e ensaios realizados em bancadas foram realizados em triplicata. O mesmo ocorre com as determinações cromatográficas e espectroscópicas. Os resultados quantitativos foram apresentados na forma de média mais ou menos o erro absoluto. O erro foi calculado pela Equação 7. O valor de $t$ de Student possui $95 \%$ de confiabilidade e 2 graus de liberdade. No caso das curvas analíticas o erro é apresentado na forma de desvio-padrão. ${ }^{63}$

$$
e=\frac{t \cdot s}{\sqrt{n}}
$$

Onde: e é o erro absoluto t é o valor de t de Student 
S é o valor do desvio-padrão

n é o número de repetições

Os cromatogramas e espectros foram apresentados após tratamento no software Microlab $^{\circledR}$ Origin $^{\circledR}$ versão 8 . Os testes e análises estatísticas foram realizados no software IDAMS Statistical Software ${ }^{\circledR}$ desenvolvido pela UNESCO.

\subsection{Caracterização dos sedimentos}

Os sedimentos analisados foram coletados em corpos d'água lênticos distribuídos em três ambientes distintos ao longo de uma gradiente de degradação ambiental em uma paisagem agrícola. A amostragem foi realizada em poças, brejos, lagoas, dutos e canaletas, reservatórios, entre outros. A região analisada pertence ao entorno da cidade de Luís Antônio, estado de São Paulo (SP), Brasil. As amostras foram nomeadas em função do uso dado à terra, por assim dizer:

(i) Zona Agrícola (ZA): ambiente de cultivo extensivo e latifundiário de cana-de-açúcar além de outras culturas rotativas de menor importância econômica. A amostragem foi composta por 47 pontos de coleta;

(ii) Zona Pecuária (ZP): ambiente de pastagem para o gado de corte e leiteiro. Região localizada na confluência com o perímetro urbano adjacente. A amostragem foi realizada em 20 pontos.

(iii ) Estação Ecológica (EE): ambiente de referência com reduzida ação antrópica, coberto por cerradão, mata estacional semi-decídua, localizado na Estação Ecológica e Experimental de Jataí. Foram coletadas amostras em 17 pontos diferentes. 
Na Figura 10 está apresenta a área geral onde as amostragens foram realizadas. Em anexo, encontram-se apresentadas as coordenadas geográficas e as imagens de satélite dos pontos de coleta.

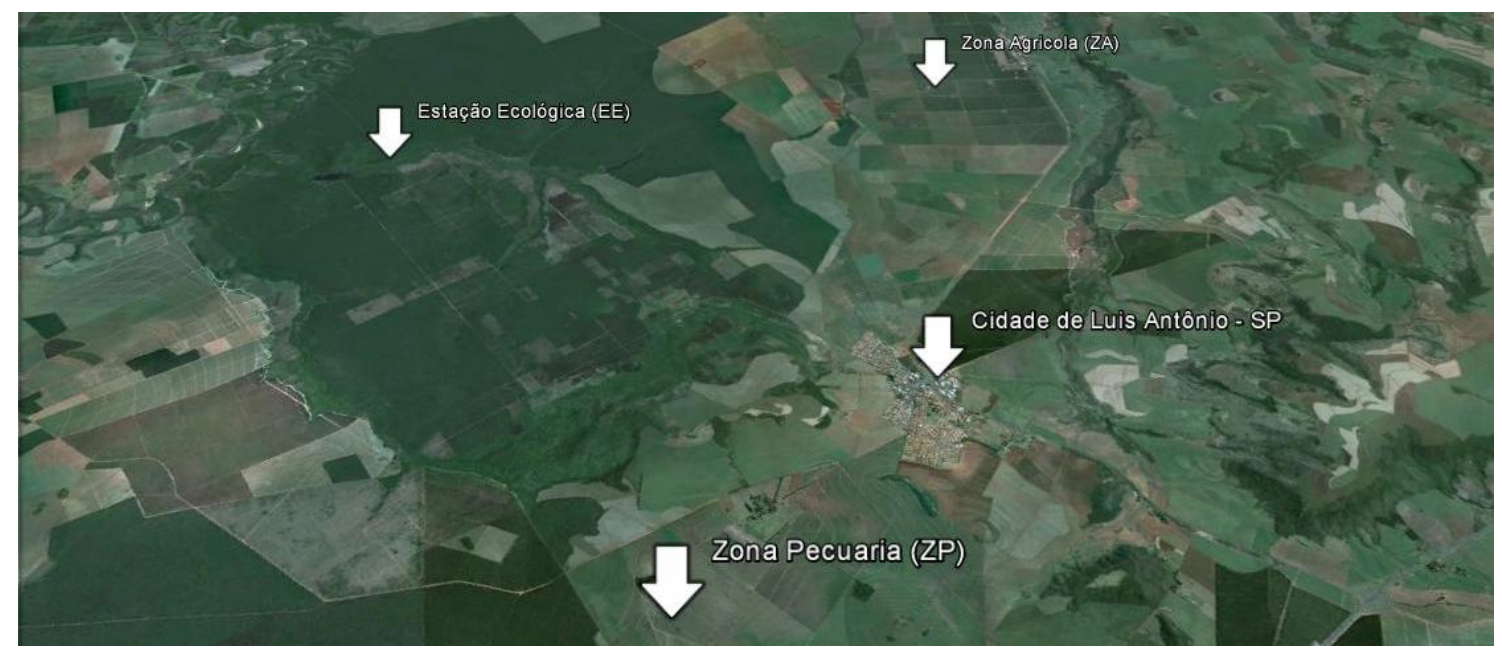

Figura 10 - Localização geográfica das áreas analisadas

As amostras foram coletadas pelo 'Grupo de Ecologia Teórica e Aplicada em Paisagens Modificadas' da Escola de Artes, Ciências e Humanidades (EACH) - Universidade de São Paulo (USP), sob orientação do professor Dr. Luís César Schiesari.

Estas amostras foram secas em estufa a $(105 \pm 5)^{\circ} \mathrm{C}$ por 48 horas, maceradas até homogeneidade e, em seguida, peneiradas a $2 \mathrm{~mm}$. Foram determinadas as propriedades químicas dos sedimentos, como: $\mathrm{pH}$, teor de matéria orgânica, teor de carbono orgânico total, capacidade de troca catiônica, teor dos ácidos húmicos; e físicas: humidade e classe textural. Nestas determinações utilizaram-se as metodologias propostas pela Empresa Brasileira de Pesquisa Agropecuária (EMBRAPA) e pelo Instituto Agronômico de Campinas (IAC). ${ }^{64-65}$

Um estudo espectroscópico dos ácidos húmicos foi realizado após sua extração e purificação. Os experimentos de espectroscopia na região do infravermelho por transformada de Fourier (FTIR) foram realizados para obtenção de informações sobre a composição dos grupos funcionais presentes na estrutura dos ácidos húmicos. As análises espectroscópicas na região do visível e de fluorescência indicaram o grau de humificação dos sedimentos analisados. 
Foi analisado o efeito do uso da terra (para agricultura, pecuária ou estação ecológica) nas características físicas e químicas de seus sedimentos. Para determinação destas características, foram utilizados os procedimentos abaixo descritos.

\subsubsection{Sólidos totais - Humidade}

Para determinação do teor de sólidos totais, cerca de $10 \mathrm{~g}$ (com precisão de 0,1 mg) do material foram colocados em um cadinho previamente tarado e levado a estufa a (105 \pm $5)^{\circ} \mathrm{C}$ até peso constante. Após seu resfriamento em um dessecador, determinou-se seu percentual de sólidos totais. Entende-se como teor de humidade a diferença entre os sólidos totais e o peso total da amostra. ${ }^{65}$

\subsubsection{Potencial de hidrogênio $(\mathrm{pH})$}

Para a determinação do potencial de hidrogênio $(\mathrm{pH}), 10 \mathrm{~g}$ (com precisão de 0,1 mg) da amostra foram dissolvidos em $50 \mathrm{~mL}$ de solução de cloreto de cálcio $\left(\mathrm{CaCl}_{2}\right)$ 0,01 mol L-1, com agitação periódica e ocasional durante 30 minutos, tendo, então, o pH determinado. As leituras foram realizadas em temperatura de $25^{\circ} \mathrm{C}{ }^{65}$

\subsubsection{Teor de matéria orgânica}

Na determinação do teor de matéria orgânica, pesaram-se $10 \mathrm{~g}$ (com precisão de $0,1 \mathrm{mg}$ ) do material, submetendo-o a uma calcinação à temperatura de $550^{\circ} \mathrm{C}$ durante um período de 4 horas. Após seu resfriamento em um dessecador, determinou-se seu percentual de matéria orgânica. Entende-se como teor de matéria orgânica, a diferença entre os sólidos totais e o conteúdo mineral obtido após a calcinação. ${ }^{65}$

\subsubsection{Teor de carbono orgânico total}

As análises de carbono orgânico total (TOC, do inglês: total organic carbon) foram realizadas oxidando $0,1 \mathrm{~g}$ das amostras a $900^{\circ} \mathrm{C}$ utilizando um fluxo de $\mathrm{O}_{2}$ a $0,3 \mathrm{~L} \mathrm{~min}{ }^{-1}$. Utilizou-se um espectrofotômetro próprio para determinação de carbono com detector operante na região do infravermelho.

\subsubsection{Capacidade de troca catiônica (CTC)}


A capacidade de troca catiônica (CTC) foi calculada pela relação existente entre a acidez trocável e as bases trocáveis. ${ }^{65}$

(i) Acidez trocável (A): em um erlenmeyer de $125 \mathrm{~mL}$ foram pesados 5,00 g de amostra. Em seguida, adicionaram-se $50 \mathrm{~mL}$ de uma solução de cloreto de potássio $(\mathrm{KCl}), 1,00 \mathrm{~mol} \mathrm{~L}^{-1}$. Agitou-se a mistura por 30 minutos e, em seguida, a suspensão foi filtrada em papel de filtro, adicionando-se duas porções de $10 \mathrm{~mL}$ da solução de $\mathrm{KCl}$ 1,00 mol $\mathrm{L}^{-1}$. Titulou-se o filtrado com solução de hidróxido de sódio $(\mathrm{NaOH})$ 0,01 mol L ${ }^{-1}$. Pela Equação 8, determinou-se a acidez trocável. $\mathrm{O}$ valor obtido corresponde à soma das concentrações dos íons $\mathrm{Al}^{+3} \mathrm{e}$ $\mathrm{H}^{+}$.

$\mathrm{A}=\left[\mathrm{Al}^{+3}\right]+\left[\mathrm{H}^{+}\right]=\left(\frac{\mathrm{C} \cdot \mathrm{V}}{\mathrm{m}}\right) \cdot 100$ Equação (8)

Onde: $\quad$ A é a acidez trocável $\left(\mathrm{cmol}_{\mathrm{c}} \mathrm{kg}^{-1}\right)$

C é a concentração da solução de $\mathrm{NaOH}\left(\mathrm{mol} \mathrm{L}^{-1}\right)$

V é o volume de base gasto na titulação (L)

$\mathrm{m}$ é a massa de amostra $(\mathrm{kg})$

(ii) Bases Trocáveis (S): Foram adicionados $5 \mathrm{~g}$ da amostra em um erlenmeyer de $125 \mathrm{~mL}$ juntamente com $50 \mathrm{~mL}$ de uma solução de cloreto de amônio $\left(\mathrm{NH}_{4} \mathrm{Cl}\right)$ 1,00 mol L-1. Agitou-se ocasionalmente a suspensão durante 30 minutos e, em seguida, permaneceu em repouso por 24 horas. A suspensão foi filtrada e a solução obtida foi enviada para análise dos cátions metálicos: cálcio $\left(\mathrm{Ca}^{+2}\right)$, magnésio $\left(\mathrm{Mg}^{+2}\right)$, sódio $\left(\mathrm{Na}^{+}\right)$e potássio $\left(\mathrm{K}^{+}\right)$. Estas determinações foram realizadas no Laboratório de Saneamento (SHS) da Escola de Engenharia de São Carlos (EESC) - Departamento de Hidráulica e 
Saneamento (SHS) da Universidade de São Paulo (USP). As bases trocáveis foram calculadas pela soma dos íons metálicos, conforme mostra a Equação 9.

$$
\mathrm{S}=\left[\mathrm{Ca}^{+2}\right]+\left[\mathrm{Mg}^{+2}\right]+\left[\mathrm{Na}^{+}\right]+\left[\mathrm{K}^{+}\right]
$$

Equação (9)

Onde: $\quad$ S são as bases trocáveis $\left(\mathrm{cmol}_{\mathrm{c}} \mathrm{kg}^{-1}\right)$

[ ] são as concentrações dos íons analisados $\left(\mathrm{cmol}_{c} \mathrm{~kg}^{-1}\right)$

Foram calculados dois tipos de capacidade de troca catiônica: a CTC efetiva e a CTC a pH 7. $\mathrm{A} \mathrm{CTC} \mathrm{a} \mathrm{pH} 7$ corresponde à soma das concentrações dos íons analisados na determinação da acidez e das bases trocáveis, conforme apresentado na Equação 10. Esta equação pode ser simplificada aplicando um cálculo direto, de acordo com a Equação 11. A CTC efetiva corresponde a CTC a pH7 menos a concentração dos íons $\mathrm{Al}^{+3}$, conforme calculado pela Equação 12.

$$
\begin{aligned}
& \mathrm{CTC}_{\mathrm{pH} 7}=\left[\mathrm{Al}^{+3}\right]+\left[\mathrm{H}^{+}\right]+\left[\mathrm{Ca}^{+2}\right]+\left[\mathrm{Mg}^{+2}\right]+\left[\mathrm{Na}^{+}\right]+\left[\mathrm{K}^{+}\right] \\
& \mathrm{CTC}_{\mathrm{pH7}}=\mathrm{A}+\mathrm{S} \\
& \mathrm{CTC}_{\mathrm{ef}}=\mathrm{CTC}_{\mathrm{pH} 7}-\left[\mathrm{Al}^{+3}\right]
\end{aligned}
$$$$
\text { Equação (10) }
$$ 


\subsubsection{Classe textural}

A classe textural dos sedimentos foi determinada via análise granulométrica. Para isso, em um becker de $250 \mathrm{~mL}$ foram pesados $20 \mathrm{~g}$ da amostra e adicionados $100 \mathrm{~mL} \mathrm{da}$ solução dispersante. A solução dispersante foi preparada adicionando $45,7 \mathrm{~g}$ de hexametafosfato de sódio em 1 litro de água destilada, permanecendo em agitação até dissolução completa do reagente. O sedimento e a solução dispersante permaneceram em agitação mecânica a $30 \mathrm{rpm}$ durante dezesseis horas. A suspensão foi transferida para uma proveta de $500 \mathrm{~mL}$ ( $5 \mathrm{~cm}$ de diâmetro) passando por uma peneira com malha de $0,05 \mathrm{~mm}$. 0 volume da proveta foi completado com água destilada. O material retido na peneira de 0,05 $\mathrm{mm}$ foi lavado com um jato forte de água e seco em estufa a $(105 \pm 5)^{\circ} \mathrm{C}$ até peso constante. $^{64}$

A análise granulométrica foi dividida em duas etapas: análise de argila e silte (partículas menores que 0,05 mm) e análise das partículas maiores que silte, ou seja, areia, pedregulhos e rochas. ${ }^{64}$

(i) Argila e silte: as determinações das frações silte e argila foram realizadas pelo método do densímetro. Inicialmente, a mistura foi agitada até completa suspensão das partículas. O densímetro foi inserido na proveta e o tempo exato do início da sedimentação foi anotado. Foram realizadas medições da densidade e da temperatura nos tempos: $0,5,1,2,4,8,15$ e 30 minutos e $1,2,4,8$ e 24 horas, a contar do início da sedimentação. Aproximadamente entre 15 e 20 segundos antes de cada leitura, o densímetro foi mergulhado lenta e cuidadosamente na dispersão. Após a leitura, o densímetro foi retirado da dispersão e colocado em uma proveta com água limpa, à mesma temperatura e volume da dispersão. O diâmetro máximo das partículas do sedimento em suspensão foi calculado de acordo com a Equação 13. O percentual deste particulado na suspensão foi calculado pela equação $14 .^{64,66}$ 


$$
\begin{aligned}
& d=\sqrt{\frac{1000 \cdot \mu}{\delta-\delta_{d}} \cdot \frac{a}{t}} \\
& Q=N \cdot \frac{\delta}{\delta-\delta_{d}} \cdot \frac{V \cdot \delta_{c} \cdot\left(L-L_{d}\right)}{\frac{M_{L}}{(100+h)} \cdot 100}
\end{aligned}
$$

Onde: Q é a porcentagem de particulado na suspensão (\%)

d é o diâmetro máximo das partículas $(\mathrm{mm})$

$\mu$ é o coeficiente de viscosidade da água (tabelado)

$\delta$ é a massa específica dos grãos do solo (tabelado)

$\delta_{d}$ é a massa específica do meio dispersor $\left(\mathrm{g} \mathrm{cm}^{-3}\right)$

a é a altura de queda das partículas (tabelado)

t é o tempo de sedimentação (s)

$\mathrm{N}$ é o percentual de material peneirado em $2 \mathrm{~mm}(\%)$

$V$ é o volume da suspensão (mL)

L é a densidade na suspensão $\left(\mathrm{g} \mathrm{cm}^{-3}\right)$

$L_{d}$ é a densidade no meio dispersor (tabelado)

$\mathrm{M}_{\mathrm{h}}$ é o peso do material úmido (g)

h é a humidade do material (\%)

Para efeito de cálculo, foram utilizados os valores de $\delta_{d}$ e $\delta_{c}$ iguais a $1,0 \mathrm{~g} \mathrm{~cm}^{-3}$, o valor de $V$ foi de $1.000 \mathrm{~mL}$. Os valores tabelados se encontram na norma NBR 7181:1984. ${ }^{66}$

(ii ) Pedregulho e areia: as determinações das frações pedregulho e areia foram realizadas via peneiramento, utilizando o material retido na peneira de $0,05 \mathrm{~mm}$. Foi utilizado um jogo de peneiras com as malhas: 4,$8 ; 9,5 ; 19,0 ; 25,0 ; 38,0$ e $50,0 \mathrm{~mm}$. O sistema contendo todas as peneiras foi mantido em mesa agitadora durante dez 
minutos. O peso retido em cada fração foi anotado para cálculos posteriores. Calculou-se o percentual retido em cada peneira fazendo comparação com o peso inicial do sedimento (100\%). A malha da peneira utilizada equivale ao $d$ calculado na Equação 13.0 percentual do sedimento retido na respectiva malha equivale ao $Q$ calculado na Equação $14{ }^{64,66}$

Os sedimentos foram classificados de acordo com os percentuais dos seus componentes. Esta classificação é feita em função dos intervalos de $d$. Soma-se os respectivos valores de $Q$ em cada faixa para se ter a composição graunolétrica. Os componentes e seus intervalos granulométricos se encontram na Tabela $3 .{ }^{64}$

\begin{tabular}{lc}
$\begin{array}{l}\text { TABELA 3 - Classificação Granulométrica } \\
\text { Componente }\end{array}$ & Diâmetro Máximo \\
\hline Argila & $0,002>d>0,002 \mathrm{~mm}$ \\
Silte & $0,05>d>0,25 \mathrm{~mm}$ \\
Areias: & $0,25>d>0,5 \mathrm{~mm}$ \\
Fina & $0,5>d>2 \mathrm{~mm}$ \\
Média & $d>2 \mathrm{~mm}$ \\
Grossa &
\end{tabular}

A classe textural foi determinada de acordo com o diagrama proposto pelo IAC. Este diagrama recebe o nome de triângulo para determinação de classes texturais e é apresentado na Figura $11 .^{64}$ 


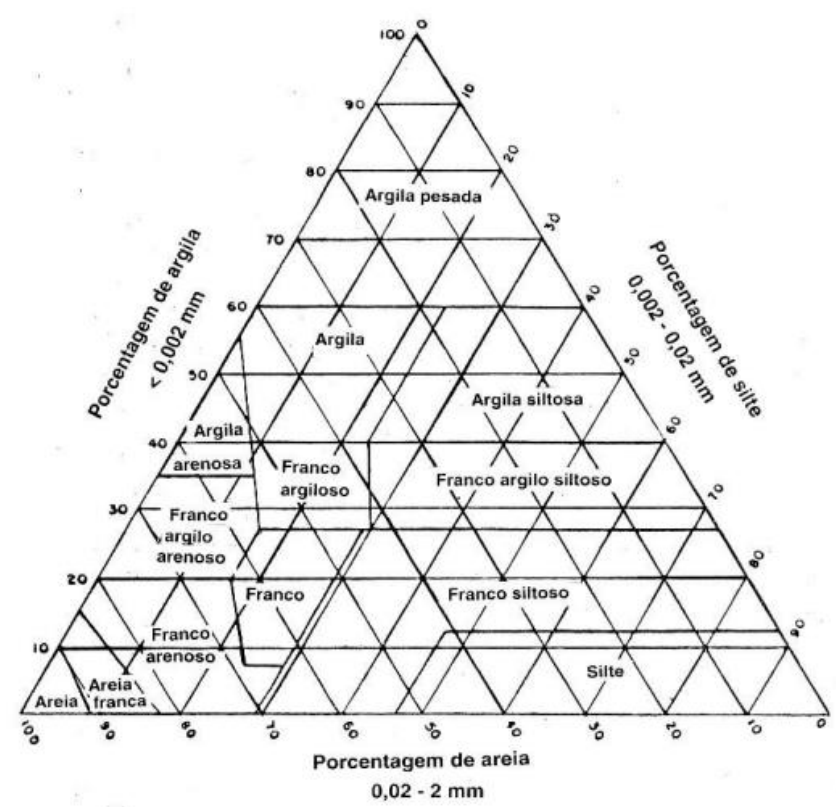

Figura 11 - Triângulo para determinação de classes texturais.

\subsubsection{Fracionamento das substâncias húmicas}

O fracionamento das substâncias húmicas teve como objetivo o isolamento dos ácidos húmicos. Os sedimentos foram submetidos a um processo de extração e purificação por diferença de solubilidade. A metodologia utilizada foi a sugerida pela Sociedade Internacional de Substâncias Húmicas (IHSS). A extração foi realizada de acordo com os cinco passos a seguir: ${ }^{67}$

(i) Em um becker de $1 \mathrm{~L}$ foram adicionados $100 \mathrm{~g}$ de sedimento e $1 \mathrm{~L}$ de solução de $\mathrm{HCl} 0,1 \mathrm{~mol} \mathrm{~L}^{-1}$. A solução permaneceu em agitação manual durante 1 hora e, em seguida, esteve em repouso por mais 2 horas para decantação.

(ii ) O sobrenadante (ácidos húmicos, fúlvicos e resíduos de humina) foi separado por sifonação. O precipitado (humina) foi descartado. Ao sobrenadante foi adicionado $1 \mathrm{~L}$ de solução de $\mathrm{NaOH} 0,1 \mathrm{~mol} \mathrm{~L}^{-1}$. A solução permaneceu em agitação manual durante 4 horas e, em seguida, manteve-se em repouso por mais 16 horas. 
(iii) Após a decantação, o precipitado (humina) foi descartado. 0 sobrenadante (ácidos húmicos e fúlvicos) foi centrifugado durante 20 minutos a 10.000 rpm para a eliminação da argila.

(iv) Com o auxílio de um conta-gotas, o sobrenadante foi acidificado adicionando uma solução de $\mathrm{HCl} 6 \mathrm{~mol} \mathrm{~L}^{-1}$ até obtenção do $\mathrm{pH}$ da solução entre 1 e 2 . A suspensão repousou por mais 12 horas.

( v ) Ao término, os ácidos húmicos estavam isolados no precipitado enquanto que o ácido fúlvico permanecia em solução. Os ácidos húmicos foram separados por sifonação.

\subsubsection{Purificação dos ácidos húmicos}

Os ácidos húmicos isolados foram purificados para eliminação de íons e substâncias indesejadas. A metodologia utilizada foi a sugerida pela IHSS. A purificação foi realizada de acordo com os cinco passos a seguir. ${ }^{67}$

(i) Inicialmente, os ácidos húmicos foram redissolvidos em solução de

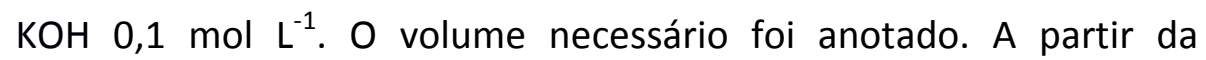
Equação 15 calculou-se a massa de $\mathrm{KCl}$ necessária para completar uma concentração de íons $\mathrm{K}^{+}$equivalente a $3,0 \mathrm{~mol} \mathrm{~L}^{-1}$.

$$
m_{\mathrm{KCl}}=14,91 . \mathrm{V}_{\mathrm{KOH}}
$$

Onde: $\quad \mathrm{m}_{\mathrm{KCl}}$ é a massa de $\mathrm{KCl}(\mathrm{g})$

$$
V_{\text {KOH }} \text { é o volume gasto na redissolução (L) }
$$


A massa de $\mathrm{KCl}$ calculada foi adicionada à solução sendo, em seguida, centrifugada a 15.000 rpm durante 20 minutos para a eliminação dos sólidos suspensos (impurezas).

(ii) Ao sobrenadante obtido adicionou-se a solução de $\mathrm{HCl} 6,0 \mathrm{~mol} \mathrm{~L}^{-1}$ com agitação simultânea até que fosse atingido um pH da solução com valor entre 1 e 2 . A suspensão foi então mantida em repouso por 16 horas. A solução foi centrifugada a $10.000 \mathrm{rpm}$ durante 10 minutos. O sobrenadante foi descartado.

(iii ) Em um becker de plástico, adicionou-se ao sistemas as soluções de $\mathrm{HCl} 0,1 \mathrm{~mol} \mathrm{~L}^{-1}$ e $\mathrm{HF}$ 0,3 $\mathrm{mol} \mathrm{L}^{-1}$ até completa suspensão dos ácidos húmicos, permanecendo a solução em repouso durante 16 horas. A solução foi centrifugada a 12.000 rpm durante 20 minutos.

(iv) O precipitado foi transferido para uma membrana de diálise. As membranas foram preparadas segundo a metodologia de Mc Phie (1971). ${ }^{68}$ O material permaneceu em diálise em água ultrapura com constante reposição. A diálise procedeu até que a água apresentasse um teste negativo de cloreto. O teste cloreto consiste no gotejamento de nitrato de prata $\left(\mathrm{AgNO}_{3}\right)$ em uma alíquota da água de diálise. Alguma ausência de precipitado indica não haver mais cloreto em solução. Este procedimento foi mantido durante aproximadamente sete dias, fazendo-se a troca da água duas vezes por dia. Após a diálise, as amostras foram congeladas e liofilizadas. Após a liofilização os ácidos húmicos foram macerados e armazenados em dessecador.

Na Figura 12 estão apresentados os procedimentos para o fracionamento das substâncias húmicas e para a purificação dos ácidos húmicos. Uma linha tracejada separa ambos os procedimentos. 


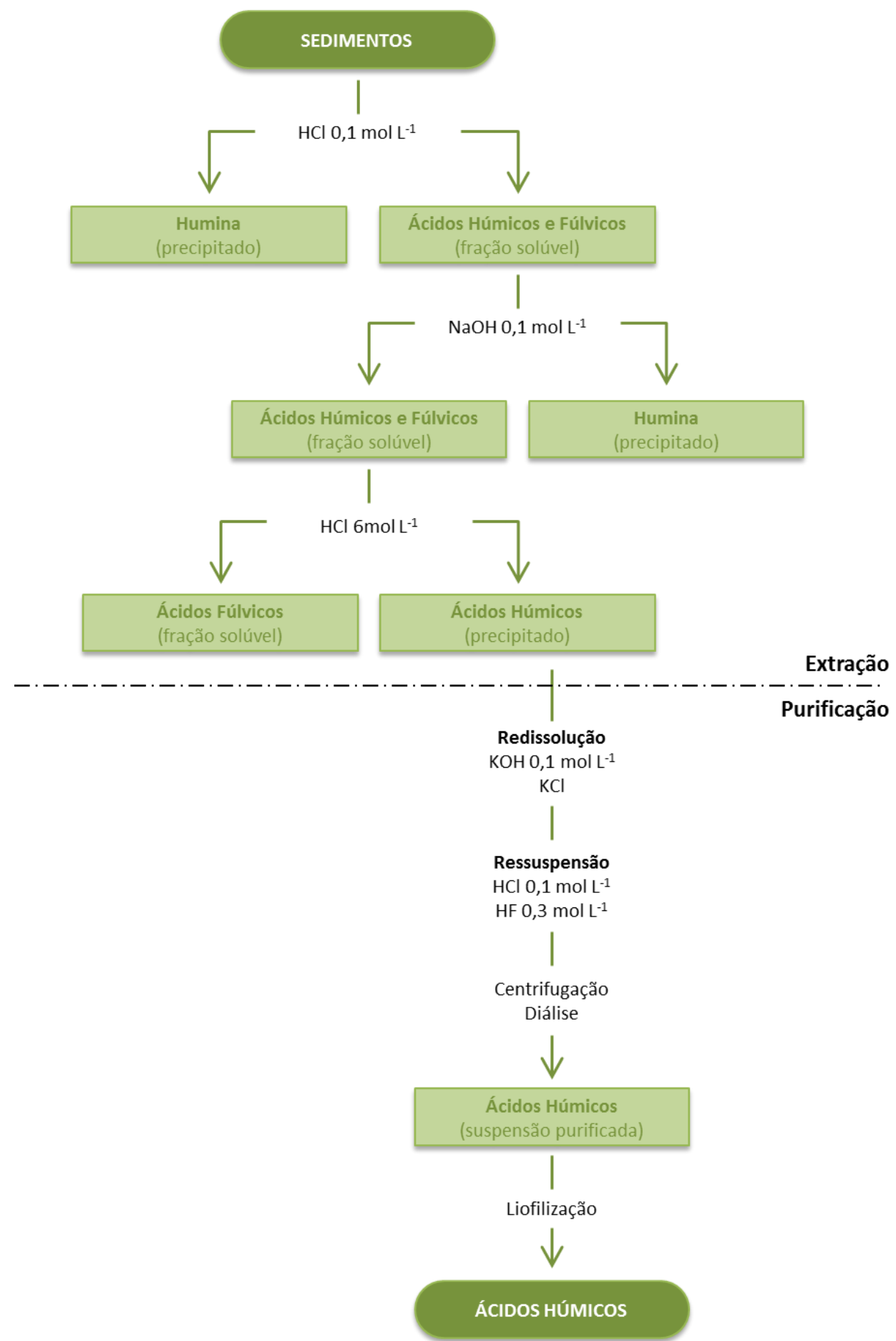

FONTE: Adaptado de Landgraf et al. (2005) ${ }^{1}$

Figura 12 - Fracionamento e purificação dos ácidos húmicos. 


\subsubsection{Caracterização dos ácidos húmicos}

Um estudo espectroscópico dos ácidos húmicos foi realizado após sua extração e purificação. Foram realizadas análises de espectroscopia na região do infravermelho além das técnicas utilizadas na determinação do grau de humificação. O grau de humificação foi determinado por três metodologias diferentes: método Vis, método Milori e o método Kalbitz, as quais tiveram seus resultados comparados. Os dois últimos métodos citados foram determinados via espectroscopia de fluorescência (EF).

(i) Espectroscopia na região do infravermelho (FTIR): os espectros dos ácidos húmicos na região do infravermelho foram obtidos utilizando pastilhas de $\mathrm{KBr}$, com resolução de $4 \mathrm{~cm}^{-1}$ e 32 acumulações. Foram utilizadas aproximadamente $3,0 \mathrm{mg}$ de amostra e $97,0 \mathrm{mg}$ de $\mathrm{KBr}$. Foram analisados os números de onda no intervalo entre 4000 e 400 $\mathrm{cm}^{-1}$.

(ii ) Determinação do grau de humificação: o grau de humificação foi determinado a partir de um estudo espectroscópico a partir de soluções de ácido húmico em bicarbonato de sódio $\left(\mathrm{NaHCO}_{3}\right)$. As soluções foram preparadas por diluição de soluções de $2 \mathrm{mg}$ de amostra em $10 \mathrm{~mL}$ da solução de $\mathrm{NaHCO}_{3} 0,05 \mathrm{~mol} \mathrm{~L}^{-1}$ e com pH 8. A solução foi diluída para $20 \mathrm{mg} \mathrm{L}^{-1}$ para realização dos ensaios Os métodos utilizados na determinação do grau de humificação são:

(ii.i ) Método Vis: os espectros de absorção de radiação visível foram adquiridos no intervalo entre 200 e 800 nm. O grau de humificação, segundo este método, foi determinado pela razão entre as absorbâncias referentes aos comprimentos de onda 465 e 665 nm. ${ }^{69}$

(ii.ii ) Método Milori: os espectros de fluorescência foram obtidos por emissão com excitação em 465nm, em um intervalo de varredura entre 480 e $700 \mathrm{~nm}$ e com filtro aberto. A determinação do grau de humificação foi baseada na integração da área do espectro referente a este intervalo. ${ }^{69}$ 
(ii.iii) Método Kalbitz: os espectros de fluorescência foram obtidos no modo sincronizado no intervalo entre 300 e $520 \mathrm{~nm}$ simultaneamente, com filtro aberto e diferença de comprimento de onda $(\Delta \lambda)$ igual a $55 \mathrm{~nm}$. A determinação do índice de humificação foi realizada a partir da razão entre as intensidades de fluorescência em 400 e $360 \mathrm{~nm}$, ou em 470 e $360 \mathrm{~nm}^{70}$

\subsection{Validação do método analítico}

O herbicida etilclorimun foi determinado e quantificado via cromatografia líquida de alta eficiência com detector de ultravioleta (HPLC - UV). A instrumentação do cromatógrafo utilizado se encontra na relação do item 4.1.1. Os parâmetros cromatográficos e as metodologias utilizadas no preparo das soluções utilizadas se encontram nos itens a seguir.

\subsubsection{Preparo da solução estoque e soluções iniciais}

A partir do padrão de etilclorimuron (sólido) foi preparado um volume de $100 \mathrm{~mL}$ de uma solução estoque de concentração $100 \mathrm{mg} \mathrm{L}^{-1}$. Para isso, foram utilizadas $0,0100 \mathrm{~g}$ do padrão, completando o volume com acetonitrila.

A partir desta solução estoque foram preparadas duas soluções iniciais, uma de concentração $10 \mathrm{mg} \mathrm{L}^{-1}$ e outra de $1 \mathrm{mg} \mathrm{L}^{-1}$, chamadas de $S_{i}$ e $S_{i i}$, respectivamente, ambas com volume de $10 \mathrm{~mL}$. Para o preparo de $S_{i}$ foi utilizado o volume de $1 \mathrm{~mL}$ da solução estoque, e para a $S_{i i}$ foram necessários $0,1 \mathrm{~mL}$. Todas as soluções foram transferidas para vials com tampa e estocadas em um congelador a $4^{\circ} \mathrm{C}$.

\subsubsection{Preparo das soluções analíticas}

Foram preparadas dez soluções analíticas para validação do método proposto. 0 volume foi de $10 \mathrm{~mL}$ e as concentrações: 0,$1 ; 0,5 ; 1,0 ; 5,0 ; 50,0 ; 100,0 ; 250,0 ; 500,0 ; 750,0$ e $1.000,0$ ug L $^{-1}$, todas preparadas a partir das soluções iniciais. Os volumes necessários para o preparo destas soluções encontram-se citados na Tabela 4. 
Depois de adicionadas as quantidades citadas de solução inicial, o volume foi completado até o menisco utilizando acetonitrila. $\mathrm{O}$ volume foi ajustado com uma pipeta Pasteur para evitar possíveis erros de diluição e para facilitar o ajuste do menisco.

Tabela 4 - Volumes necessários para preparo das soluções analíticas

\begin{tabular}{lccc}
\hline Ponto & Solução / ug L ${ }^{-1}$ & Volume $\left(\mathbf{S}_{\mathrm{i}}\right) / \mathrm{uL}$ & Volume $\left(\mathbf{S}_{\mathrm{ii}}\right) / \mathrm{uL}$ \\
\hline P1 & 0,1 & 1,0 & - \\
P2 & 0,5 & 5,0 & - \\
P3 & 1,0 & 10,0 & - \\
P4 & 5,0 & 50,0 & - \\
P5 & 50,0 & 500,0 & - \\
P6 & 100,0 & - & 100,0 \\
P7 & 250,0 & - & 250,0 \\
P8 & 500,0 & - & 500,0 \\
P9 & 750,0 & - & 750,0 \\
P10 & $1.000,0$ & - & $1.000,0$ \\
\hline
\end{tabular}

\subsubsection{Parâmetros Cromatográficos}

Os parâmetros cromatográficos em validação foram selecionados após exaustivos testes preliminares. São eles:

(i) Coluna: RP-18 5um de $250 \times 4,6 \mathrm{~mm}$

(ii ) Composição da fase móvel: $60 \% \mathrm{CH}_{3} \mathrm{CN}+40 \%\left(\mathrm{H}_{2} \mathrm{O} 0,1 \% \mathrm{H}_{3} \mathrm{PO}_{4}\right)$

(iii ) Eluição isocrática

(iv) Fluxo da fase móvel: $1,4 \mathrm{~mL} \mathrm{~min}^{-1}$

( v ) $\quad \mathrm{pH}_{\text {Solução da Fase Móvel: }}$ 2,0 


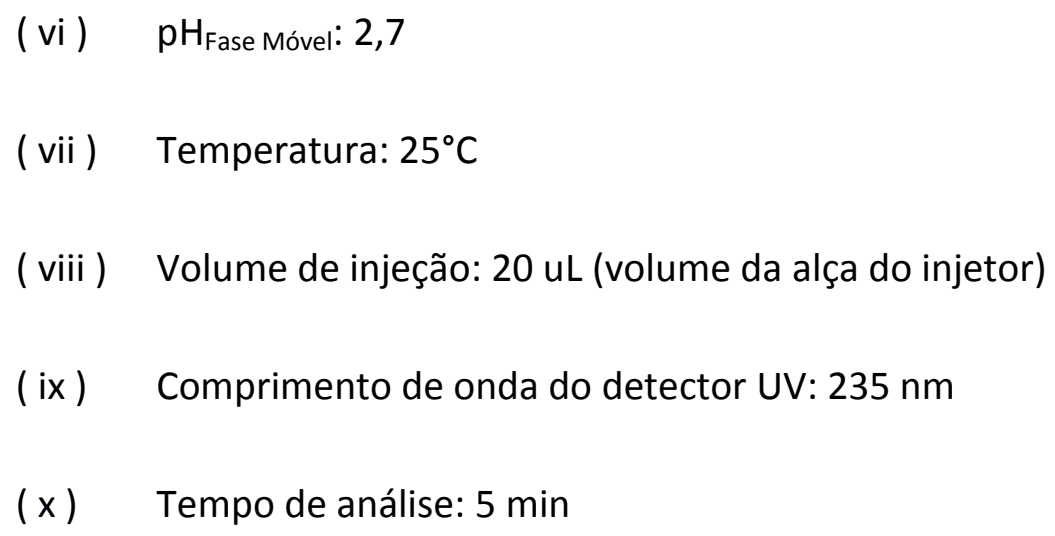

Estes parâmetros cromatográficos foram validados pelos itens de validação que abaixo estão discutidos no tocante aos métodos experimentais, cálculos e testes estatísticos.

Nas tabelas onde os resultados estão apresentados, comparam-se os valores aqui obtidos com aqueles dos itens de validação cabíveis de valores orientativos ou normativos para cada documento: INMETRO e ANVISA. Quando o valor é compatível à norma, constará que Sim e o valor será validado. Quando este valor for rejeitado, constará que Não, ou seja, não será validado. Para os parâmetros cujos valores prescritos não existem, constará que Não Contempla.

\subsubsection{Seletividade}

A seletividade é o primeiro parâmetro de validação que deve ser analisado. Este fato é devido a sua influência sobre os demais critérios analisados.

Os ensaios para análise da seletividade foram realizados em duas etapas:

(i) Determinação cromatográfica do analito (etilclorimuron) isento da matriz (sedimento), ou seja, a solução padrão.

(ii ) Determinação cromatográfica da matriz na ausência do analito, ou seja, apenas o sedimento.

Inicialmente, o herbicida etilclorimuron foi determinado por HPLC - UV seguindo os parâmetros cromatográficos citados no item anterior. O tempo de retenção obtido foi anotado. Em seguida, os sedimentos foram analisados segundo a mesma metodologia 
aplicada na análise do herbicida. O procedimento de separação e purificação do analito foi realizado de acordo com o item 4.5.3.

Caso a matriz possuísse picos cromatográficos com o mesmo tempo de retenção do herbicida em estudo, seria necessária uma revisão da metodologia adotada, uma vez que os demais critérios de validação estariam comprometidos.

\subsubsection{Linearidade}

Para determinação da linearidade, foi construída uma curva analítica com 10 pontos, referentes às soluções preparadas no item 4.8.2. Por regressão linear (método dos mínimos quadrados) foi determinada a equação da reta (Equação 16) correspondente à curva analítica. Os parâmetros lineares $a$ e $b$ e seus desvios-padrão, o coeficiente de correlação e o desvio da concentração, foram calculados de acordo com as equações de 17 a $24 .^{63}$

$$
\begin{aligned}
& y=a \cdot x+b \\
& a=\frac{n \cdot \sum\left(x_{i} \cdot y_{i}\right)-\left(\sum x_{i} \cdot \sum y_{i}\right)}{n \sum\left(x_{i}^{2}\right)-\left(\sum x_{i}\right)^{2}} \\
& b=\frac{\sum\left(x_{i}^{2}\right) \cdot \sum y_{i}-\sum\left(x_{i} \cdot y_{i}\right) \sum x_{i}}{n \sum\left(x_{i}^{2}\right)-\left(\sum x_{i}\right)^{2}} \\
& S_{a}=\sqrt{\frac{n \cdot S_{y}^{2}}{\operatorname{det} D}}
\end{aligned}
$$

$$
\begin{aligned}
& S_{b}=\sqrt{\frac{S_{y}^{2} \cdot \sum\left(x_{i}^{2}\right)}{\operatorname{det} D}} \\
& S_{y}=\sqrt{\frac{\sum\left(d_{i}^{2}\right)}{n-2}}
\end{aligned}
$$


$d_{i}=y_{i}-\left(a \cdot x_{i}\right)-b$

Equação (22)

$D=\left|\begin{array}{cc}\sum\left(\mathrm{x}_{\mathrm{i}}^{2}\right) & \sum \mathrm{x}_{\mathrm{i}} \\ \sum \mathrm{x}_{\mathrm{i}} & \mathrm{n}\end{array}\right|$

Equação (23)

$$
R^{2}=\frac{\left[\sum\left(x_{i}-M_{x}\right) \cdot\left(y_{i}-M_{y}\right)\right]^{2}}{\sum\left(x_{i}-M_{x}\right)^{2} \cdot \sum\left(y_{i}-M_{y}\right)^{2}}
$$

Onde: y ou $y_{i}$ é a resposta medida (área do pico cromatográfico) a é o coeficiente angular, a inclinação da curva analítica $x$ ou $x_{i}$ é a concentração analisada b é o coeficiente linear, a interseção da reta com o eixo y $\mathrm{n}$ é o número de pontos da curva analítica $S_{a}$ é o desvio-padrão do coeficiente angular a $\mathrm{S}_{\mathrm{b}}$ é o desvio-padrão do coeficiente linear $\mathrm{b}$ $S_{y}$ é o desvio-padrão da concentração $D_{i}$ é o desvio vertical $\mathrm{R}^{2}$ é o coeficiente de correlação da reta $M_{x}$ e $M_{y}$ são as médias de $x$ e $y$

\subsubsection{Faixa de Trabalho e Faixa Linear}

A faixa de trabalho compreende o intervalo entre a menor e a maior concentração determinada pelo método (de acordo com as soluções preparadas na Tabela 4).

As faixas lineares são os intervalos contidos na faixa de trabalho que corresponderam a uma tendência linear única. Estas faixas devem possuir seus parâmetros lineares melhores que a faixa de trabalho separadamente. Neste sentido, os valores para os limites de detecção e quantificação (determinados via curva analítica) são aprimorados, alcançando concentrações menores. Também foi observado o coeficiente de correlação 
linear. A faixa de trabalho foi ajustada em faixas lineares até obtenção dos valores para o $\mathrm{R}^{2}$ mais próximos a 1 .

\subsubsection{Limite de detecção e de quantificação}

Os limites de detecção e quantificação (LOD e LOQ) foram calculados de acordo com as equações 25 e 26 . O cálculo se baseou no método da curva analítica.

$$
\begin{aligned}
& \mathrm{LOD}=3 \cdot\left(\frac{\mathrm{S}_{\mathrm{A}}}{\mathrm{b}}\right) \\
& \mathrm{LOQ}=10 \cdot\left(\frac{\mathrm{S}_{\mathrm{A}}}{\mathrm{b}}\right)
\end{aligned}
$$

Onde: LOD é o limite de detecção $\left(\mathrm{mol} \mathrm{L}^{-1}\right)$

LOQ é o limite de quantificação $\left(\mathrm{mol} \mathrm{L}^{-1}\right)$

$S_{a}$ é o desvio-padrão de a (coeficiente angular)

b é o intercepto da curva analítica (coeficiente linear)

\subsubsection{Sensibilidade}

A sensibilidade do método foi determinada utilizando a equação da reta obtida para a faixa de trabalho e, caso ocorra, para as faixas lineares.

Segundo orientação do INMETRO, a sensibilidade é dada pelo termo $a$ da equação da reta, referente ao coeficiente angular da curva analítica.

Por considerar inadequada a definição dada pela ANVISA para o parâmetro da sensibilidade, considera-se irrelevante o cálculo da sensibilidade segundo a orientação dada por aquele órgão.

\subsubsection{Recuperação}

Os ensaios para recuperação foram realizados de acordo com a metodologia proposta pelo INMETRO. A ANVISA não considera a recuperação um conceito para validação de métodos analíticos, apenas para os bioanalíticos. 
Para verificar a recuperação do método foram adicionados $10 \mathrm{~mL}$ de solução do herbicida em $1 \mathrm{~g}$ de sedimento. Foram realizados ensaios para três concentrações: 10,0; 100,0 e 1000,0 ug L ${ }^{-1}$.

As análises foram realizadas em frascos de vidro de $200 \mathrm{~mL}$. Os recipientes foram postos em agitação orbital por 15 minutos e, em seguida, o analito isolado e purificado de acordo com o item 4.5 .3 e quantificado via determinação cromatográfica.

Este procedimento também foi realizado para uma amostra de sedimento não fortificada. Para isso, injetou-se o padrão analítico com a mesma concentração analisada.

Pelas áreas obtidas, calculou-se a recuperação do método (Equação 27). Os cálculos foram realizados para cada concentração analisada.

$$
R(\%)=\left(\frac{A_{f}-A_{n}}{A_{p}}\right) \cdot 100
$$

Onde: $\quad R(\%)$ é o percentual de recuperação

$A_{f}$ é a área do pico cromatográfico da amostra fortificada

$A_{n}$ é a área do pico cromatográfico da amostra não fortificada

$A_{p}$ é a área do pico cromatográfico do padrão analítico

\subsubsection{Exatidão}

A orientação da ANVISA e do INMETRO para determinação da exatidão ocorre por metodologias distintas.

O INMETRO, em nota (página 10 do documento orientativo), diz que a exatidão é avaliada numericamente via recuperação do método. ${ }^{58}$ Neste sentido, foram utilizados os resultados obtidos na recuperação do método para o cálculo da exatidão.

A ANVISA recomenda um cálculo para determinação da exatidão, de acordo com a Equação 29: 


$$
E=\left(\frac{C_{f}}{C_{p}}\right) \cdot 100
$$

Onde: E é a exatidão do método

$\mathrm{C}_{\mathrm{f}}$ é a concentração experimental (obtida) $\left(\mathrm{mol} \mathrm{L}^{-1}\right)$

$C_{p}$ é a concentração teórica (esperada) $\left(\mathrm{mol} \mathrm{L}^{-1}\right)$

A concentração experimental $\left(C_{f}\right)$ foi obtida a partir da integração da área do pico cromatográfico da amostra fortificada. Para a concentração teórica $\left(C_{p}\right)$, este valor foi calculado a partir da área do pico cromatográfico do padrão analítico. Neste sentido, esperase que os valores da exatidão sejam semelhantes àqueles obtidos nos ensaios de recuperação, uma vez que os valores de $A_{n}$ da Equação 27 deverão ser iguais a zero. A matriz não fortificada corresponde ao branco analítico. Caso os valores de $A_{n}$ sejam diferentes de zero, trata-se de um erro inicial na validação, um indicativo de que seletividade do método não foi garantida.

A ANVISA recomenda que os ensaios para determinação da exatidão sejam verificados a partir de, no mínimo, 9 determinações contemplando a faixa de trabalho do método, contendo três concentrações: uma baixa, uma média e outra alta, com três replicatas cada.

\subsubsection{Precisão}

A precisão foi analisada com base nos resultados obtidos na análise da recuperação do método. De acordo com o INMETRO e com a ANVISA, a precisão deve ser avaliada pelo coeficiente de variação (CV), calculado a partir da Equação 28.

$$
C V=\left(\frac{S_{A}}{M_{A}}\right) \cdot 100
$$

Onde: CV é o coeficiente de variação

$M_{A}$ é a média das áreas obtidas

$\mathrm{S}_{\mathrm{A}}$ é o desvio-padrão das áreas obtidas 


\subsubsection{2 $\underline{\text { Robustez }}$}

Conforme orientado pelo INMETRO, a robustez do método foi determinada via teste estatístico de Youden. Os parâmetros analisados foram aqueles recomendados pela ANVISA, a saber:

(i) $\underline{\mathrm{pH}}: 2,0$ e 2,2

(ii ) Composição da fase móvel: 60 e $58 \%$ de acetonitrila

(iii ) Fluxo da fase móvel: 1,4 e 1,2 $\mathrm{mL} \mathrm{min}^{-1}$

$\mathrm{O}$ pH se refere ao potencial hidrogeniônico da solução que compõe a fase móvel. O pH foi ajustado utilizando ácido fosfórico $\left(\mathrm{H}_{3} \mathrm{PO}_{4}\right)$ 85\%.

A combinação ensaiada para resolução do teste de Youden se encontra na Tabela 5. Os valores que são aqueles utilizados na validação do método receberam uma letra maiúscula como código de identificação ( $A, B$ e $C$ ). Os valores referentes às pequenas variações receberam como código uma letra minúscula ( $a, b$ e c). Cada combinação (numerada de 1 a 8) recebeu uma letra para identificação dos resultados (de $s$ a $z$ ).

Tabela 5 - Combinações ensaiadas para teste estatístico de Youden

\section{Combinação ensaiada}

\begin{tabular}{lllllllll} 
& $\mathbf{1}$ & $\mathbf{2}$ & $\mathbf{3}$ & $\mathbf{4}$ & $\mathbf{5}$ & $\mathbf{6}$ & $\mathbf{7}$ & $\mathbf{8}$ \\
\hline pH da solução da fase móvel & 2 & 2,2 & 2 & 2,2 & 2 & 2,2 & 2 & 2,2
\end{tabular}

pH da solução da fase móvel

$\begin{array}{lllllll}(\mathrm{A}) & (\mathrm{a}) & (\mathrm{A}) & \text { (a) } & \text { (A) } & \text { (a) } & \text { (A) }\end{array}$

Composição da fase móvel/ \% $\mathrm{CH}_{3} \mathrm{CN}$

$\begin{array}{llllllll}60 & 60 & 60 & 60 & 58 & 58 & 58 & 58\end{array}$

$\begin{array}{lllllll}(\mathrm{B}) & (\mathrm{B}) & (\mathrm{B}) & (\mathrm{B}) & \text { (b) } & \text { (b) } & \text { (b) }\end{array}$

Fluxo / $\mathrm{mL} \mathrm{min}^{-1}$

$\begin{array}{llllllll}1,4 & 1,4 & 1,2 & 1,2 & 1,4 & 1,4 & 1,2 & 1,2\end{array}$
(C)
(C)
(c)
(c) $\quad(\mathrm{C})$
(C)
(c) (c)

v

$\begin{array}{lll}x & y & z\end{array}$


O teste de Youden permite analisar o efeito de cada parâmetro, isoladamente, na robustez do método. Este cálculo foi realizado subtraindo os resultados obtidos com letras minúsculas por aqueles simbolizados por letras maiúsculas para cada uma das situações. Nas equações abaixo são apresentados os cálculos pertinentes. Os cálculos para o efeito do pH $(\mathrm{A} / \mathrm{a})$, da composição da fase móvel $(\mathrm{B} / \mathrm{b})$ e do fluxo da fase móvel $(\mathrm{C} / \mathrm{C})$ na robustez do método foram realizados de acordo com as equações 30, 31 e 32, respectivamente. Os efeitos obtidos para todos os parâmetros serão apresentados na forma de gráfico de barras.

$$
\begin{aligned}
& \mathrm{A} / \mathrm{a}=\frac{\mathrm{s}+\mathrm{u}+\mathrm{w}+\mathrm{y}}{4}-\frac{\mathrm{t}+\mathrm{v}+\mathrm{x}+\mathrm{z}}{4} \\
& \mathrm{~B} / \mathrm{b}=\frac{\mathrm{s}+\mathrm{t}+\mathrm{u}+\mathrm{v}}{4}-\frac{\mathrm{w}+\mathrm{x}+\mathrm{y}+\mathrm{z}}{4} \\
& \mathrm{C} / \mathrm{c}=\frac{\mathrm{s}+\mathrm{t}+\mathrm{w}+\mathrm{x}}{4}-\frac{\mathrm{u}+\mathrm{v}+\mathrm{y}+\mathrm{z}}{4}
\end{aligned}
$$

Onde: $\mathrm{A} / \mathrm{a}$ é o efeito do $\mathrm{pH}$ na robustez

B/b é o efeito da composição da fase móvel na robustez

$\mathrm{c} / \mathrm{c}$ é o efeito do fluxo da fase móvel na robustez

s à z são as letras para identificação dos resultados

\subsection{Dinâmica do herbicida}

\subsubsection{Preparo da solução estoque}

A partir do herbicida comercial (Nortox ${ }^{\circledR}$ Clorimuron Master ${ }^{\circledR}$ ) foram preparados $100 \mathrm{~mL}$ de uma solução estoque de concentração igual a $500 \mathrm{mg} \mathrm{L}^{-1}$. Para isso foi utilizada a massa $200 \mathrm{mg}$ (considerando as impurezas) de produto, completando o volume com acetonitrila. 


\subsubsection{Preparo das soluções analíticas}

A partir da solução estoque foram preparadas dez soluções analíticas para construção das isotermas de adsorção. O volume foi de $50 \mathrm{~mL}$ e as concentrações: 100, 200, 400, 600 e 800 ug L L $^{-1}$ e 1, 2, 3, 4 e $5 \mathrm{mg} \mathrm{L}^{-1}$. Os volumes de solução estoque utilizados foram, respectivamente: $10,20,40,60,80,100,200,300,400$ e 500 uL.

Para a cinética de adsorção, foram preparados $500 \mathrm{~mL}$ de uma solução com concentração de 600 ug L $\mathrm{L}^{-1}$. Para isso, utilizou-se 600 uL da solução estoque. A priori, buscou-se reproduzir um preparado com concentração semelhante à indicada pelo fabricante $\left(60 \mathrm{~g} \mathrm{~L}^{-1} \mathrm{ha}^{-1}\right)$. Contudo não é possível conhecer a massa de solo presente nesta extensão de terra nem mesmo a quantidade de herbicida carreado até os sedimentos. $\mathrm{A}$ concentração preparada representa uma quantidade de analito intermediária, nem tão alta a ponto de não ser possível verificar sua adsorção, nem tão baixa de forma que não possibilite sua deteç̧ão ou quantificação.

\subsubsection{Construção da isoterma de adsorção}

Em erlenmeyeres de $150 \mathrm{~mL}$ foram adicionados $1,0 \mathrm{~g}$ de sedimento juntamente com $10 \mathrm{~mL}$ da solução do herbicida e $5 \mathrm{uL}$ de uma solução de cloreto de cálcio $\left(\mathrm{CaCl}_{2}\right)$ 0,01 $\mathrm{mol} \mathrm{L}^{-1}$ como eletrólito-suporte, fornecendo força iônica equivalente à solução do solo.

O recipiente foi mantido em agitação orbital em mesa agitadora durante 24 horas. O analito em solução foi purificado via filtração de acordo com o item 4.5.3. Em seguida, o herbicida etilclorimuron foi quantificado por HPLC-UV. A partir das áreas dos picos cromatográficos calculou-se a concentração do herbicida remanescente em solução $\left(C_{s}\right)$. Este procedimento foi realizado para todas as soluções analíticas preparadas no item anterior.

A concentração do herbicida adsorvida nos sedimentos é, em termos termodinâmicos, a concentração de equilíbrio $\left(C_{e}\right)$. Esta concentração foi determinada pela diferença entre a concentração do herbicida em solução $\left(C_{S}\right)$ e a concentração inicial $\left(C_{i}\right)$. $A$ concentração inicial foi determinada cromatograficamente injetando 50 uL da solução do herbicida antes do início da agitação orbital.

Os dados das concentrações obtidas foram aplicados aos modelos matemáticos para construção das isotermas de Langmuir e Freundlich. 


\subsubsection{Isoterma de Freundlich}

Para construção da isoterma de Freundlich, inicialmente foi calculada a concentração de equilíbrio (quantidade de herbicida adsorvida na superfície do sedimento). Seu cálculo foi determinado pela Equação 33.

$\mathrm{C}_{\mathrm{e}}=\mathrm{C}_{\mathrm{i}}-\mathrm{C}_{\mathrm{s}}$

Onde: $\quad C_{e}$ é a concentração de equilíbrio $\left(\mathrm{mg} \mathrm{L}^{-1}\right)$

$\mathrm{C}_{\mathrm{i}}$ é a concentração inicial do herbicida $\left(\mathrm{mg} \mathrm{L}^{-1}\right)$

$C_{S}$ é a concentração do herbicida em solução $\left(\mathrm{mg} \mathrm{L}^{-1}\right)$

Em seguida, foi determinada a quantidade adsorvida por grama de sedimento. Este cálculo se baseou na diferença entre a concentração inicial do herbicida e a concentração de equilíbrio em função da massa de sedimento utilizado na adsorção, de acordo com a Equação 34 .

$$
\frac{X}{M}=\frac{\left(C_{i}-C_{e}\right) \cdot V}{m}
$$

Onde: $\frac{X}{M}$ é a quantidade adsorvida por grama de sedimento $\left(\mathrm{mg} \mathrm{kg}^{-1}\right)$

$C_{i}$ é a concentração inicial do herbicida $\left(\mathrm{mg} \mathrm{L}^{\left.L^{-1}\right)}\right.$

$\mathrm{C}_{\mathrm{e}}$ é a concentração de equilíbrio $\left(\mathrm{mg} \mathrm{L}^{-1}\right)$

V é o volume da solução de herbicida (L)

$\mathrm{m}$ é a massa de sedimento $(\mathrm{kg})$

De acordo com o modelo matemático de Freundlich (Equação 3), ainda não é possível construir a isoterma de adsorção. Isso se dá pela presença de constantes que fazem parte da equação e são intrínsecas para cada par de adsorvente e adsorbato em estudo. As constantes são o $K_{f}$ e o $1 / n$ e podem ser determinadas após a linearização da equação da 
isoterma de Freundlich, deixando-a nos moldes de uma equação da reta. Na Equação 35 está apresentada a equação linear para a isoterma de Freundlich.

$$
\log \frac{X}{M}=\left(\frac{1}{n}\right) \cdot \log C_{e}+\log K_{f}
$$

Onde: $\frac{\mathrm{X}}{\mathrm{M}}$ é a quantidade adsorvida por grama de sedimento $\left(\mathrm{mg} \mathrm{kg}^{-1}\right)$

$\frac{1}{n}$ é a intensidade da adsorção

$\mathrm{C}_{\mathrm{e}}$ é a concentração de equilíbrio $\left(\mathrm{mg} \mathrm{L}^{-1}\right)$

$\mathrm{K}_{\mathrm{f}}$ é a constante de Freundlich $\left(\mathrm{Lg}^{-1}\right)$

Relacionando esta equação com uma equação da reta genérica $(y=a \cdot x+b)$ é possível determinar as constantes e demais parâmetros contidos no modelo de adsorção proposto por Freundlich. Foram calculados os parâmetros lineares $a$ e $b$ utilizando o método dos mínimos quadrados. 0 valor de $1 / n$ é o próprio termo a da equação da reta. 0 valor de $\mathrm{K}_{\mathrm{f}}$ foi determinado aplicando a função inversa à logarítmica ao valor de $b$.

\subsubsection{Isoterma de Langmuir}

Os cálculos envolvidos na construção das isotermas de Langmuir são mais simples que aqueles utilizados no modelo de Freundlich. $O$ valor de $C_{s}$ obtido na determinação cromatográfica é aplicado diretamente na equação matemática sem a necessidade de outros cálculos. O cálculo da quantidade adsorvida por grama de sedimento $\left(\frac{X}{M}\right)$ foi realizado conforme a Equação 34, apresentado no item anterior. A Equação 36 apresenta a forma linearizada da isoterma de Langmuir (Equação 2).

$$
\frac{1}{(\mathrm{X} / \mathrm{M})}=\frac{1}{\mathrm{~K}_{\mathrm{L}} \cdot \mathrm{Q}} \cdot \frac{1}{\mathrm{C}_{\mathrm{S}}}+\frac{1}{\mathrm{Q}}
$$


Onde: $\frac{X}{M}$ é a quantidade adsorvida por grama de sedimento $\left(\mathrm{mg} \mathrm{k}^{-1}\right)$

$\mathrm{K}_{\mathrm{L}}$ é a constante de Langmuir $\left(\mathrm{L} \mathrm{kg}^{-1}\right)$

Q é a quantidade máxima adsorvida $\left(\mathrm{mg} \mathrm{k}^{-1}\right)$

$\mathrm{C}_{\mathrm{S}}$ é a concentração do herbicida em solução $\left(\mathrm{mg} \mathrm{L}^{-1}\right)$

Relacionando esta equação com uma equação da reta genérica, foram calculados os parâmetros lineares $a$ e $b$. A partir destes valores foram calculados os valores de $\mathrm{K}_{\mathrm{L}} \mathrm{e} \mathrm{Q}$. $\mathrm{O}$ valor de $Q$ foi calculado dividindo 1 pelo valor de $b$ da equação da reta. $O$ valor de $K_{L}$ foi obtido dividindo 1 pelo produto dos valores de $Q$ e de $a$ da equação da reta.

\subsubsection{Correlação entre os modelos de isoterma}

Para cada conjunto de adsorvente e adsorbato existe apenas um modelo de adsorção: Freundlich ou Langmuir. Outras isotermas podem ser encontradas na literatura, porém são modelos matemáticos aprimorados a partir destes dois e, também, não possuem muita aplicação nas análises ambientais.

Para saber qual modelo de isoterma melhor se adequa ao binário etilclorimuron e os sedimentos estudados, confrontou-se os coeficientes de correlação linear. Comparando os resultados, a isoterma com maior $\mathrm{R}^{2}$ indicará o melhor modelo que melhor elucida $\mathrm{O}$ processo sortivo analisado.

O coeficiente de correlação linear foi calculado para cada modelo de isoterma em sua forma linearizada. O valor de $\mathrm{R}^{2}$ foi calculado de acordo com a Equação 24.

\subsubsection{Cinética de adsorção}

Em erlenmeyeres de $150 \mathrm{~mL}$ foram adicionados $1,0 \mathrm{~g}$ de sedimento juntamente com $10 \mathrm{~mL}$ da solução do herbicida (preparada de acordo com o item 4.9.2) e 5 uL de uma solução de cloreto de cálcio $\left(\mathrm{CaCl}_{2}\right)$ 0,01 mol L ${ }^{-1}$. O recipiente foi mantido em agitação orbital em mesa agitadora durante tempos pré-determinados. Os tempos foram: 0, 5, 10, 30 e 60 $\min ; 3,6,12,15,24$ e 48 h. 0 analito foi filtrado e, em seguida, o herbicida etilclorimuron foi quantificado por HPLC-UV. 
Verificou-se através das equações 5 e 6, qual cinética melhor elucida o processo de adsorção analisado: pseudo-primeira-ordem ou pseudo-segunda-ordem. Para isso as variáveis foram isoladas e integradas em intervalos pré-determinados. As condições limites foram, para $C_{a d s}$, de 0 até $C_{a d s}$ e, para t, de 0 até t. As formas integradas de cada cinética de pseudo-primeira-ordem e pseudo-segunda-ordem encontram apresentadas nas equações 37 e 38 , respectivamente.

$$
\begin{aligned}
& \operatorname{In}\left(C_{\max }-C_{a d s}\right)=\operatorname{In}\left(C_{e}\right)-k_{1} t \\
& \frac{t}{C_{a d s}}=\frac{1}{k_{2} \cdot C_{e}^{2}}+\frac{t}{C_{e}}
\end{aligned}
$$

Onde: $\mathrm{t}$ é o tempo de contato $(\mathrm{h})$

$\mathrm{C}_{\mathrm{ads}}$ é a concentração adsorvida em certo $\mathrm{t}\left(\mathrm{mg} \mathrm{L}^{-1}\right)$

$\mathrm{C}_{\mathrm{e}}$ é a concentração do analito no equilíbrio $\left(\mathrm{mg} \mathrm{L}^{-1}\right)$

$\mathrm{C}_{\max }$ é a concentração máxima adsorvida $\left(\mathrm{mg} \mathrm{L}^{-1}\right)$

$k_{1}$ é a constante de velocidade - pseudo-primeira-ordem $\left(\min ^{-1}\right)$

$\mathrm{k}_{2}$ é a constante de velocidade - pseudo-primeira-ordem $\left(\mathrm{L} \mathrm{mg}^{-1} \mathrm{~min}^{-1}\right)$

É possível observar que ambas as equações podem ser comparadas a uma equação da reta. Neste sentido, através de uma regressão linear é possível determinar a concentração do analito no equilíbrio $\left(C_{e}\right)$ e as constantes de velocidade $\left(k_{1}\right.$ e $\left.k_{2}\right)$. Para facilitar os cálculos, considerou-se que, na cinética de pseudo-primeira-ordem, o valor de $C_{e}$ é a concentração adsorvida no último tempo de análise (48 h), ou seja, a concentração máxima adsorvida $\left(C_{\max }\right)$. Esta consideração foi feita apenas para o termo $\ln \left(C_{\max }-C_{a d s}\right)$.

Comparando as retas, aquela com $\mathrm{R}^{2}$ mais próximo a 1 nos indicará o modelo que melhor elucida a cinética de adsorção do herbicida. 


\section{$5 \quad$ RESULTADOS E DISCUSSÃO}

\subsection{Caracterização dos sedimentos}

\subsubsection{Caracterização física e química dos sedimentos}

A Tabela 6 apresenta os resultados obtidos nas caracterizações dos sedimentos analisados.

TABELA 6 - Características físicas e químicas das amostras dos sedimentos analisadas

\begin{tabular}{|c|c|c|c|}
\hline & Zona Agrícola & Zona Pecuária & Estação Ecológica \\
\hline Humidade & $44,37 \pm 1,43$ & $59,29 \pm 2,18$ & $46,99 \pm 2,70$ \\
\hline pH & $4,93 \pm 0,05$ & $4,51 \pm 0,02$ & $4,16 \pm 0,02$ \\
\hline \multicolumn{4}{|l|}{ СTC } \\
\hline Acidez trocável & $11,42 \cdot 10^{-3} \pm 00,00 \cdot 10^{-3}$ & $17,14 \cdot 10^{-3} \pm 00,00 \cdot 10^{-3}$ & $44,29 \cdot 10^{-3} \pm 00,00 \cdot 10^{-3}$ \\
\hline Soma das Bases & $15,41 \pm 0,00$ & $19,37 \pm 0,00$ & $0,9997 \pm 0,0000$ \\
\hline $\mathrm{CTC}_{\mathrm{ef}}$ & $55,48 \pm 0,00$ & $114,43 \pm 0,00$ & $24,87 \pm 0,00$ \\
\hline $\mathrm{CTC}_{\mathrm{pH} 7}$ & $15,42 \pm 0,00$ & $19,38 \pm 0,00$ & $1,044 \pm 0,00$ \\
\hline Matéria orgânica & $10,72 \pm 0,12$ & $16,12 \pm 0,21$ & $8,37 \pm 0,13$ \\
\hline TOC & $3,14 \pm 0,04$ & $3,00 \pm 0,12$ & $2,57 \pm 0,15$ \\
\hline Ácidos Húmicos & $4,54 \pm 0,00$ & $3,50 \pm 0,00$ & $4,00 \pm 0,00$ \\
\hline \multicolumn{4}{|l|}{ Granulometria: } \\
\hline Argila & 27,50 & 35,00 & 13,20 \\
\hline Silte & 17,50 & 45,20 & 11,10 \\
\hline Areia Fina & 27,00 & 13,00 & 35,70 \\
\hline Areia Média & 27,10 & 6,80 & 37,70 \\
\hline Areia Grossa & 0,90 & 0,20 & 2,30 \\
\hline Pedregulho & 0,00 & 0,00 & 0,00 \\
\hline Classe textural: & Franco argilo arenoso & Franco argilo siltoso & Franco arenoso \\
\hline
\end{tabular}


A fim de comparar os resultados obtidos, foi utilizado como ferramenta estatística o teste $t$ de Student com 99,9\% de confiabilidade e 2 graus de liberdade. ${ }^{63}$ Os itens abaixo discutem as características dos sedimentos analisadas.

(i) Humidade: Os testes estatísticos indicaram que a humidade apresentou diferença significativa entre a amostra Zona Pecuária e os demais sedimentos (aproximadamente 25\%). A diferença entre as amostras Zona Agrícola e Estação Ecológica foi próxima a 5\%. Os diferentes valores de humidade podem estar relacionados à granulometria, aos teores de matéria orgânica e dos ácidos húmicos.

(ii ) $\mathrm{pH}$ : Os valores de $\mathrm{pH}$ obtidos são típicos dos solos brasileiros, ou seja, com caráter ácido. ${ }^{71}$ Estatisticamente, todos os valores apresentaram diferenças significativas entre si. O pH da solução desses sedimentos é um parâmetro importante, pois possui influência direta na solubilidade e degradação do herbicida. Em geral, as sulfonilureias são ácidos fracos e possuem $\mathrm{pK}_{\mathrm{a}}$ na faixa entre 3 e $5,^{32}$ como os valores de $\mathrm{pH}$ são aproximadamente iguais a 4, espera-se que as moléculas do herbicida estejam desprotonadas, conferindo polaridade negativa à sua estrutura molecular. Neste sentido, o processo de sorção pode ser favorecido, uma vez que é a retenção do herbicida junto aos cátions metálicos presentes na composição dos sedimentos seria, em tese, intensificada (interações químicas via ligação dipolo-dipolo). ${ }^{72}$

(iii) CTC: A capacidade de troca catiônica (CTC) é outro parâmetro relevante que pode influenciar na adsorção dos compostos orgânicos. A troca de íons metálicos entre a superfície da fração sólida dos sedimentos e os cátions metálicos presentes na solução do solo pode levar à criação de lacunas com carga negativa nas partículas dos sedimentos, o que favoreceria a retenção do herbicida (interações físicas via forças de van der Waals). ${ }^{73}$ Comparando os resultados 
obtidos, os diferentes valores de acidez trocável e das soma das bases resultaram em valores discrepantes entre os valores de CTC. Analisando a $\mathrm{CTC}_{\mathrm{ef}}$, todas as amostras apresentaram diferenças significativas. Os valores foram mais que o dobro na comparação entre as amostras Zona Pecuária e as demais (aproximadamente 100\% de diferença em comparação a amostra Zona Agrícola e 300\% para amostra Estação Ecológica). Os sedimentos da Estação Ecológica apresentaram menor $\mathrm{CTC}_{\mathrm{ef}}\left(24,87 \mathrm{cmol}_{\mathrm{c}} \mathrm{kg}^{-1}\right)$. Analisando a $\mathrm{CTC}_{\mathrm{pH}}$, os sedimentos da amostra Estação Ecológica apresentram maior diferença em comparação as demais, as quais estatisticamente não apresentaram diferenças. A diferença entre as CTCs é justificada pela diferença da concentração de alumínio nas amostras. Quanto maior o teor de $\mathrm{Al}^{+3}$, maior a diferença entre a $\mathrm{CTC}_{\mathrm{ef}}$ e a CTC $\mathrm{CH}_{\mathrm{pH}}$.

(iv) Matéria Orgânica: Analisando os teores de matéria orgânica (MO), os sedimentos da amostra Zona Pecuária apresentaram diferença significativa se comparado às demais amostras (aproximadamente $60 \%$ de diferença em comparação a amostra Zona Agrícola e 100\% para amostra Estação Ecológica). A amostra Estação Ecológica apresentou um teor menor de matéria orgânica $(8,37 \%)$, porém esta diferença é insignificante se comparado ao teor da amostra Zona Agrícola (10,72\%). Em geral, a atividade agrícola e pecuária tende a incorporar, frequentemente, matéria orgânica à cobertura do solo, 0 que interfere diretamente na qualidade e composição dos sedimentos presentes nesta região. Esta matéria orgânica é, em termos de decomposição física, química e biológica, recente. Para a atividade pecuária estará compreendido, principalmente, os dejetos dos animais ali confinados (gado de corte e leiteiro). No caso da atividade agrícola, têm-se os resíduos agrícolas, tais como folhas, cascas, produtos de podas, entre outros. No tocante aos sedimentos da Estação Ecológica, ressalta-se o bioma desta área de proteção. 0 cerrado, diferente da maioria dos ecossistemas tropicais, apresenta 
um baixo teor de biomassa vegetal, principal fonte de matéria orgânica nos solos tropicais. $^{74}$ Neste sentido, justifica-se a disparidade entre os teores assim discutidos.

(v) TOC: Analisando os teores de carbono orgânico total (TOC), nenhuma das amostras apresentou diferenças significativas entre si. Analisando os intervalos de confiança, os sedimentos das amostras Zona Agrícola e Zona Pecuária confluíram seus resultados. A amostra Estação Ecológica apresentou menor teor de TOC.

(vi ) Ácidos Húmicos: Os teores dos ácidos húmicos não apresentaram diferenças significativas na comparação entre as três amostras de sedimento analisadas. As diferenças entre os teores de matéria orgânica e dos ácidos húmicos foram discutidas e interpretadas em função dos diferentes graus de humificação. Embora a amostra Zona Pecuária possua um maior teor de matéria orgânica, esta é, provavelmente, pouco humificada, o que implica no menor teor de ácido húmico. No item 5.1 .3 serão discutidos os graus de humificação.

( vii ) Classe Textural: Os sedimentos analisados apresentaram diferentes composições granulométricas. As amostras Zona Agrícola e Estação Ecológica apresentaram um maior teor de areia (54 e 75\%, respectivamente). A amostra Zona Pecuária foi a que apresentou um maior percentual de argila (35\%) e silte (45\%). O diâmetro das partículas está relacionado a sua área superficial. Partículas menores (por exemplo, argila e silte) possuem maior área superficial e, com isso, a retenção de compostos orgânicos e inorgânicos é mais intensa. Em geral estas partículas apresentam maior CTC e maior retenção de humidade, fatos condizentes com os resultados obtidos. ${ }^{2,6,73}$

Em resumo, a atividade agrícola e pecuária alteraram as propriedades físicas e químicas dos sedimentos inseridos em uma paisagem sob manejo e ação antrópica. Em 
geral, dois parâmetros foram os mais relevantes: a classe textural e o teor de matéria orgânica dos sedimentos, ambas atuando de forma mais acentuada nos sedimentos da Zona Pecuária. A diminuição da granulometria das partículas constituintes dos sedimentos e a incorporação de matéria orgânica apresentou efeito direto na qualidade dos sedimentos da região analisada, aumentando a capacidade de troca catiônica (CTC), a humidade, entre outros. $^{2,6}$

Uma vez que estes sedimentos apresentaram diferentes características e propriedades, no item 5.3.4 será analisado o efeito destes parâmetros na dinâmica dos herbicidas sulfonilureia.

Para finalizar as discussões sobre as análises e caracterizações dos sedimentos analisados, faltam avaliar as características e influências das substâncias húmicas. Após isolamento e purificação, os ácidos húmicos foram caracterizados. Os itens a seguir apresentam os resultados e discussões pertinentes.

\subsubsection{Espectroscopia na região do infravermelho (FTIR) dos ácidos húmicos}

A Figura 13 apresenta os espectros de FTIR dos ácidos húmicos dos sedimentos analisados.

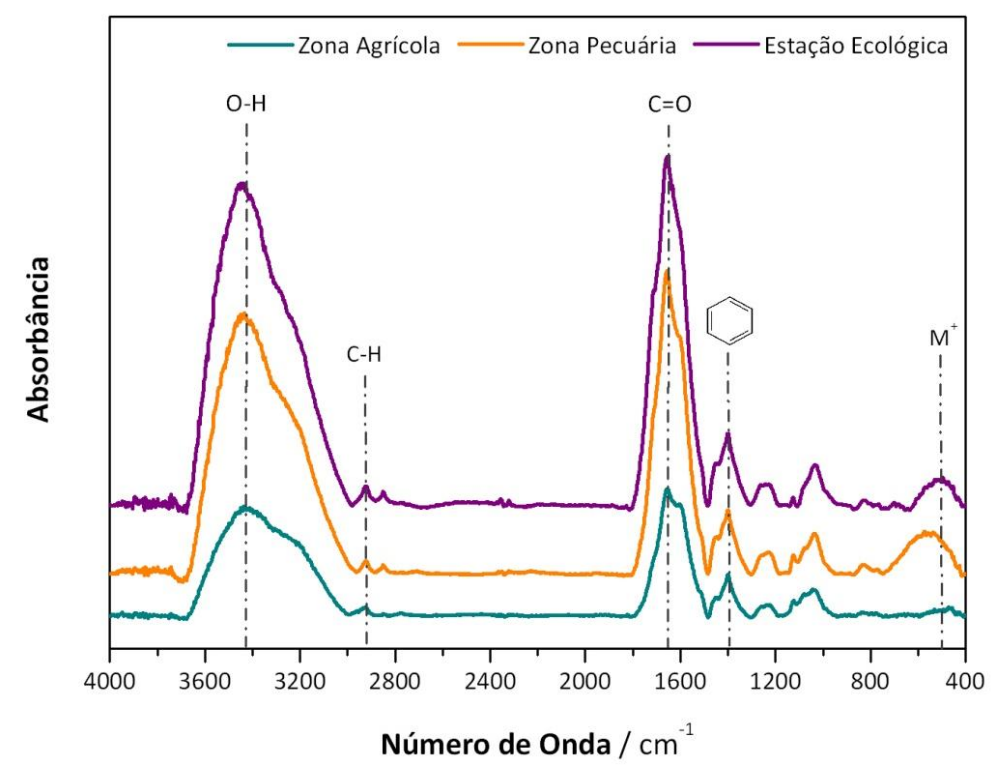

Figura 13 - Espectros de FTIR dos ácidos húmicos analisados. 
Nas últimas décadas, muitos trabalhos de divulgação científica foram publicados com o intuito de identificar os grupos químicos presentes nos ácidos húmicos dos solos e sedimentos. Os espectros obtidos foram analisados de acordo com alguns destes trabalhos. $^{75,79}$

Comparando os espectros das três amostras de sedimentos analisadas, aparentemente todas apresentaram uma composição semelhante. Pequenas diferenças nas intensidades foram observadas em algumas bandas. Este fato está relacionado ao teor de certos constituintes na composição dos ácidos húmicos.

A banda mais larga e de maior intensidade localizada na região entre 3.600 e 3.070 $\mathrm{cm}^{-1}$ é atribuída às vibrações de estiramento $\mathrm{OH}$ presentes em grande quantidade na matéria orgânica e na estrutura dos ácidos húmicos. Também há possibilidade deste número de onda ser referente ao estiramento das ligações NH. Nesta banda pode-se indicar a presença de humidade, um inconveniente na análise espectroscópica por FTIR. ${ }^{79}$

Após esta região, duas pequenas bandas são observadas na região entre 2.918 e $2.925 \mathrm{~cm}^{-1}$. Estas bandas indicam a presença de grupos metilenos e metil por meio de suas vibrações assimétricas. ${ }^{79}$ Estes grupos evidenciam a presença de cadeias alifáticas na estrutura dos ácidos húmicos. ${ }^{75-76}$ Outras regiões seriam aquelas próximas a $1.456 \mathrm{~cm}^{-1}$, relativas à deformação das ligações $\mathrm{CH}$ dos grupos $\mathrm{CH}_{2}$ e $\mathrm{CH}_{3}$ alifáticos. No tocante a intensidade destas, quanto maior a absorbância nessas regiões, maior o indicativo de uma matéria orgânica mais recente ou com pequeno grau de humificação. ${ }^{76}$

A região entre 1450 e $1500 \mathrm{~cm}^{-1}$ é característica das vibrações de núcleos aromáticos (ligação dupla entre carbonos). ${ }^{79} \mathrm{~A}$ banda de $1.580 \mathrm{~cm}^{-1}$ é intensa quando os grupos fenila dos ácidos húmicos estão conjugados com insaturações ou mesmo ligados a átomos com pares de elétrons livres. ${ }^{77}$ Nesta região ocorre a sobreposição desta banda com aquela referente à deformação das ligações $\mathrm{CH}$ dos grupos $\mathrm{CH}_{2}$ e $\mathrm{CH}_{3}$ alifáticos.

Quanto a presença das carbonilas, a região próxima a $1.700 \mathrm{~cm}^{-1}$ corresponde às vibrações da ligação dupla entre os átomos de carbono e oxigênio pertencentes às cetonas, quinonas e grupos carboxílicos. ${ }^{79}$ A protonação dos ácidos carboxílicos a carboxilatos faz com que a banda referente se desloque. O número de onda referente a deformação axial assimétrica dos íons carboxilatos ocorre aproximadamente entre 1.646 e $1.637 \mathrm{~cm}^{-1} .78$

No final do espectro, próximo a região do comprimento de onda igual a $500 \mathrm{~cm}^{-1}$, há uma banda geralmente atribuída à presença de impurezas minerais presentes na estrutura 
dos ácidos húmicos. ${ }^{75}$ Esta banda não foi detectada na amostra Zona Agrícola. Possivelmente o teor determinado foi mínimo, impossibilitando a detecção.

\subsubsection{Determinação do grau de humificação}

O grau de humificação foi determinado via espectroscopia na região do visível (Vis) e de fluorescência (EF). Duas metodologias foram utilizadas na determinação do grau de humificação por espectroscopia de fluorescência, os métodos propostos por Milori et. al $(2002)^{69}$ e Kalbitz, Geyer e Geyer (1999). ${ }^{70}$

A Figura 14 apresenta os espectros na região do visível dos ácidos húmicos analisados.

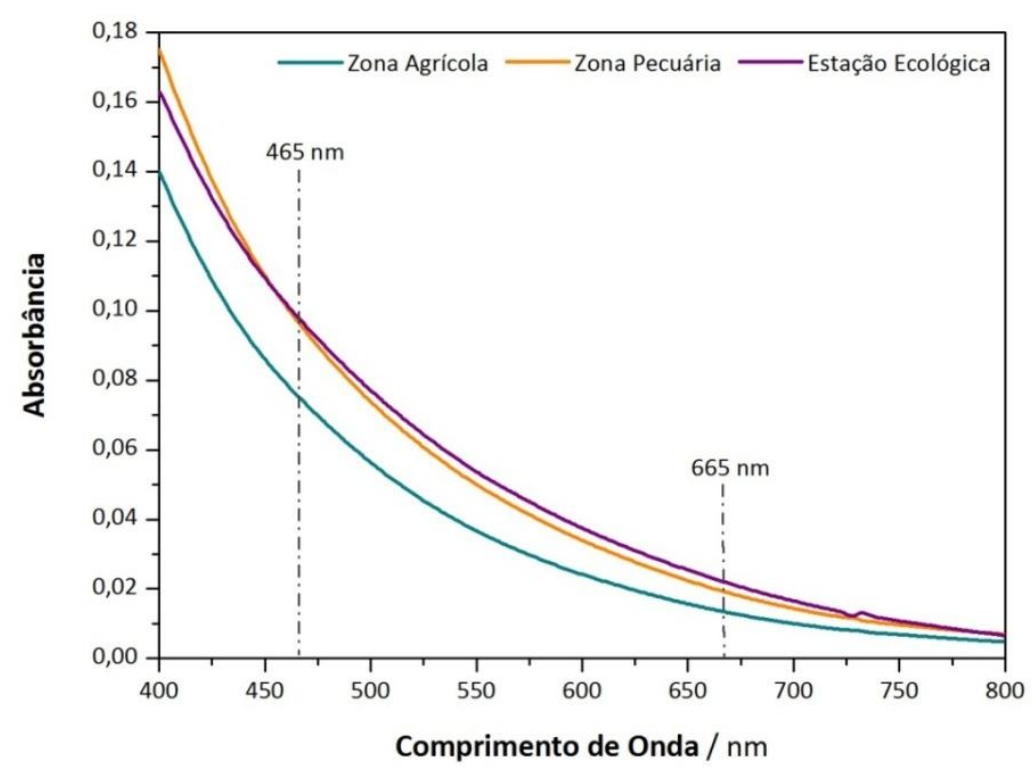

Figura 14 - Espectros na região do visível dos ácidos húmicos analisados.

O processo de humificação está relacionado ao aumento do tamanho e massa molecular dos grupos químicos presentes na matéria orgânica. Assim, os grupos alifáticos se condensam, aumentando a aromaticidade de suas moléculas. ${ }^{80}$ Os grupos aromáticos tendem a absorver bastante radiação visível devido ao grande volume de elétrons $\pi$ presentes. Já as cadeias carbônicas alifáticas apresentam apenas elétrons $\sigma$, os quais absorvem pouca radiação em sua estrutura. ${ }^{79}$ 
O parâmetro utilizado na determinação do grau de humificação por meio do método Vis é a razão entre a absorbância em 465 nm e 665 nm. Essa razão é chamada de E4/E6 e é independente da concentração dos ácidos húmicos em solução. O valor da relação E4/E6 está relacionado ao grau de condensação dos constituintes aromáticos. Segundo a teoria da lignina para o processo de humificação, quanto maior o grau de evolução da matéria orgânica humificada, maior o número de unidades aromáticas presentes. ${ }^{81}$

O uso da razão E4/E6 na inferência de propriedades estruturais de substâncias húmicas está baseado no fato de que a queda da absorbância, com o aumento do comprimento de onda, seria proporcional à diminuição de conjugação nos diferentes sistemas orgânicos. A relação E4/E6 é uma medida da inclinação da reta formada entre a absorbância em 465 nm e em 665 nm. Sistemas com conjugação mais estendida apresentam maior absorção no azul (465 nm). A relação E4/E6 reflete qualitativamente a inclinação da reta (Absorbância vs comprimento de onda). ${ }^{81}$

Devido à grande variedade de grupos cromóforos presentes nas moléculas dos ácidos húmicos, a espectroscopia de radiação visível não garante a seletividade dos grupos químicos que evidenciam a humificação da matéria orgânica. Este fato ocasiona a sobreposição de várias bandas, não existindo regiões com máximos de absorção bem definidos. Esta limitação tem gerado discussões e críticas sobre o uso deste procedimento, porém, mesmo assim, esta metodologia é largamente utilizada. Outras técnicas espectroscópicas têm sido utilizadas para melhor elucidar o mecanismo por detrás do processo de humificação. ${ }^{14}$ Entre outras técnicas empregadas, vêm se destacando a espectroscopia de fluorescência (EF). ${ }^{69-70}$

A análise por fluorescência leva em consideração o sinal detectado proveniente da energia liberada pelos grupos cromóforos excitados por radiação eletromagnética. Fluorescência é a capacidade de uma substância emitir luz quando exposta a emissão de radiação. Esta emissão ocorre com comprimento de onda menor que a energia inicial incidida. Com isso, a energia liberada será maior, uma vez que o comprimento de onda é inversamente proporcional à energia. ${ }^{82} \mathrm{Em}$ geral, os grupos cromóforos detectados por fluorescência podem ser detectados por espectroscopia na região do visível, porém, nem todos os grupos que absorvem esta radiação possuem capacidade de fluorescer. Esse fato aumenta a seletividade dos métodos baseados na fluorescência e agrega mais valor aos resultados obtidos. $^{82}$ 
A dificuldade para diferenciar os índices de humificação observados pelo método Vis não ocorreu em ambas as metodologias via espectroscopia de fluorescência.

Os espectros de fluorescência obtidos pelo método Milori e Kalbitz estão apresentados nas figuras 15 e 16, respectivamente.

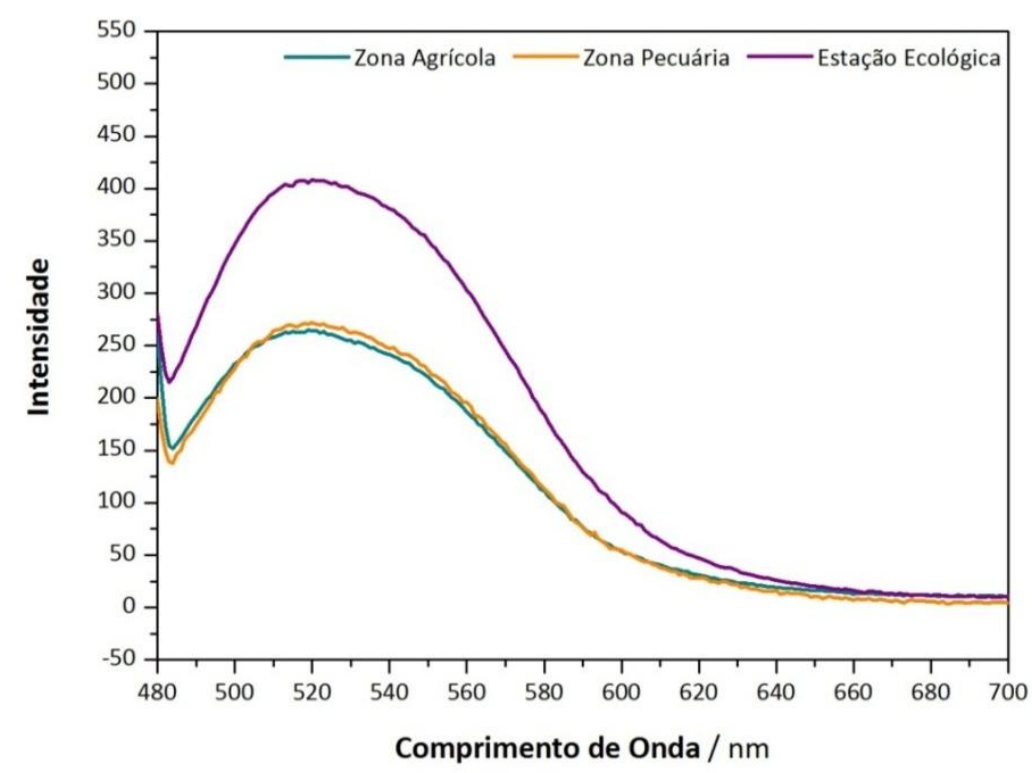

Figura 15 - Espectros de fluorescência obtidos pelo método Milori.

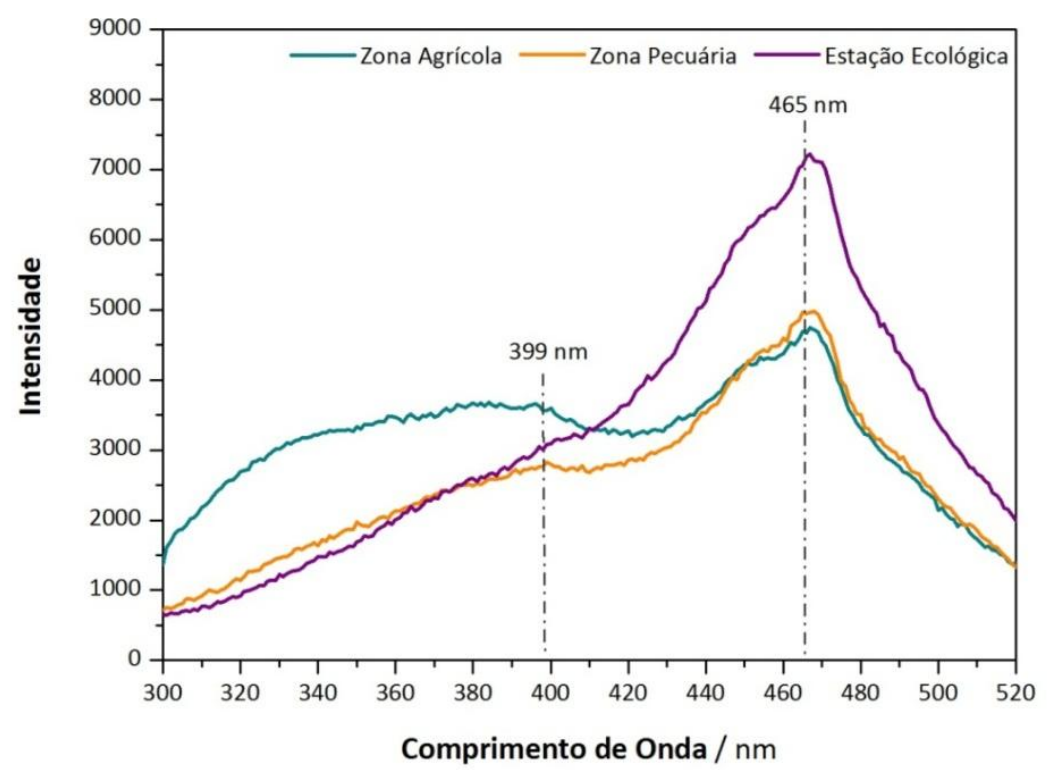

Figura 16 - Espectros de fluorescência obtidos pelo método Kalbitz. 
Quando uma amostra é excitada com um laser na região do azul, o espectro de emissão é uma banda larga sem estruturas significativas. Esta excitação é mais ressonante com estruturas mais complexas. Assim, as variações na intensidade de emissão do espectro obtido podem ser associadas às variações estruturais dos fluoróforos (grupos químicos que florescem) presentes na molécula dos ácidos húmicos. A área sob a emissão de fluorescência é, na região do azul, proporcional ao grau de humificação. ${ }^{69}$

O método de Kalbitz utiliza a técnica de fluorescência em modo de excitação com varredura sincronizada. O cálculo do índice de humificação é dado pela razão entre as intensidades obtidas nos comprimentos de onda em 465, relacionado principalmente a fluorescência dos grupos aromáticos, e em $399 \mathrm{~nm}$, referente aos grupos alifáticos. ${ }^{70}$

Os graus de humificação foram calculados para as três metodologias analisadas. Os resultados obtidos estão apresentados na Tabela 7.

TABELA 7 - Índices de humificação das amostras de sedimento analisadas

\begin{tabular}{lccc}
\hline & Zona Agrícola & Zona Pecuária & Estação Ecológica \\
\hline Método Vis & $5,23 \pm 0,53$ & $5,04 \pm 0,23$ & $4,65 \pm 0,64$ \\
Método Milori & $(26,13 \pm 1,22) \cdot 10^{3}$ & $(25,98 \pm 1,01) \cdot 10^{3}$ & $(37,07 \pm 1,80) \cdot 10^{3}$ \\
Método Kalbitz & $1,64 \pm 0,29$ & $1,79 \pm 0,05$ & $2,19 \pm 0,10$ \\
\hline
\end{tabular}

Para facilitar a visualização dos resultados, a Figura 17 apresenta os graus de humificação por um gráfico de barras.

Não é possível estabelecer uma relação linear entre as três metodologias analisadas: Vis, Milori e Kalbitz. Os valores encontrados para cada amostra só servem para comparações dentro da mesma metodologia adotada. 


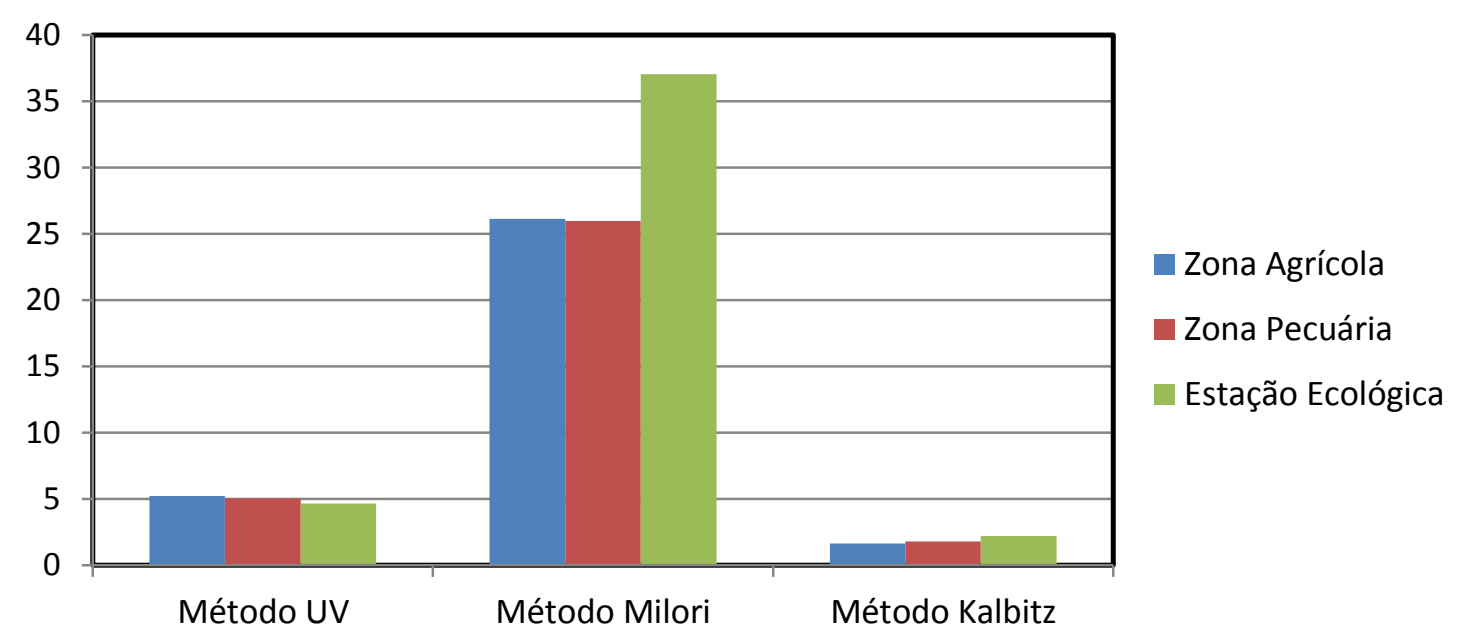

Figura 17 - Grau de humificação dos sedimentos analisados.

Os itens a seguir discutirão os resultados obtidos para cada método analisado.

(i) Método Vis: Analisando os espectros obtidos, as amostras Zona Pecuária e Estação Ecológica se sobrepuseram em alguns pontos. A amostra Zona Agrícola apresentou menor absorbância nos dois comprimentos de onda analisados: 665 e $465 \mathrm{~nm}$. O método que utiliza radiação visível não foi o adequado para diferenciar o grau de humificação das três amostras de sedimento. Os intervalos de confiança obtidos se sobrepuseram para todos os três resultados. Um teste estatístico $t$ de Student indicou que não existem diferenças significativas entre as três amostras analisadas.

(ii ) Método Milori: Analisando os graus de humificação obtidos, as amostras Zona Agrícolas e Zona Pecuária não apresentaram diferenças significativas. A amostra Estação Ecológica se diferenciou de ambas as demais. A diferença entre os graus de humificação é de aproximadamente $30 \%$. Ao analisar os espectros de fluorescência, é possível observar a sobreposição dos espectros das amostras Zona Pecuária e Agrícola. A emissão da amostra Estação Ecológica é visivelmente maior em comparação às demais amostras. 
(iii ) Método Kalbitz: Os graus de humificação obtidos são condizentes àqueles obtidos segundo o método Milori. Os valores calculados para as amostras Zona Agrícolas e Zona Pecuária não apresentaram diferenças significativas. A amostra Estação Ecológica se diferenciou de ambas as demais. A diferença entre os graus de humificação é de aproximadamente $20 \%$. A mesma tendência dos espectros obtidos pelo método Milori foi observada no método Kalbitz.

De acordo com os métodos utilizados e as discussões pertinentes, a amostra Estação Ecológica é a que possui maior grau de humificação. A principal justificativa, como dito anteriormente é, principalmente, a pequena reposição de matéria orgânica no solo, o que se justifica pelo baixo teor de biomassa do cerrado enquanto bioma.

Nos terras com uso destinado à agricultura e à pecuária, o solo é constantemente manejado, o que implica na reposição constante de matéria orgânica. Quanto mais intensa a reposição, menor o grau de humificação (maior quantidade de matéria orgânica recente, pouco humificada).

Agora são conhecidas as características físicas e químicas dos sedimentos, bem como seus teores de ácidos húmicos e seus respectivos graus de humificação. Com isso, é possível interpretar, com maior respaldo, os possíveis efeitos destes sedimentos na dinâmica do herbicida etilclorimuron.

A quantificação do herbicida etilclorimuron, nos sedimentos acima caracterizados, será determinada via HPLC - UV. Para isso, é necessário validar o método analítico para garantir a qualidade e agregar valor aos resultados obtidos.

O item seguinte apresenta os resultados obtidos na validação da metodologia analítica para determinação dos herbicidas sulfonilureias em sedimentos via HPLC - UV.

\subsection{Validação do Método Analítico}

\subsubsection{Seletividade}

Para realização de análises químicas, qualitativa ou quantitativa, em que é utilizada como detector uma fonte de radiação ultravioleta, é necessário conhecer o comprimento de 
onda onde a absorção de energia é máxima. Para isso foi obtido o espectro na região do ultravioleta para o herbicida etilclorimuron dissolvido em acetonitrila. O espectro obtido está apresentado na Figura 18.

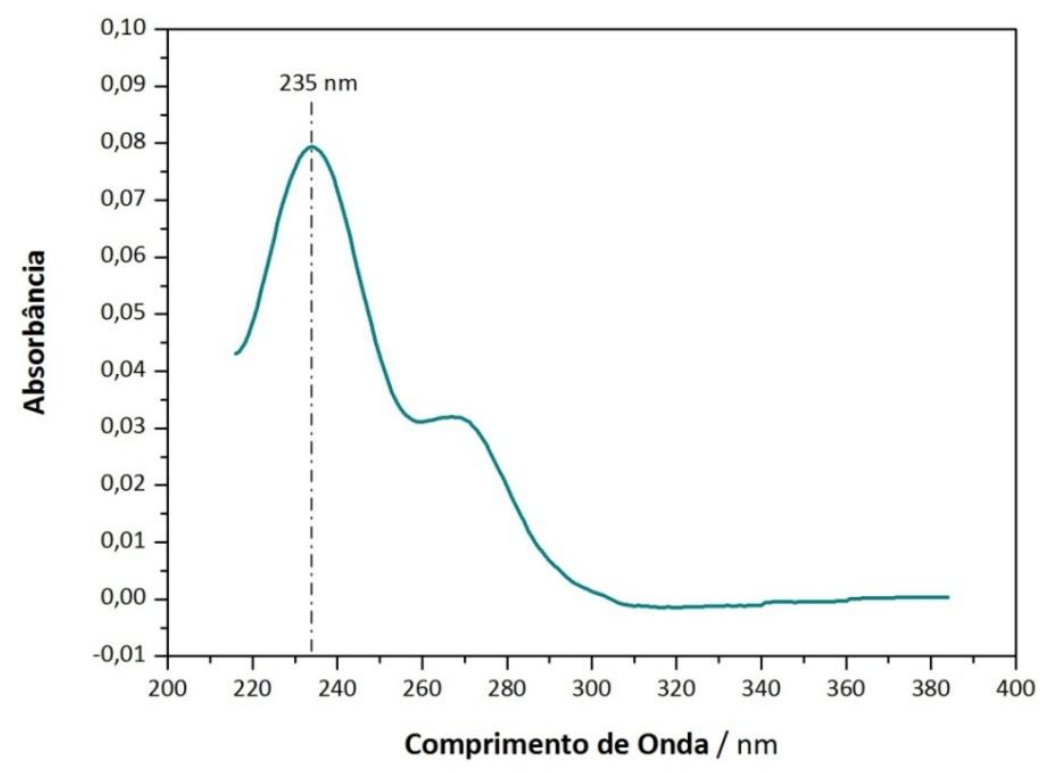

Figura 18 - Espectro na região do ultravioleta para o herbicida etilclorimuron.

O comprimento de onda de $235 \mathrm{~nm}$ foi o que apresentou maior absorção da radiação ultravioleta. Este comprimento de onda foi utilizado na calibração do detector UV do HPLC.

Analisou-se a presença de picos cromatográficos com tempos iguais em ambos os cromatogramas, o do herbicida (padrão analítico) e dos sedimentos (matriz). A ocorrência de qualquer pico em ambos os cromatogramas comprometeria a validação do método, pois não garantiria sua seletividade.

A Figura 19 apresenta o cromatograma do herbicida etilclorimuron (padrão analítico) obtido por HPLC - UV. 


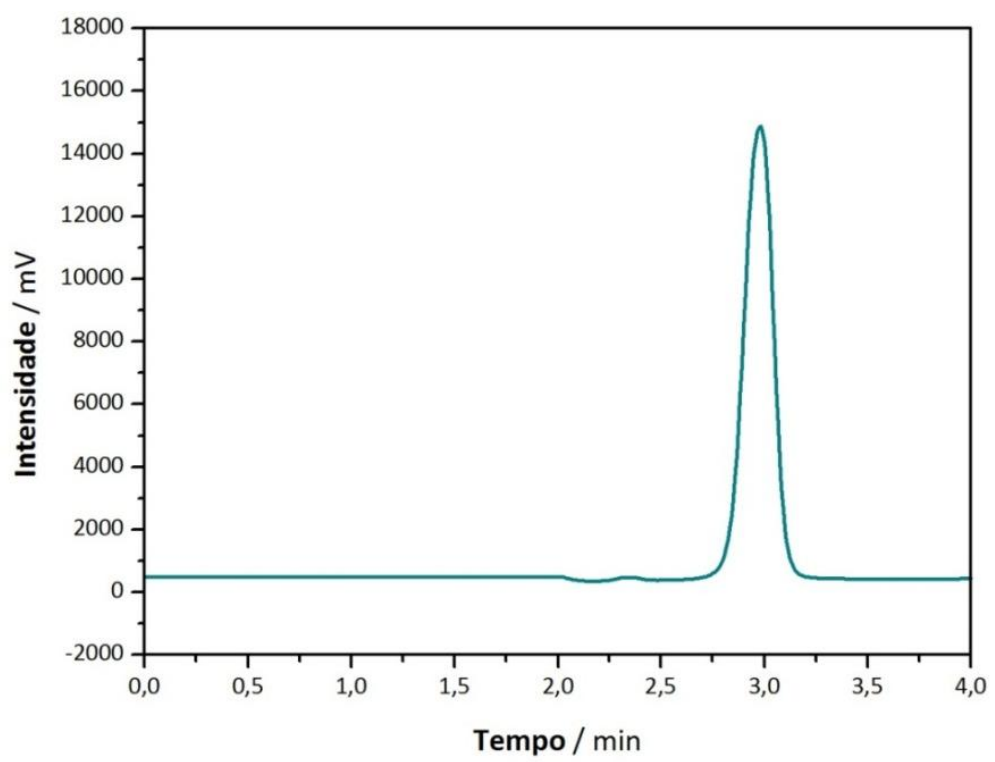

Figura 19 - Cromatograma do herbicida etilclorimuron.

Observando o resultado obtido, a retenção do analito deu-se até os 2,91 minutos da determinação cromatográfica. A concentração utilizada foi de $100 \mathrm{ug} \mathrm{L}^{-1}$ utilizando os parâmetros cromatográficos citados no item 4.8.3.

A Figura 20 apresenta os cromatogramas das 3 amostras de sedimentos analisadas.

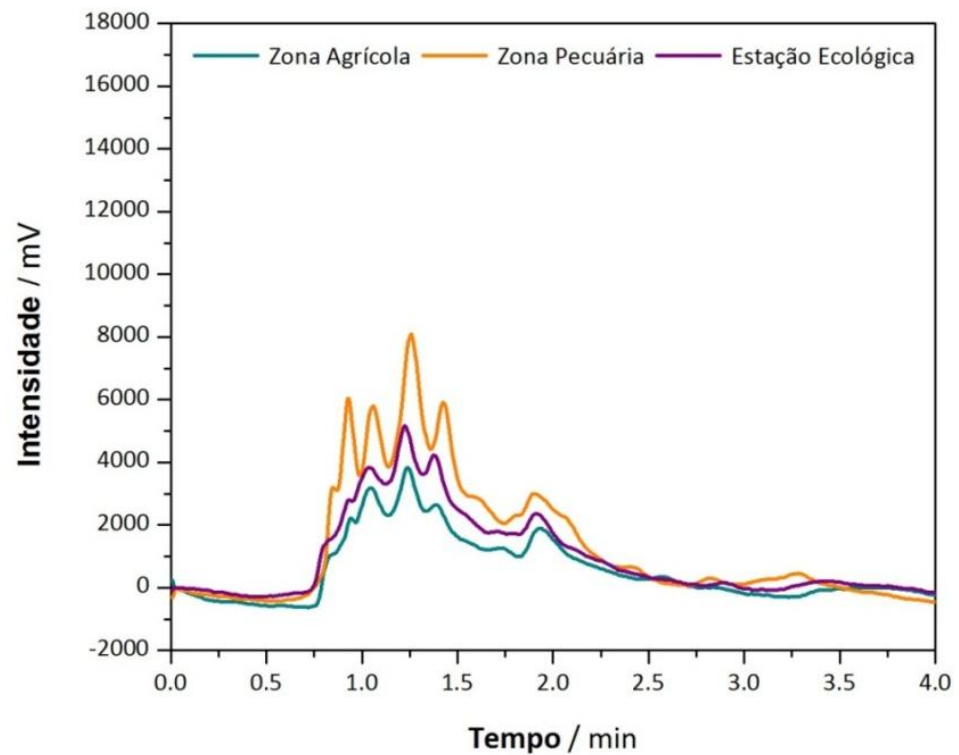

Figura 20 - Cromatograma dos sedimentos analisados. 
É possível observar que, no tempo de retenção do analito de interesse, não foram detectados outros picos cromatográficos com tempos de retenção coincidentes entre a matriz e o herbicida etilclorimuron. Com isso, é garantida a seletividade do método.

\subsubsection{Linearidade - Faixa de Trabalho e Faixa Linear}

A linearidade foi determinada por meio da construção das curvas analíticas. Os cálculos para regressão linear foram realizados por meio do método dos mínimos quadrados.

Para determinação da linearidade, utilizaram-se soluções do herbicida com concentrações variando de 0,1 a 1000 ug $\mathrm{L}^{-1}$. Os picos cromatográficos só foram obtidos e quantificados a partir de $5 \mathrm{ug} \mathrm{L}^{-1}$. Neste sentido, a faixa de trabalho atendida pelo método abrangeu o intervalo entre 5 e $1000 \mathrm{ug} \mathrm{L}^{-1}$.

Pensando nos limites de detecção (LOD) e de quantificação (LOQ), os quais foram determinados via linearidade da reta, além do coeficiente de correlação linear $\left(R^{2}\right)$, consideraram-se duas possibilidades de faixa linear.

A primeira possibilidade trabalhou com uma faixa linear única $\left(F L_{i}\right)$, que corresponde ao intervalo da faixa de trabalho (5 a $1000 \mathrm{ug} \mathrm{L}^{-1}$ ). A segunda possibilidade trabalha com duas faixas lineares, uma vai de 5 a 100 ug L $^{-1}\left(\mathrm{FL}_{\mathrm{iiA}}\right)$ e outra, que compreende às concentrações de 100 a 1000 ug L $^{-1}\left(\mathrm{FL}_{\mathrm{iiB}}\right)$.

As curvas analíticas estão apresentadas na Figura 21. 

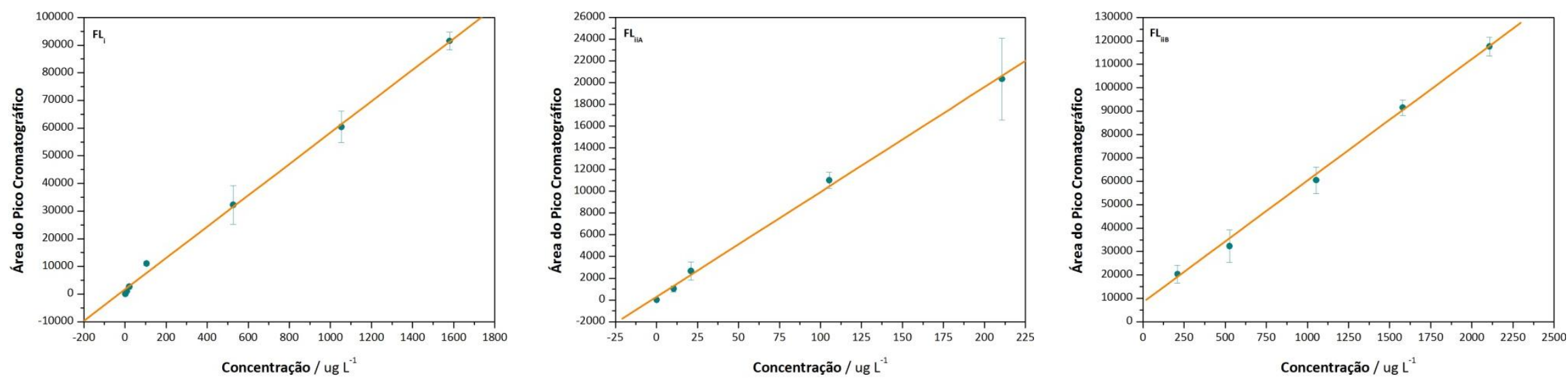

Figura 21 - Curvas analíticas do herbicida etilclorimuron. 
Trabalhando com duas faixas lineares, a escolha da equação da reta para cálculo da concentração é determinada por meio da área do pico cromatográfico. Picos com área de até 20324,33 foram tratadas por meio da equação da reta da faixa linear $\mathrm{FL}_{\mathrm{iA}}$. Acima deste valor utilizou-se a equação da reta referente à faixa linear $\mathrm{FL}_{\mathrm{iiA}}$.

É importante ressaltar que os pontos referentes a cada concentração analítica apresentam um valor diferente de sua concentração. Por exemplo, a concentração de 100 ug $\mathrm{L}^{-1}$ está indicada no gráfico próximo a 200 ug $\mathrm{L}^{-1}$. Esta segunda concentração é considerada real, pois considera a massa do padrão analítico de fato pesada e, além disso, o volume real do balão volumétrico utilizado no preparo das soluções. Neste sentido, calculouse um fator de correção para a concentração, o qual foi multiplicado por todas as concentrações teóricas utilizadas na construção das curvas analíticas. O valor do fator de correção foi de 2,1071.

Na Tabela 8 estão apresentadas as equações das retas obtidas e seus parâmetros lineares para cada faixa linear.

TABELA 8 - Equações da reta e parâmetros lineares

\begin{tabular}{|c|c|c|c|}
\hline & $\mathrm{FL}_{\mathrm{i}}$ & $\mathrm{FL}_{\mathrm{iiA}}$ & $\mathrm{FL}_{\text {iiB }}$ \\
\hline $\begin{array}{l}\text { Intervalo de } \\
\text { Concentrações }\end{array}$ & 5,0 a 1000,0 ug $\mathrm{L}^{-1}$ & 5,0 a 100,0 ug $\mathrm{L}^{-1}$ & 100,0 a 1000,0 ug $L^{-1}$ \\
\hline $\begin{array}{l}\text { Intervalo de Áreas dos } \\
\text { Picos }\end{array}$ & - & Até 20324,33 & A partir de 20324,33 \\
\hline Equação da & $y=(56,2179 \pm 1,2663) \cdot x$ & $y=(96,4999 \pm 2,6868) \cdot x$ & $y=(52,5532 \pm 2,7696) \cdot x$ \\
\hline Reta & $+(2245,0814 \pm 1020,4596)$ & $+(289,6823 \pm 284,4876)$ & $+(6827,1895 \pm 2745,0541)$ \\
\hline $\mathbf{a}$ & 56,2179 & 96,4999 & 52,5532 \\
\hline $\mathbf{S}_{\mathrm{a}}$ & 1,2663 & 2,6868 & 2,7696 \\
\hline b & 2245,0814 & 289,6823 & 6827,1895 \\
\hline$S_{b}$ & 1020,4596 & 284,4876 & 2745,0541 \\
\hline
\end{tabular}

Na Tabela 9 estão apresentados os coeficientes de correlação linear $\left(R^{2}\right)$ para as três faixas calculadas. 
TABELA 9 - Coeficientes de correlação linear $\left(R^{2}\right)$

\begin{tabular}{lccc}
\hline & & \multicolumn{2}{c}{ Validado? } \\
& Coeficiente de Correlação Linear $\left(\mathbf{R}^{2}\right)$ & ANVISA & INMETRO \\
\hline $\mathrm{FL}_{\mathrm{i}}$ & 0,9990 & $\operatorname{Sim}$ & $\mathrm{Sim}$ \\
$\mathrm{FL}_{\mathrm{iiA}}$ & 0,9988 & $\mathrm{Sim}$ & $\mathrm{Sim}$ \\
$\mathrm{FL}_{\mathrm{iiB}}$ & 0,9972 & $\operatorname{Sim}$ & $\mathrm{Sim}$ \\
\hline
\end{tabular}

De acordo com a resolução da ANVISA, todos os resultados estão de acordo com os valores orientados. A orientação é para que a linearidade seja determinada pela análise de, no mínimo, 5 concentrações diferentes. A mesma recomendação é feita pelo INMETRO. No tocante ao $R^{2}$, um coeficiente de correlação maior que 0,999 é considerado uma evidência de um ajuste ideal dos dados para a linha da regressão. Para a ANVISA, a correlação mínima aceitável deve ser igual ou superior a 0,99. Para o INMETRO esse valor é de 0,9. Assim sendo, em todas as situações foram contempladas as recomendações mínimas exigidas.

\subsubsection{Sensibilidade}

Não há um consenso entre os documentos do INMETRO e da ANVISA sobre o que é e como determinar a sensibilidade.

Neste item a sensibilidade será avaliada via inclinação da reta, atendendo as orientações do INMETRO. No item seguinte (5.2.4) são discutidos os limites de detecção, atendendo assim a recomendação da ANVISA. Na Tabela 10 estão apresentados os valores obtidos para a sensibilidade.

TABELA 10 - Sensibilidade do método

\section{Validado?}

Sensibilidade

ANVISA

$56,2179 \pm 1,2663$

$96,4999 \pm 2,6868$
INMETRO

Não Contempla

Não Contempla 
Analisando o coeficiente de variação angular (valor de $a$ da curva analítica) das retas obtidas, a faixa linear $\mathrm{FL}_{\mathrm{iiA}}$ é a que apresenta uma maior sensibilidade. Comparando com a faixa linear $\mathrm{FL}_{\mathrm{i}}$, este valor é bastante significativo. A diferença na sensibilidade entre estas duas faixas lineares é de aproximadamente $41,74 \%$. Considerando ser relevante uma sensibilidade alta para as concentrações baixas (mais difíceis de serem detectadas) é justificável a utilização de duas faixas lineares ao invés de apenas uma. Como a faixa linear $\mathrm{FL}_{\mathrm{iiB}}$ trabalha com concentrações elevadas (acima de $100 \mathrm{ug} \mathrm{L}^{-1}$ ), esta foi desconsiderada.

\subsubsection{Limite de detecção (LOD) e limite de quantificação (LOQ)}

Os limites de detecção (LOD) e de quantificação (LOQ) foram determinados via linearidade da curva analítica, considerando as duas possibilidades de faixa linear. Os valores de LOD e LOQ são significativamente inferiores quando a faixa de trabalho é dividida em duas faixas lineares. A faixa linear $\mathrm{FL}_{\mathrm{iiB}}$ foi desconsiderada por não contemplar as concentrações mais baixas distribuídas ao longo da faixa de trabalho. Os valores de LOD e LOQ estão apresentados nas tabelas 11 e 12, respectivamente.

TABELA 11 - Limites de detecção (LOD)

\begin{tabular}{lccc}
\hline & Limite de Deteç̧ão (LOD) / ug L & \multicolumn{2}{c}{ Validado? } \\
& & ANVISA & INMETRO \\
\hline $\mathrm{FL}_{\mathrm{i}}$ & 54,4556 & Não Contempla & Não Contempla \\
$\mathrm{FL}_{\mathrm{iiA}}$ & 8,8442 & Não Contempla & Não Contempla \\
\hline
\end{tabular}

TABELA 12 - Limites de quantificação (LOQ)

\begin{tabular}{lccr}
\hline & Limite de Quantificação (LOQ) / ug L & & Validado? \\
& & ANVISA & INMETRO \\
\hline $\mathrm{FL}_{\mathbf{i}}$ & 181,5187 & Não Contempla & Não Contempla \\
$\mathrm{FL}_{\mathrm{iiA}}$ & 29,4809 & Não Contempla & Não Contempla \\
\hline
\end{tabular}


O valor do limite de detecção da faixa $\mathrm{FL}_{\mathrm{iiA}}$ é aproximadamente $575 \%$ menor que este limite em $\mathrm{FL}_{\mathrm{i}}$. Para o limite de quantificação esta diferença é de $517 \%$. Esta considerável diferença é mais uma evidência para a utilização de duas faixas lineares.

Os documentos do INMETRO e da ANVISA não contemplam um valor a se validar para estes parâmetros. Tratando-se de pesticidas ou outras moléculas com ação danosa ao homem ou ao meio ambiente, são as agências e autarquias públicas de regulamentação ambientais que determinam estes parâmetros como Valor Máximo Permitido (VMP), e cabe aos métodos analíticos validarem os limites de detecção e quantificação atendendo a esta exigência.

Atualmente as legislações ambientais se restringem principalmente aos documentos normativos que garantem a qualidade da água para consumo humano. A legislação da União Europeia estabelece limites rígidos para a concentração de pesticidas para esta finalidade, sendo no máximo $0,1 \mathrm{ug} \mathrm{L}^{-1}$ para ensaios individuais e 0,5 ug L ${ }^{-1}$ para o somatório de todos os pesticidas em uma mesma amostra. No caso das águas superficiais que poderão ser destinadas ao abastecimento público, este valor é de 1 ug $\mathrm{L}^{-1}$ para cada pesticida individualmente e de 5 ug L ${ }^{-1}$ para a soma destes. ${ }^{83}$ No Brasil, o Ministério da Saúde através da portaria MS 2914 de 2011 estabelece os valores máximos permitidos para 36 pesticidas. ${ }^{84}$ Atualmente, existem 398 princípios ativos e 1002 formulações registradas no Brasil, além de produtos não regulamentados que continuam sendo utilizado pelos agricultores. ${ }^{85} \mathrm{Ou}$ seja, poucos pesticidas são contemplados por esta resolução, aproximadamente $9 \%$.

Esta mesma carência de VMPs ocorre quando a matriz analisada é o solo. A norma 420 do Conselho Nacional do Meio Ambiente (CONAMA) contempla vinte espécies metálicas, e aproximadamente cinquenta moléculas orgânicas, dentre estas, pouco mais de 20 são utilizados em formulações de pesticidas. O herbicida etilclorimuron, ou qualquer outra sulfonilureia, não é citado. No tocante aos sedimentos não há regulamentação alguma, nacional ou internacional.

Outro parâmetro regulatório utilizado pelos órgãos de segurança e vigilância ambiental são os LMR (Limites Máximos de Resíduos). Estes valores são um binômio pesticida/cultura. Para cada pesticida há um valor de concentração máximo para um determinado pesticida. No âmbito internacional, estes limites são estabelecidos pela FAO (Organização das Nações Unidas para Agricultura e Alimentação) e pela OMS (Organização 
Mundial da Saúde). A autarquia federal que contempla um maior número de LMR é a estadunidense EPA. Para as culturas de soja e amendoim, a EPA estabelece os valores 0,05 e $0,02 \mathrm{mg} \mathrm{L}^{-1}$ para seus respectivos $\mathrm{LMR}$. Os valores de LOD e LOQ contemplam a concentração máxima permitida para a cultura da soja, porém ambos os valores ficam acima do permitido para o amendoim. Como a regulamentação da ANVISA permite o comércio do herbicida etilclorimuron apenas para aplicação em culturas da soja, este fato não é tido como um fator limitante para o método desenvolvido. ${ }^{86}$

\subsubsection{Recuperação do método}

A recuperação é um parâmetro de validação prescrito apenas para o INMETRO. A ANVISA considera a recuperação como sendo a exatidão do método.

Os percentuais de recuperação obtidos e os fatores de recuperação $\left(f_{R}\right)$ estão apresentados na Tabela 13.

O INMETRO não contempla um valor para a recuperação do método. Quanto maior a concentração utilizada nos ensaios da recuperação do método, menor foi o efeito da matriz (causado pela presença do sedimento). Isso fez com que os percentuais de recuperação fossem maiores para concentrações mais elevadas.

Relembrando os valores obtidos no item anterior (5.2.4), o qual discute os limites de detecção e quantificação, o LOQ e LOD calculados foram, respectivamente, 29,48 e 8,84 ug $\mathrm{L}^{-1}$. Considerando que a recuperação é um ensaio quantitativo, a concentração analítica de $10 \mathrm{ug} \mathrm{L}^{-1}$ se encontra abaixo do limite de quantificação, logo se justifica a dificuldade do método em obter um percentual considerável, próximo a 100\%, para esta concentração.

Comparando os percentuais de recuperação obtidos e seus respectivos erros absolutos, houve diferença significativa apenas ao comparar as concentrações analíticas analisadas em 1000 e 100 ug $\mathrm{L}^{-1}$ na amostra de sedimentos da zona agrícola, aproximadamente $72 \%$ de diferença. Nas demais amostras analisadas, tais comparações não excederam $20 \%$ de diferença. 
TABELA 13 - Recuperação do método

\begin{tabular}{|c|c|c|c|c|c|}
\hline & \multirow{2}{*}{ Concentração/ ug L $\mathrm{L}^{-1}$} & \multirow{2}{*}{ Recuperação/ \% } & \multirow{2}{*}{$\mathbf{f}_{\mathrm{R}}$} & \multicolumn{2}{|c|}{ Validado? } \\
\hline & & & & ANVISA & INMETRO \\
\hline & 1000 & $133,33 \pm 0,66$ & 0,7513 & - & Não Contempla \\
\hline \multirow[t]{3}{*}{$\begin{array}{l}\text { Zona } \\
\text { Agrícola }\end{array}$} & 100 & $77,15 \pm 6,04$ & 1,3262 & - & Não Contempla \\
\hline & 10 & $54,26 \pm 1,23$ & 1,7730 & - & Não Contempla \\
\hline & 1000 & $97,58 \pm 5,74$ & 1,0406 & - & Não Contempla \\
\hline \multirow[t]{3}{*}{$\begin{array}{l}\text { Zona } \\
\text { Pecuária }\end{array}$} & 100 & $82,59 \pm 4,45$ & 1,2346 & - & Não Contempla \\
\hline & 10 & $58,79 \pm 2,66$ & 1,6863 & - & Não Contempla \\
\hline & 1000 & $94,98 \pm 7,97$ & 1,0707 & - & Não Contempla \\
\hline \multirow[t]{2}{*}{ Estação Ecológica } & 100 & $84,84 \pm 1,01$ & 1,2658 & - & Não Contempla \\
\hline & 10 & $71,05 \pm 0,65$ & 1,3605 & - & Não Contempla \\
\hline
\end{tabular}

Os fatores de recuperação $\left(f_{R}\right)$ foram utilizados para ajustar as concentrações obtidas para um valor real, desconsiderando o efeito causado pela matriz. Os valores das concentrações foram multiplicados por seu respectivo fator, cada qual dentro de sua faixa de concentração analisada na recuperação.

\subsubsection{Precisão}

A precisão foi calculada segundo os resultados obtidos na recuperação do método. Os valores estão apresentados em porcentagem dos coeficientes de variação. Os resultados obtidos estão apresentados na Tabela 14.

De acordo com as recomendações da ANVISA, não são admitidos coeficientes de variação acima de 15\%. Para o INMETRO, uma tabela é vinculada ao documento estipulando os coeficientes de variação em função de cada concentração analisada. Para as concentrações de 1000, 100 e 10 ug L $^{-1}$ estes valores são 16, 23 e 32\%, respectivamente. 
TABELA 14 - Precisão do método

\begin{tabular}{|c|c|c|c|c|}
\hline & \multirow{2}{*}{ Concentração / ug $\mathrm{L}^{-1}$} & \multirow{2}{*}{ Coeficiente de Variação / \% } & \multicolumn{2}{|c|}{ Validado? } \\
\hline & & & ANVISA & INMETRO \\
\hline & 1000 & 0,49 & Sim & Sim \\
\hline \multirow[t]{3}{*}{$\begin{array}{l}\text { Zona } \\
\text { Agrícola }\end{array}$} & 100 & 7,83 & Sim & Sim \\
\hline & 10 & 2,26 & Sim & Sim \\
\hline & 1000 & 5,88 & Sim & Sim \\
\hline \multirow[t]{3}{*}{$\begin{array}{l}\text { Zona } \\
\text { Pecuária }\end{array}$} & 100 & 5,39 & Sim & Sim \\
\hline & 10 & 4,53 & Sim & Sim \\
\hline & 1000 & 8,40 & Sim & Sim \\
\hline \multirow[t]{2}{*}{$\begin{array}{l}\text { Estação } \\
\text { Ecológica }\end{array}$} & 100 & 1,19 & Sim & Sim \\
\hline & 10 & 0,92 & Sim & Sim \\
\hline
\end{tabular}

Para a ANVISA e para o INMETRO, os valores obtidos em todos os ensaios para precisão foram validados. Os coeficientes de variação não seguiram uma lógica linear no tocante às proporções crescentes das concentrações em função dos resultados obtidos. Ora as concentrações elevadas apresentaram um menor valor obtido de coeficiente de variação e, para outras amostras de sedimento, este comportamento não foi observado, apresentando valores maiores para ensaios utilizando concentrações elevadas.

\subsubsection{Exatidão}

A exatidão do método foi calculada de acordo com a metodologia proposta pela ANVISA. Os resultados obtidos estão apresentados na Tabela 15.

Segundo a ANVISA, o método é exato se possuir um alcance entre 80 e $120 \%$ da concentração analítica inicial.

O método proposto atendeu as recomendações feitas pela ANVISA na maioria das situações. Não foram validadas as determinações realizadas nas concentrações de $10 \mathrm{ug} \mathrm{L^{-1 }}$. Os valores encontrados não contemplaram um valor dentro do intervalo entre 80 e $120 \%$ recomendados pela ANVISA. Estes valores são justificados, pois a concentração analítica 
analisada está abaixo do limite de deteç̧ão e rente ao limite de quantificação $(29,48$ e 8,84 ug $\mathrm{L}^{-1}$, respectivamente), dificultando a análise quantitativa.

TABELA 15 - Exatidão do método

\begin{tabular}{|c|c|c|c|c|}
\hline & \multirow{2}{*}{ Concentração/ ug L $\mathrm{L}^{-1}$} & \multirow{2}{*}{ Exatidão / \% } & \multicolumn{2}{|c|}{ Validado? } \\
\hline & & & ANVISA & INMETRO \\
\hline & 1000 & $133,33 \pm 0,66$ & Não & - \\
\hline \multirow{3}{*}{$\begin{array}{l}\text { Zona } \\
\text { Agrícola }\end{array}$} & 100 & $77,15 \pm 6,04$ & Sim & - \\
\hline & 10 & $54,26 \pm 1,23$ & Não & - \\
\hline & 1000 & $97,58 \pm 5,74$ & Sim & - \\
\hline \multirow[t]{3}{*}{$\begin{array}{l}\text { Zona } \\
\text { Pecuária }\end{array}$} & 100 & $82,59 \pm 4,45$ & Sim & - \\
\hline & 10 & $58,79 \pm 2,66$ & Não & - \\
\hline & 1000 & $94,98 \pm 7,97$ & Sim & - \\
\hline \multirow[t]{2}{*}{$\begin{array}{l}\text { Estação } \\
\text { Ecológica }\end{array}$} & 100 & $84,84 \pm 1,01$ & Sim & - \\
\hline & 10 & $71,05 \pm 0,65$ & Não & - \\
\hline
\end{tabular}

\subsection{8 $\quad$ Robustez}

A robustez do método foi analisada aplicando pequenas alterações nos parâmetros cromatográficos em validação. Estas variações implicaram em alterações nas áreas dos picos cromatográficos e no tempo de retenção do herbicida etilclorimuron. Devido à relação linear que existe entre as áreas dos picos e a concentração analítica, a concentração inicial (100 ug $\mathrm{L}^{-1}$ ) foi quantificada com diferentes valores referentes a cada situação analisada.

A Tabela 16 apresenta as concentrações analíticas obtidas e os tempos de retenção para cada uma das situações analisadas.

Analisando os resultados abaixo apresentados, os valores obtidos para o tempo de retenção e para a concentração analítica indicaram uma perturbação causada pelas variações nos parâmetros cromatográficos. A diminuição no fluxo da fase móvel causou um acréscimo de aproximadamente 1 minuto em quase todos os ensaios em que ocorreu a variação deste parâmetro. 
TABELA 16 - Robustez do método

\begin{tabular}{lccccc}
\hline \multicolumn{7}{c}{ Parâmetros Cromatográficos Analisados } & $\begin{array}{c}\text { Concentração } \\
\text { Cetectada / mol L }\end{array}$ & $\begin{array}{c}\text { Tempo de } \\
\text { Retenção / min } \\
\text { móvel / \% CH } \mathrm{CN}^{-1}\end{array}$ & Fluxo / $\mathrm{mL} \mathrm{min}^{-1}$ & & \\
\hline $\mathbf{1}$ & $\mathbf{p H}$ & 60 & 1,4 & $103,99 \pm 2,54$ & $3,22 \pm 0,01$ \\
$\mathbf{2}$ & 2,2 & 60 & 1,4 & $103,38 \pm 3,71$ & $3,25 \pm 0,01$ \\
$\mathbf{3}$ & 2 & 60 & 1,2 & $104,37 \pm 0,85$ & $3,76 \pm 0,02$ \\
$\mathbf{4}$ & 2,2 & 60 & 1,2 & $112,94 \pm 7,55$ & $3,78 \pm 0,01$ \\
$\mathbf{5}$ & 2 & 58 & 1,4 & $120,82 \pm 2,72$ & $3,65 \pm 0,01$ \\
$\mathbf{6}$ & 2,2 & 58 & 1,4 & $111,82 \pm 0,89$ & $3,60 \pm 0,01$ \\
$\mathbf{7}$ & 2 & 58 & 1,2 & $127,08 \pm 5,42$ & $4,25 \pm 0,00$ \\
$\mathbf{8}$ & 2,2 & 58 & 1,2 & $124,42 \pm 0,71$ & $4,22 \pm 0,01$ \\
\hline
\end{tabular}

O aumento no tempo de retenção é mais significativo nas combinações em que ocorreu a diminuição no percentual de solvente na fase móvel. O aumento do percentual da solução na composição da fase móvel aumentou a interação entre o analito e a fase estacionária da coluna cromatográfica (octadecilsilano - C18), consequentemente, ocorreu um aumento na solubilidade do analito no leito da coluna cromatográfica, fazendo que este ficasse retido por mais tempo, aumentando seu tempo de retenção.

Conforme apresentado na Tabela 2, em valores de $\mathrm{pH}$ muito baixos a solubilidade do herbicida varia com insignificância. Neste sentido, pequenas variações nos valores de pH próximos a 2 alterariam muito pouco a solubilidade do herbicida, permanecendo com valores bem próximos a 1,5 mg mL ${ }^{-1} \cdot{ }^{35-36}$ Como a concentração analisada foi de $100,0 \mathrm{ug} \mathrm{L}{ }^{-1}$, a solubilidade do herbicida estaria mais de 20.000 vezes acima do tabelado, interferindo pouco neste quesito.

A Figura 22 apresenta os resultados obtidos quando se aplica o teste estatístico de Youden aos valores apresentados na Tabela 16. Este gráfico nos mostra, de forma clara e intuitiva, cada parâmetro cromatográfico analisado, indicando quais destes são os mais efetivos na perturbação da robustez do método cromatográfico. 


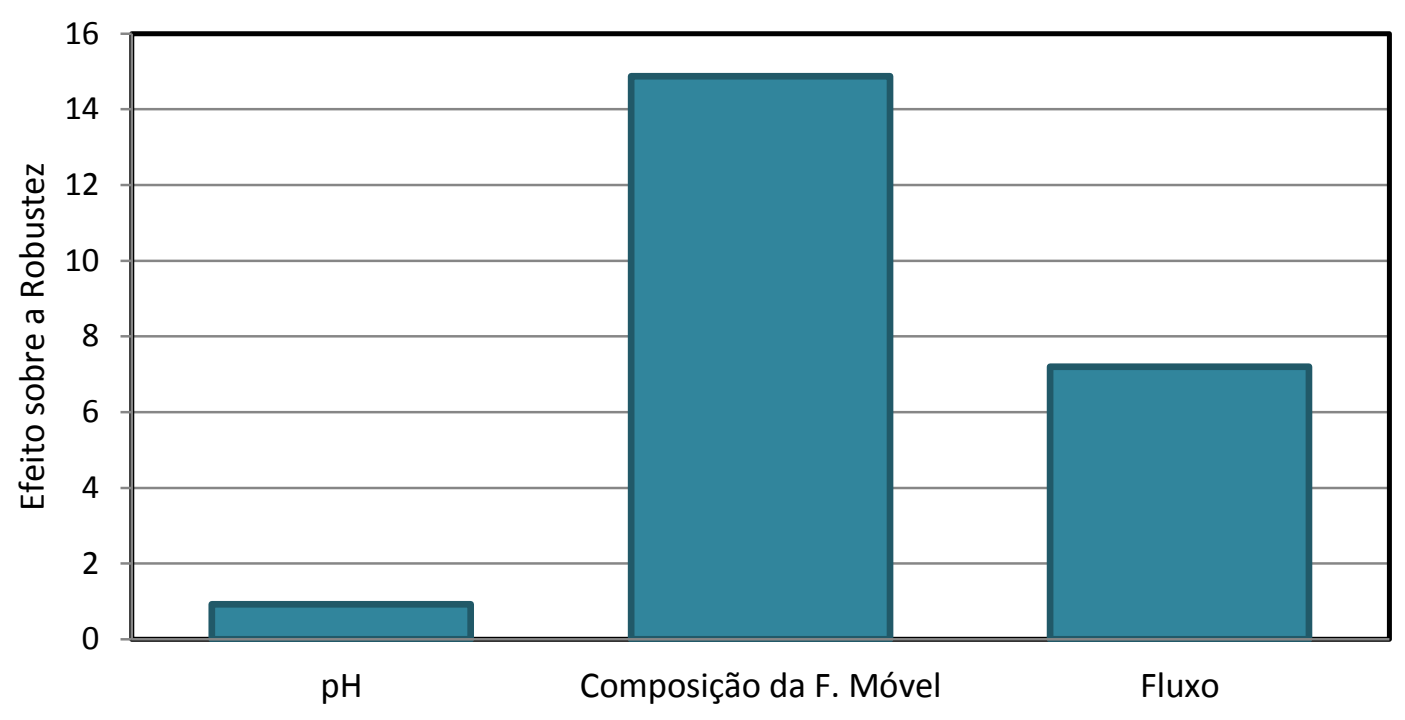

Figura 22 - Efeitos sobre a robustez do método analítico.

O teste estatístico de Youden analisa, especificamente, a robustez do método em função da concentração detectada pelo método. Neste sentido, o pH da solução que compõe a fase móvel apresentou menor efeito sobre a robustez na comparação com os demais parâmetros, seguido pelo fluxo e, por último, a composição da fase móvel.

De acordo com os resultados apresentados, o uso de bombas desreguladas, sem a devida calibração, poderia, em termos de garantia dos valores agregados, apresentar problemas na quantificação e reprodução dos valores encontrados para este método. A bomba, parte fundamental na instrumentação dos cromatógrafos modernos, é o que regula o fluxo e a composição da fase móvel. ${ }^{40}$ 


\subsubsection{RESUMO - Validação do Método Analítico}

A Tabela 17 apresenta um resumo dos resultados obtidos na validação da metodologia analítica para determinação cromatográfica do herbicida etilclorimuron em sedimentos. Esta tabela tem por finalidade facilitar a visualização e compreensão geral dos dados acima apresentados.

TABELA 17 - Resumo dos resultados obtidos na validação da metodologia analítica

\begin{tabular}{|c|c|c|c|c|}
\hline \multirow{3}{*}{ Seletividade } & \multirow{3}{*}{$\begin{array}{l}\lambda(U V) \\
t_{r}\end{array}$} & \\
\hline & & \multicolumn{3}{|l|}{$235 \mathrm{~nm}$} \\
\hline & & \multicolumn{3}{|l|}{$2,91 \mathrm{~min}$} \\
\hline \multicolumn{2}{|l|}{ Linearidade } & \multicolumn{3}{|c|}{$\begin{array}{l}y=(96,4999 \pm 2,6868) \cdot x+(289,6823 \pm 284,4876) \\
R^{2}=0,9988\end{array}$} \\
\hline 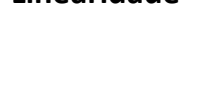 & $\mathrm{FL}_{\text {iib }}$ & \multicolumn{3}{|c|}{$\begin{array}{l}y=(52,5532 \pm 2,7696) \cdot x+(6827,1895 \pm 2745,0541) \\
R^{2}=0,9972\end{array}$} \\
\hline Sensibilidade & & \multicolumn{3}{|l|}{$96,4999 \pm 2,6868$} \\
\hline LOD & & 8,8442 ug L $^{-1}$ & & \\
\hline \multirow[t]{3}{*}{ LOQ } & & \multicolumn{3}{|l|}{29,4809 ug $L^{-1}$} \\
\hline & Concentração & $\begin{array}{l}\text { Zona } \\
\text { Agrícola }\end{array}$ & $\begin{array}{l}\text { Zona } \\
\text { Pecuária }\end{array}$ & Estação Ecológica \\
\hline & 1000 ug $L^{-1}$ & $(133,33 \pm 0,66) \%$ & $(97,58 \pm 5,74) \%$ & $(94,98 \pm 7,97) \%$ \\
\hline \multirow[t]{3}{*}{ Recuperação } & 100 ug $L^{-1}$ & $(77,15 \pm 6,04) \%$ & $(82,59 \pm 4,45) \%$ & $(84,84 \pm 1,01) \%$ \\
\hline & 10 ug $L^{-1}$ & $(54,26 \pm 1,23) \%$ & $(58,79 \pm 2,66) \%$ & $(71,05 \pm 0,65) \%$ \\
\hline & 1000 ug L ${ }^{-1}$ & 0,49 & 5,88 & 8,40 \\
\hline \multirow[t]{3}{*}{ Precisão } & 100 ug $L^{-1}$ & 7,83 & 5,39 & 1,19 \\
\hline & 10 ug $L^{-1}$ & 2,26 & 4,53 & 0,92 \\
\hline & 1000 ug L ${ }^{-1}$ & $(133,33 \pm 0,66) \%$ & $(97,58 \pm 5,74) \%$ & $(94,98 \pm 7,97) \%$ \\
\hline \multirow[t]{2}{*}{ Exatidão } & 100 ug $L^{-1}$ & $(77,15 \pm 6,04) \%$ & $(82,59 \pm 4,45) \%$ & $(84,84 \pm 1,01) \%$ \\
\hline & 10 ug $L^{-1}$ & $(54,26 \pm 1,23) \%$ & $(58,79 \pm 2,66) \%$ & $(71,05 \pm 0,65) \%$ \\
\hline
\end{tabular}




\subsection{Dinâmica do herbicida no ambiente}

\subsubsection{Cinética de Adsorção}

Para entendermos o fenômeno da sorção, principal atividade que rege a dinâmica (movimento ou transporte) dos compostos orgânicos no ambiente, é importante sabermos, em curto tempo, qual a capacidade de retenção do analito em estudo presente em uma matriz ambiental.

Realizado um estudo cinético, verificou-se a quantidade do herbicida adsorvida em função do tempo (48 horas de análise). Os resultados obtidos se encontram na Figura 23.

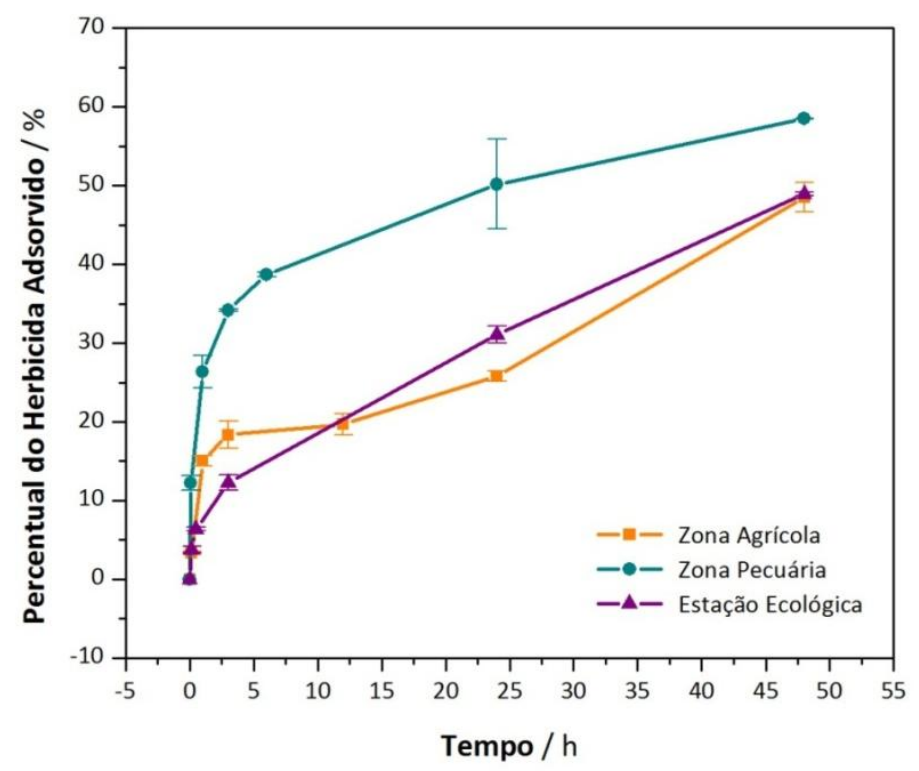

Figura 23 - Cinética de adsorção do herbicida etilclorimuron em sedimentos.

A Tabela 18 apresenta o percentual e a concentração do herbicida etilclorimuron adsorvido em função do tempo. A concentração foi calculada via curva analítica. Teoricamente, a concentração inicial do herbicida utilizada na adsorção era de 600 ug $\mathrm{L}^{-1}$, porém, com o peso real da amostra e o desvio da concentração, a concentração analítica foi de 657,83 ug L $^{-1}$. 
TABELA 18 - Percentual e concentração adsorvida

\begin{tabular}{|c|c|c|c|c|c|c|c|}
\hline & \multicolumn{6}{|c|}{ Tempo } & \multirow{2}{*}{ Adsorção } \\
\hline & $0 \mathrm{~min}$ & $10 \mathrm{~min}$ & $1 \mathrm{~h}$ & $3 \mathrm{~h}$ & $24 \mathrm{~h}$ & $48 \mathrm{~h}$ & \\
\hline \multirow{2}{*}{$\begin{array}{l}\text { Zona } \\
\text { Agrícola }\end{array}$} & 0,00 & $3,39 \pm 0,19$ & $15,06 \pm 0,66$ & $18,36 \pm 1,70$ & $25,80 \pm 0,63$ & $48,58 \pm 1,90$ & $\%$ do Herbicida Adsorvido \\
\hline & 0,00 & $(2,12 \pm 0,12) \cdot 10^{2}$ & $(9,36 \pm 0,41) \cdot 10^{2}$ & $(11,68 \pm 1,08) \cdot 10^{2}$ & $(16,70 \pm 0,41) \cdot 10^{2}$ & $(29,07 \pm 0,14) \cdot 10^{2}$ & $\mathrm{C}_{\mathrm{ads}} / \mathrm{ug} \mathrm{kg} \mathrm{kg}^{-1}$ \\
\hline \multirow{2}{*}{$\begin{array}{l}\text { Zona } \\
\text { Pecuária }\end{array}$} & 0,00 & $12,23 \pm 0,95$ & $26,36 \pm 2,08$ & $34,16 \pm 0,16$ & $50,19 \pm 5,68$ & $58,53 \pm 0,05$ & $\%$ do Herbicida Adsorvido \\
\hline & 0,00 & $(7,74 \pm 0,60) \cdot 10^{2}$ & $(16,85 \pm 0,13) \cdot 10^{2}$ & $(21,97 \pm 0,10) \cdot 10^{2}$ & $(32,54 \pm 0,38) \cdot 10^{2}$ & $37,97 \pm 0,06) \cdot 10^{2}$ & $\mathrm{C}_{\mathrm{ads}} / \mathrm{ug} \mathrm{kg} \mathrm{kg}^{-1}$ \\
\hline \multirow{2}{*}{$\begin{array}{l}\text { Estação } \\
\text { Ecológica }\end{array}$} & 0,00 & $3,76 \pm 0,40$ & $6,35 \pm 0,23$ & $12,26 \pm 1,00$ & $31,10 \pm 1,06$ & $48,93 \pm 0,23$ & \% do Herbicida Adsorvido \\
\hline & 0,00 & $(2,35 \pm 025) \cdot 10^{2}$ & $(3,89 \pm 0,14) \cdot 10^{2}$ & $(7,77 \pm 0,63) \cdot 10^{2}$ & $(20,13 \pm 0,68) \cdot 10^{2}$ & $(31,67 \pm 0,15) \cdot 10^{2}$ & $\mathrm{C}_{\mathrm{ads}} / \mathrm{ug} \mathrm{kg}{ }^{-1}$ \\
\hline
\end{tabular}


Analisando os resultados obtidos, foi possível observar as diferentes tendências das curvas que expressam, em termos analíticos, a quantidade adsorvida em função do tempo de contato entre a solução do herbicida e os sedimentos.

Em termos quantitativos, os sedimentos das amostras Zona Agrícola e Estação Ecológica apresentaram quantidades adsorvidas semelhantes no início (primeiras 3 horas) e no término (em 24 e 48 horas) do processo sortivo. Desde os primeiros tempos, a amostra Zona Pecuária apresentou maior capacidade de adsorção e, ao término da análise, é notória a diferença entre os percentuais adsorvidos desta amostra em comparação as demais.

Comparando as quantidades adsorvidas, a diferença no tempo final (48 horas), para as amostras Zona Agrícola e Estação Ecológica foi menor que 1\%. Em termos de quantidade adsorvida, este valor correspondeu aproximadamente ao valor de $260 \mathrm{ug} \mathrm{kg}^{-1}$. Sendo assim, considera-se que não há diferenças entre o máximo adsorvido, neste tempo, para estas amostras. Na comparação com a amostra Zona Pecuária, a diferença entre os percentuais adsorvidos foi de aproximadamente $17 \%$. Em termos de quantidade adsorvida, este valor correspondeu a 890 ug $\mathrm{kg}^{-1}$.

Estatisticamente, analisando via teste $t$ de student com $99 \%$ de confiabilidade e 2 graus de liberdade, as amostras Zona Agrícola e Estação Ecológica não apresentaram diferenças significativas quanto aos teores e percentuais adsorvidos. Já na comparação destas amostras com a Zona Pecuária, ambos os sedimentos adsorveram com diferenças significativas, tanto na comparação com o teor, quanto para o percentual adsorvido.

Ao analisar este tipo de gráfico (Figura 23) é possível associar o comportamento da curva característica à dinâmica do herbicida, em que se ordena o tempo de contato em função da quantidade ou percentual adsorvido. Mesmo sendo uma representação válida, este tipo de gráfico nos dá poucas informações acerca do processo sortivo: tipo de adsorção (química ou física), concentração de equilíbrio e a constante de velocidade. Estes parâmetros são de grande importância na análise de um sistema cinético e, sobretudo na dinâmica destes herbicidas nos sedimentos analisados.

Para obtenção destas informações, realizou-se um estudo cinético baseado na ordem da reação. Utilizaram-se os dados obtidos na análise anterior às hipóteses da cinética de pseudo-primeira-ordem e pseudo-segunda-ordem. 
Nas figuras 24 e 25 são apresentados os resultados obtidos para as formas linearizadas das equações de pseudo-primeira-ordem e pseudo-segunda-ordem, respectivamente.

Na Tabela 19 são apresentadas as equações das retas para cada tipo de cinética analisada, assim como os coeficientes de correlação $\left(R^{2}\right)$, as constantes de velocidade e as concentrações de equilíbrio.

TABELA 19 - Cinéticas de adsorção e seus parâmetros lineares

\begin{tabular}{|c|c|c|c|c|}
\hline & & $\begin{array}{c}\text { Zona } \\
\text { Agrícola }\end{array}$ & $\begin{array}{c}\text { Zona } \\
\text { Pecuária }\end{array}$ & $\begin{array}{l}\text { Estação } \\
\text { Ecológica }\end{array}$ \\
\hline \multirow{4}{*}{$\begin{array}{l}\text { Pseudo } \\
\text { Primeira } \\
\text { Ordem }\end{array}$} & Eq. da Reta & $\begin{aligned} y & =(-0,0250 \pm 0,0081) \cdot x \\
& +(5,6982 \pm 0,0893)\end{aligned}$ & $\begin{aligned} y & =(-0,0690 \pm 0,0145) \cdot x \\
& +(5,6866 \pm 0,1480)\end{aligned}$ & $\begin{aligned} y & =(-0,0388 \pm 0,0035) \cdot x \\
& +(5,8168 \pm 0,0381)\end{aligned}$ \\
\hline & $\mathbf{R}^{2}$ & 0,6309 & 0,8116 & 0,9651 \\
\hline & $\mathbf{k}_{1} / \min ^{-1}$ & 0,02503 & 0,06903 & 0,03882 \\
\hline & $C_{e} /$ ug L $^{-1}$ & 298,3538 & 294,9158 & 335,9256 \\
\hline \multirow{4}{*}{$\begin{array}{l}\text { Pseudo } \\
\text { Segunda } \\
\text { Ordem }\end{array}$} & Eq. da Reta & $\begin{aligned} y & =(0,0051 \pm 0,0004) \cdot x \\
& +(0,0075 \pm 0,0050)\end{aligned}$ & $\begin{aligned} y & =(0,0025 \pm 0,0001) \cdot x \\
& +(0,0029 \pm 0,0011)\end{aligned}$ & $\begin{aligned} y & =(0,0038 \pm 0,0004) \cdot x \\
& +(0,1120 \pm 0,0051)\end{aligned}$ \\
\hline & $\mathbf{R}^{2}$ & 0,9740 & 0,9936 & 0,9678 \\
\hline & $\mathbf{k}_{\mathbf{2}} / \mathrm{L} \mathrm{mg}^{-1} \min ^{-1}$ & 0,003468 & 0,002222 & 0,001331 \\
\hline & $\mathbf{C}_{\mathrm{e}} / \mathrm{ug} \mathrm{L}^{-1}$ & 196,0784 & 390,6250 & 258,3979 \\
\hline
\end{tabular}

Para saber qual cinética foi a mais adequada, foram comparados os coeficientes de correlação linear. A cinética com maior $\mathrm{R}^{2}$ indica o modelo mais adequado. Neste sentido, a cinética de pseudo-segunda-ordem apresentou melhor ajuste linear para todas as análises realizadas. Sendo assim, considera-se este modelo cinético o mais apropriado para o estudo da dinâmica dos herbicidas sulfonilureia no ambiente via adsorção em sedimentos. 

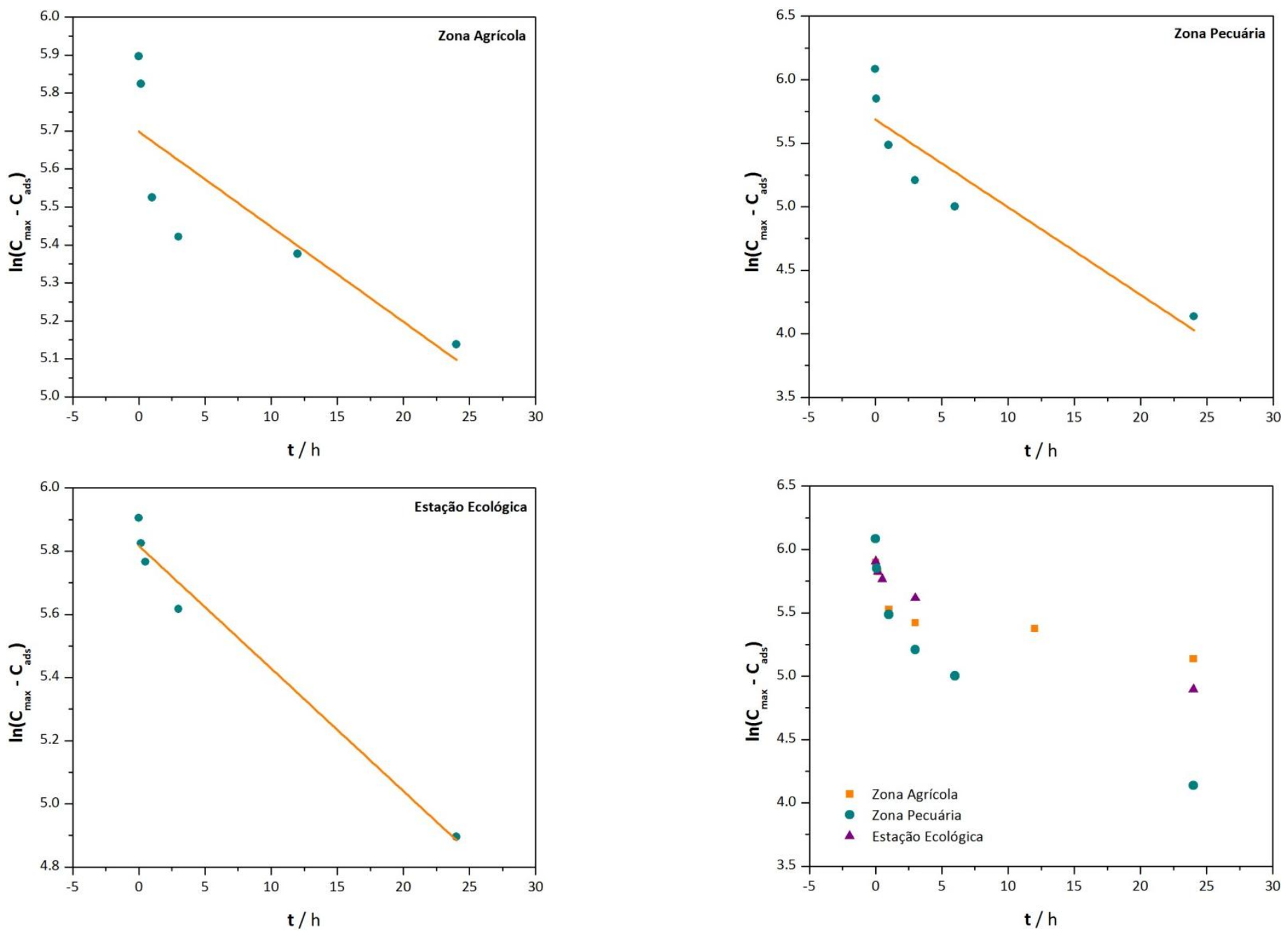

Figura 24 - Cinética de pseudo-primeira-ordem. 

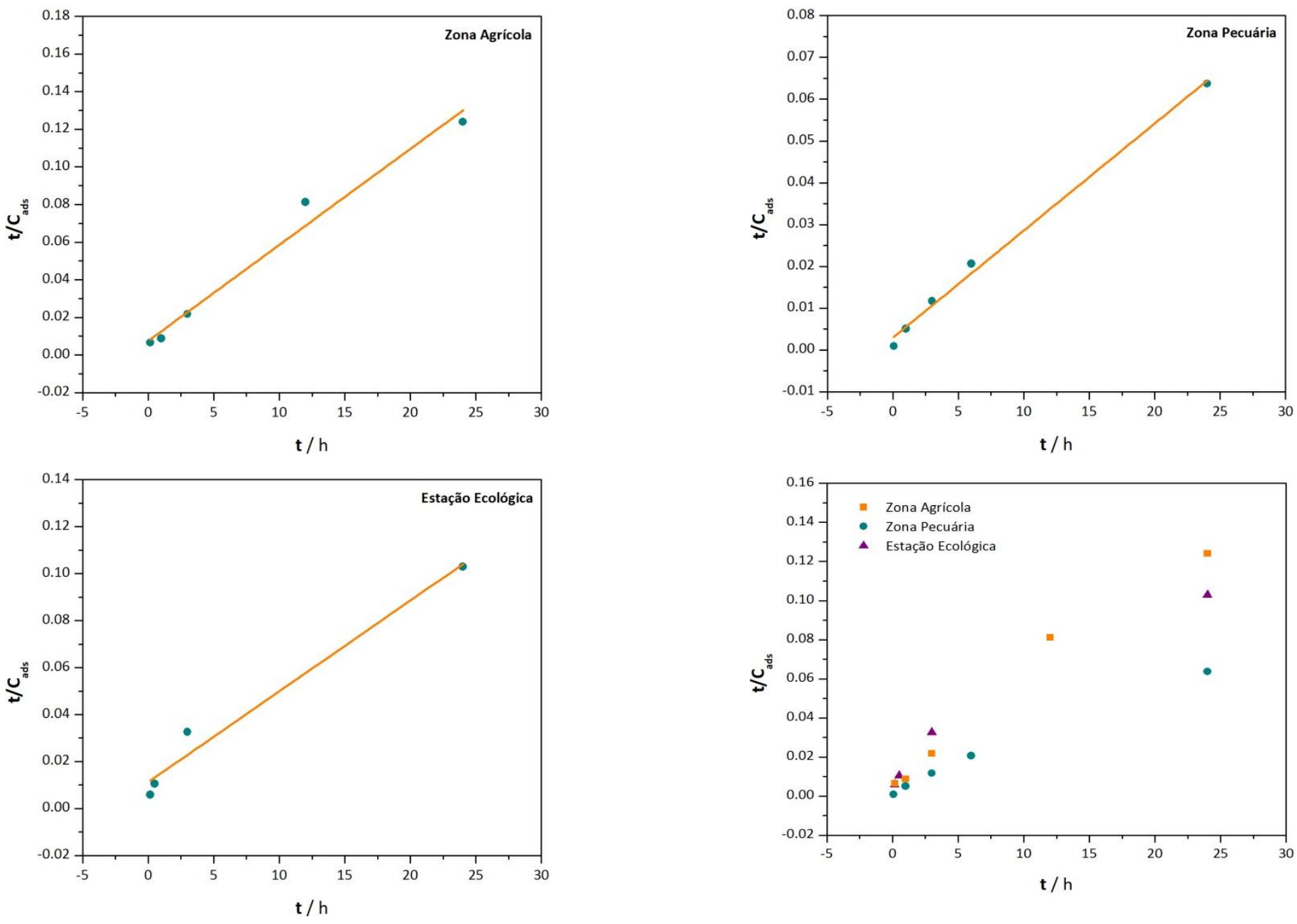

Figura 25 - Cinética de pseudo-segunda-ordem. 
A cinética de pseudo-segunda-ordem indica um aumento da velocidade em função do quadrado da concentração do herbicida em solução. Para os cálculos pertinentes, considerou-se a concentração do sedimento (sítios de adsorção) infinitamente maior que a concentração passiva de adsorção, tornando-se, neste caso, uma constante. ${ }^{43}$

Analisando os parâmetros cinéticos obtidos por meio do modelo de pseudosegunda-ordem, os valores das concentrações de equilíbrio $\left(C_{e}\right)$ são próximos ao que foi observado visualmente na Figura 23. Graficamente, quanto maior a quantidade adsorvida no tempo de contato final, maior a concentração de equilíbrio.

A concentração de equilíbrio nos indica a quantidade que se encontra adsorvida em um estado estacionário em relação à concentração do herbicida em solução (remanescente ou dessorvida). Em um nível molecular, o analito (herbicida etilclorimuron) adsorve e dessorve constantemente. No equilíbrio, a taxa na qual ocorre a adsorção é igual àquela em que a dessorção acontece. ${ }^{87-88}$

A diferença entre as concentrações de equilíbrio variou bastante entre os resultados obtidos. A maior diferença foi entre as amostras Zona Agrícola e Zona Pecuária, com 194,54 ug L ${ }^{-1}$ (99\% de diferença). Para as amostras Zona Pecuária e Estação Ecológica esta diferença foi de 132,22 ug L $^{-1}$ (51\% de diferença). As concentrações de equilíbrio mais próximas foram as das amostras Zona Agrícola e Estação Ecológica, com apenas 62,31 ug L ${ }^{-1}$ (30\% de diferença).

Outro parâmetro analisado no estudo da cinética de adsorção é a constante de velocidade. Como a cinética é de pseudo-segunda-ordem, esta constante recebe o símbolo $k_{2}$. O valor desta constante é diretamente proporcional à velocidade em que certa quantidade de moléculas do herbicida são adsorvidas até a saturação de uma camada de sítios de adsorção ou até que seja alcançado o equilíbrio. ${ }^{43,88}$

Comparando os resultados obtidos, a amostra Zona Agrícola apresentou maior constante de velocidade, seguida pelas amostras Zona Pecuária e Estação Ecológica. Analisando o gráfico da Figura 23 é possível estabelecer relações entre as constantes calculadas e o comportamento das curvas obtidas. Aparentemente, a amostra Zona Agrícola é a primeira a se estabilizar, formando um patamar próximo ao tempo de $3 \mathrm{~h}$. Em seguida, a curva volta a se inclinar indicando, possivelmente, a formação de outras camadas de adsorção. Já a amostra Estação Ecológica é a que possui menor constante de velocidade e, 
ao analisar seu gráfico, aparentemente a curva sequer alcança um equilíbrio (formação de patamares) dentro do tempo analisado (48 h).

Por ora, a discussão aqui se restringiu a comparar os valores e parâmetros cabíveis ao estudo da cinética de adsorção, no sentido de confrontar as amostras analisadas e seus respectivos resultados. Os fatores que influenciaram a dinâmica destes herbicidas, a priori, é a composição do adsorvente, uma vez que o adsorbato foi o mesmo em todas as análises. Neste sentido, é importante comparar, confrontando a composição de cada amostra de sedimento, suas características físicas e químicas, aos resultados acima discutidos.

Primeiramente são analisadas as isotermas de adsorção e, em seguida, discutidos todos os dados que tangem a dinâmica dos herbicidas sulfonilureia. Ao findar deste trabalho, será sugerido qual elemento, ou conjunto de elementos, contidos na composição destes sedimentos, influenciaram com maior intensidade o processo sortivo.

\subsubsection{Isoterma de Adsorção}

Os experimentos para construção das isotermas de adsorção foram realizados a fim de conhecer melhor o processo sortivo que envolve a dinâmica dos herbicidas etilclorimuron no ambiente. Inicialmente, a partir dos dados das concentrações obtidas via determinação cromatográfica, analisou-se a forma linearizada das isotermas de adsorção. Foram analisadas as isotermas de adsorção segundo o modelo de Freundlich e de Langmuir.

Nas figuras 26 e 27 são apresentas as isotermas linearizadas segundo o modelo de Freundlich e Langmuir, respectivamente. A partir das equações das retas obtidas, calcularam-se os parâmetros pertinentes a cada isoterma analisada. 

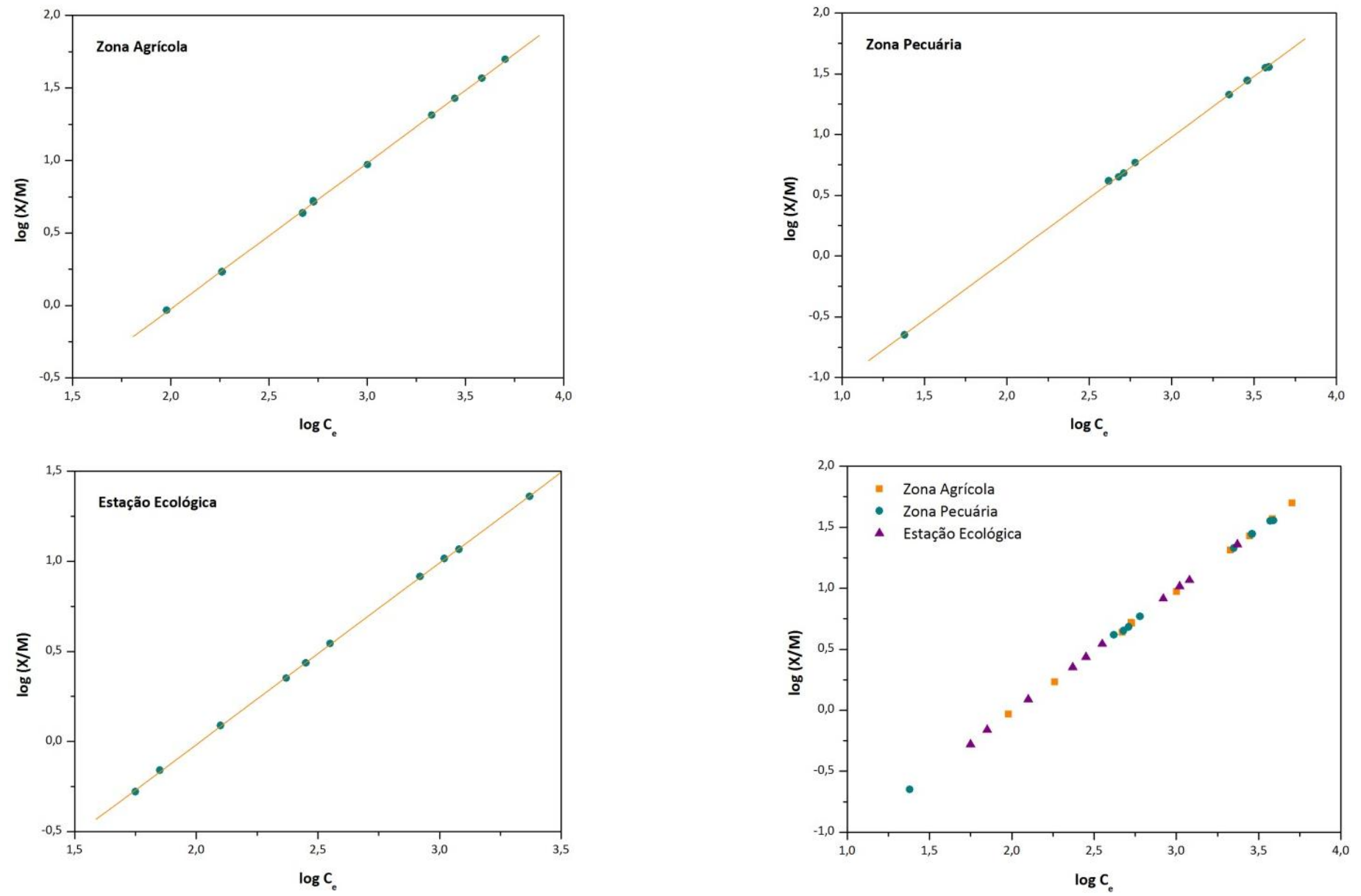

Figura 26 - Isotermas de adsorção linearizadas segundo modelo de Freundlich. 

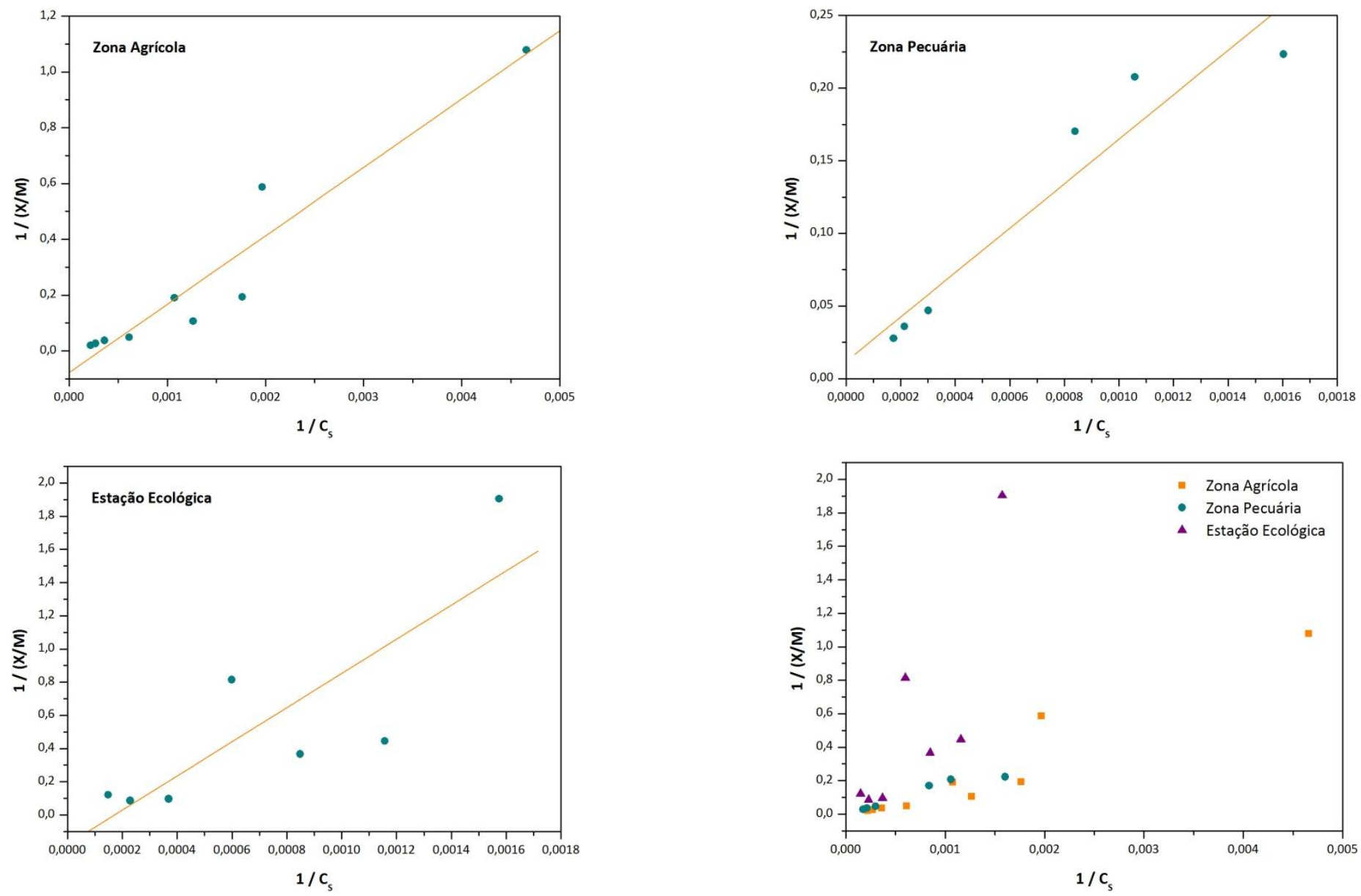

Figura 27 - Isotermas de adsorção linearizadas segundo modelo de Langmuir. 
Em uma simples análise visual é possível observar que em termos de ajuste linear as isotermas de Freundlich apresentaram uma linearidade bem maior que as isotermas de Langmuir. Mesmo assim, é importante analisar o coeficiente de correlação linear $\left(R^{2}\right)$. Para comparar os dados obtidos e calculados, foram analisadas as informações contidas na Tabela 20.

TABELA 20 - Modelos das isotermas de adsorção e seus parâmetros lineares

\begin{tabular}{|c|c|c|c|c|}
\hline & & $\begin{array}{c}\text { Zona } \\
\text { Agrícola }\end{array}$ & $\begin{array}{c}\text { Zona } \\
\text { Pecuária }\end{array}$ & $\begin{array}{l}\text { Estação } \\
\text { Ecológica }\end{array}$ \\
\hline \multirow{4}{*}{$\begin{array}{l}\text { Isoterma de } \\
\text { Freundlich }\end{array}$} & Eq. da Reta & $\begin{aligned} y & =(1,0044 \pm 0,0061) \cdot x \\
& +(-2,0315 \pm 0,0183)\end{aligned}$ & $\begin{aligned} y & =(1,0011 \pm 0,0054) \cdot x \\
& +(-2,0245 \pm 0,0163)\end{aligned}$ & $\begin{aligned} y & =(1,0078 \pm 0,0039) \cdot x \\
& +(-2,0324 \pm 0,0103)\end{aligned}$ \\
\hline & $\mathbf{R}^{2}$ & 0,9998 & 0,9999 & 0,9999 \\
\hline & $1 / n$ & 1,0044 & 1,0011 & 1,0078 \\
\hline & $K_{f} / L^{-1}$ & $9,2986.10^{-3}$ & $9,4511 \cdot 10^{-3}$ & $9,2803 \cdot 10^{-3}$ \\
\hline \multirow{4}{*}{$\begin{array}{l}\text { Isoterma de } \\
\text { Langmuir }\end{array}$} & Eq. da Reta & $\begin{aligned} y= & (245,2541 \pm 27,1504) \cdot x \\
& +(-0,0778 \pm 0,0512)\end{aligned}$ & $\begin{aligned} y= & (152,9957 \pm 23,1344) \cdot x \\
& +(0,0118 \pm 0,0201)\end{aligned}$ & $\begin{aligned} y= & (1028,7871 \pm 315,8788) \cdot x \\
& +(-0,1758 \pm 0,2697)\end{aligned}$ \\
\hline & $\mathbf{R}^{2}$ & 0,9597 & 0,9572 & 0,8244 \\
\hline & $\mathbf{Q} / \mathrm{mg} \mathrm{kg}^{-1}$ & $-12,8502$ & 84,7457 & $-5,6866$ \\
\hline & $\mathbf{K}_{\mathrm{L} /} \mathrm{L} \mathrm{kg}^{-1}$ & $-3,1730.10^{-4}$ & $7,7126.10^{-5}$ & $-1,7093.10^{-4}$ \\
\hline
\end{tabular}

Nas três amostras de sedimentos analisados, os valores de $\mathrm{R}^{2}$ indicaram melhor ajuste para as isotermas de Freundlich. Sendo assim, não faz sentido discutir os resultados obtidos para as isotermas de Langmuir.

A isoterma de Freundlich é o modelo mais utilizado nos estudos de adsorção de compostos orgânicos em amostras de interesse ambiental, tais como solo e sedimentos. A principal informação que esta isoterma nos dá é quanto à forma de recobrimento da superfície do adsorvente que, no caso do modelo de Freundlich, se dá pela formação de multicamadas. ${ }^{41,49,89}$

A formação de multicamadas é devida à heterogeneidade da superfície dos sedimentos. Em função de sua composição complexa e à grande variedade de constituintes orgânicos e minerais, não é possível estabelecer uma paridade entre os sítios de adsorção: 
sua natureza, origem, tipo de interação, entre outros. Neste sentido, espera-se que o herbicida adsorva em multicamada de forma bem mais intensa em comparação a monocamada, uma vez que a superfície do adsorvente não se satura. ${ }^{41}$ Contudo, a adsorção cessa no momento em que o equilíbrio entre a quantidade adsorvida e em solução for alcançada. $^{88}$

Nas isotermas de Freundlich, o parâmetro que indica se a isoterma é favorável ou não é a constante $1 / \mathrm{n}$ (intensidade da adsorção). O valor de $\mathrm{n}$ nos indicia o quão heterogênea é a superfície do adsorvente. Quanto maior o valor de $n$, maior será a heterogeneidade. Superfícies heterogêneas implicam em adsorções mais intensas, com maior energia de ligação. ${ }^{90-91}$ Geralmente, valores de $\mathrm{n}$ no intervalo de 1 a 10 representam condições de adsorção favorável. ${ }^{92-94}$ Analisando os valores de $\mathrm{n}$ obtidos, todos foram menores que 1 , porém são resultados bem próximos deste valor, com pequenas diferenças entre si. Espera-se que estes valores sejam independentes dos teores e quantidades envolvidos no processo sortivo, uma vez que, termodinamicamente, foram determinados em temperatura constante e em função de diferentes concentrações. Sendo assim, a priori, todos os sedimentos apresentam a mesma composição, mesmo que com teores e quantidades diferentes, justificando os valores semelhantes para as constantes de intensidade da adsorção calculados.

Analisando os valores de $\mathrm{K}_{\mathrm{f}}$, a amostra Zona Pecuária apresentou um valor superior em comparação às demais (resultado $1,80 \%$ maior), as quais não apresentam diferenças significativas entre si (apenas $0,20 \%$ de diferença). Vale ressaltar que mesmo que sejam pequenas as diferenças entre os $K_{f}$, estes valores são obtidos por meio da função inversa à logarítmica, fazendo com que pequenas variações possam resultar em grandes diferenças na comparação entre estes valores. A análise do coeficiente de adsorção $K_{f}$ permite identificar a capacidade do solo em reter determinado soluto, possibilitando a estimativa da extensão de seu movimento na fase líquida. Este coeficiente pode ser entendido como uma medida da distribuição de equilíbrio entre a fase sólida e líquida de um solo. Assim sendo, quanto maior a capacidade adsortiva, maior será o $\mathrm{K}_{\mathrm{f}}{ }^{95}$

Calculados os parâmetros matemáticos associados ao modelo de Freundlich, podem-se construir as respectivas isotermas e, a partir dos gráficos, obterem-se maiores informações sobre a dinâmica do herbicida em estudo. A Figura 28 apresenta as isotermas de Freundlich (não linearizadas) para adsorção do herbicida etilclorimuron em sedimentos. 


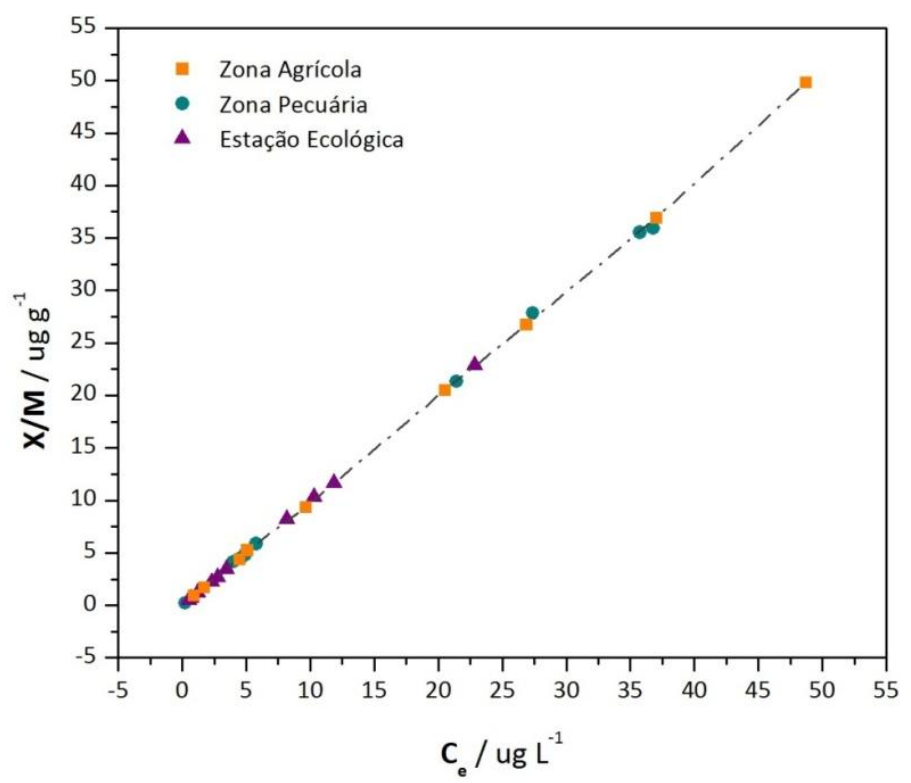

Figura 28 - Isotermas de adsorção segundo modelo de Freundlich

Analisando as isotermas obtidas é possível observar a semelhança entre as três amostras em estudo, todas seguindo uma mesma tendência, em curva linear. Ao comparar as isotermas obtidas com os esquemas representativos apresentados na Figura 9, é possível classificá-las como sendo do tipo $C^{50}$

As isotermas de tipo C são caracterizadas pela partição constante do adsorbato entre a superfície do sólido e a solução. Esta partição só ocorre em decorrência da energia de ligação que une as partes envolvidas nesta adsorção. ${ }^{50} \mathrm{~A}$ força da ligação é o que sugerirá qual tipo de interação está ocorrendo, quimiossorção ou fisiossorção. ${ }^{43}$

Em uma superfície tão heterogênica como é a dos sedimentos, não é possível afirmar que apenas um tipo de adsorção ocorra, seja química ou física. A partição constante indica que o herbicida adsorve e dessorve constantemente. Para que este fenômeno ocorra é necessário que as ligações que unem as moléculas do adsorbato aos sítios de adsorção não possuam uma energia de ligação muito forte, típica da adsorção química. ${ }^{41,43}$ Neste sentido, atribui-se fisiossorção à interação predominante entre o herbicida etilclorimuron e os sedimentos analisados, não excluindo a presença de quimiossorção, porém com menor intensidade. 


\subsubsection{RESUMO - Estudo da dinâmica dos herbicidas sulfonilureia em sedimentos}

A Tabela 21 apresenta um resumo dos resultados obtidos para a dinâmica dos herbicidas sulfonilureia (etilclorimuron) em sedimentos. Esta tabela tem por finalidade facilitar a visualização e compreensão geral dos dados acima apresentados.

TABELA 21 - Resumo dos resultados obtidos para a dinâmica do etilclorimuron

\begin{tabular}{ll} 
Modelo de Isoterma de Adsorção: & Freundlich \\
Classificação da Isoterma: & Tipo C (Constant Partition) \\
Tipo de Recobrimento: & Multicamada \\
\hline Tipo de Adsorção & Adsorção Física (Fisiossorção) \\
\hline Modelo Cinético de Adsorção: & Pseudo-Segunda-Ordem
\end{tabular}

\begin{tabular}{lccc}
\hline & $\begin{array}{c}\text { Zona } \\
\text { Agrícola }\end{array}$ & $\begin{array}{c}\text { Zona } \\
\text { Pecuária }\end{array}$ & $\begin{array}{c}\text { Estação } \\
\text { Ecológica }\end{array}$ \\
\hline $\mathbf{1} \mathbf{n}$ (intensidade da adsorção) & 1,0044 & 1,0011 & 1,0078 \\
$\mathbf{K}_{\mathbf{f}}$ (constante de Freundlich) / $\mathrm{Lg}^{-1}$ & $9,2986.10^{-3}$ & $9,4511.10^{-3}$ & $9,2803.10^{-3}$ \\
$\mathbf{k}_{\mathbf{2}}$ (constante de velocidade) / $\mathrm{mg}^{-1} \mathrm{~min}^{-1}$ & 0,003468 & 0,002222 & 0,001331 \\
$\mathbf{C}_{\mathbf{e}}$ (concentração de equilíbrio) $/ \mathrm{mg} \mathrm{L}^{-1}$ & 196,0784 & 390,6250 & 258,3979 \\
\hline
\end{tabular}

Uma vez que os principais fatores envolvidos na dinâmica do herbicida etilclorimuron estão discutidos (tipo de isoterma, sua classificação, o tipo de ligação, entre outros parâmetros), é necessário comparar os resultados acima discutidos com as características física e química dos sedimentos em estudo. 


\subsubsection{Efeito dos sedimentos na dinâmica dos herbicidas}

Neste item são discutidas as características físicas e químicas dos sedimentos e seus efeitos na dinâmica dos herbicidas sulfonilureia no ambiente. Serão estabelecidas relações entre estes resultados e aqueles encontrados nas análises da cinética e isoterma de adsorção.

A discussão foi divida em duas partes. A primeira parte analisou o efeito da composição mineral (classe textural, $\mathrm{CTC}$ e pH) na dinâmica do herbicida em sedimentos. A segunda parte analisou o efeito da composição orgânica (matéria orgânica, ácidos húmicos e TOC). Não é possível afirmar que um elemento, isoladamente, seja responsável pelos processos de retenção do herbicida em qualquer fração que seja. Porém, é possível determinar qual elemento, propriedade ou característica influenciou com maior intensidade a dinâmica do herbicida.

(i) Efeito da composição mineral: Os resultados obtidos no estudo da dinâmica do herbicida indicaram que os sedimentos da amostra Zona Pecuária apresentou maior retenção do herbicida etilclorimuron em relação às demais amostras. Nesta discussão, busca-se aproximar os resultados obtidos para a classe textural, CTC e pH a esta tendência, porém, todos os resultados obtidos nestas análises apresentaram diferenças significativas na comparação entre as três amostras de sedimentos analisadas. Neste sentido, estatisticamente não é possível analisar qual parâmetro de fato influenciou na adsorção do herbicida, porém, numericamente é possível observar que a quantidade de silte e argila presentes na amostra Zona Pecuária são maiores, aproximadamente o dobro da quantidade encontrada nas demais amostras em análise. A classe textural possui influência direta sobre a CTC, implicando em resultados de igual proporção. Estes resultados são condizentes, principalmente, com os resultados obtidos no estudo da cinética de adsorção. Neste sentido, considerase a classe textural como a característica dos sedimentos com efeito de maior significância sobre a dinâmica dos herbicidas sulfonilureia, 
ressaltando a influência da granulometria sobre a capacidade de troca catiônica.

(ii ) Efeito da composição orgânica: Seguindo a ideia acima apresentada, são correlacionados os componentes orgânicos que constituem os sedimentos na dinâmica dos herbicidas sulfonilureia. Analisando os teores de matéria orgânica, ácidos húmicos e carbono orgânico total, apenas os resultados obtidos para matéria orgânica apresentaram diferenças significativas entre as amostras analisadas. Estatisticamente, os teores de ácidos húcidos e TOC não se diferenciaram, não sendo possível atribuir seus efeitos no processo sortivo. Porém, os teores de matéria orgânica nos dão informações importantes, uma vez que o valor obtido para a amostra Zona Pecuária é o dobro na comparação com as amostras Zona Agrícola e Estação Ecológica, estas que não apresentaram diferenças entre seus resultados. Na comparação com os estudos da cinética de adsorção, estes valores acompanharam esta mesma tendência. Neste sentido, considera-se a matéria orgânica como o componente de maior influência na dinâmica dos herbicidas sulfonilureia em sedimentos.

Devido à complexidade do compartimento sólido que reveste a Terra, onde coexistem os solos e os sedimentos, não é possível garantir uma reprodutibilidade dos resultados aqui discutidos para qualquer outra matriz ambiental semelhante àquela analisada. Contudo, considera-se que o etilclorimuron apresenta uma boa retenção (58\%) em sedimentos com relativa quantidade de matéria orgânica e partículas de diâmetro menores (argila e silte), em conformidade com os resultados aqui reportados. 


\section{CONCLUSÕES}

O uso da terra para as atividades agrícola e pecuária afetaram significativamente as características e propriedades dos sedimentos analisados. As amostras coletadas na região utilizada para confinamento de gado de corte e leiteiro (Zona Pecuária) foram as mais afetadas, apresentando elevado teor de matéria orgânica recente (pouco humificada) e classe textural com predominância de argila e silte.

O uso de padrões de referência certificados aliados ao uso de vidrarias e instrumentos devidamente calibrados propiciaram os meios para a validação do método analítico. A metodologia proposta para determinação do herbicida etilclorimuron em sedimentos apresentou boa seletividade, linearidade, sensibilidade, limites de detecção e quantificação, recuperação, exatidão, precisão e robustez. Os resultados obtidos se encontraram de acordo, quando cabível de valores orientativos, com os critérios de validação da ANVISA e do INMETRO.

Foi constatada uma deficiência nas definições, linguagem, organização e disposição dos itens da Resolução RE no 899 da ANVISA, que dispõe dos critérios e procedimentos para validação de métodos analíticos e bioanalíticos. As limitações do documento INMETRO (DOQ-CGCRE-008) podem ser supridas com uma complementação a partir das edições passadas já publicadas.

Validado o método cromatográfico, foi possível estudar a dinâmica do herbicida etilclorimuron no ambiente por meio de um estudo cinético e das isotermas de adsorção. Em resumo, todas as amostras de sedimento adsorveram de acordo com o modelo de Freundlich e suas isotermas foram classificadas, segundo o sistema proposto por Giles, como sendo do tipo C (Constant Partition). A adsorção ocorreu com a formação de multicamadas e a interação entre o adsorvente e o adsorbato foi classificada como sendo de natureza física (fisiossorção), sem desconsiderar a presença de interações químicas, porém com menor influência. O modelo cinético de adsorção obtido foi de pseudo-segunda-ordem. 
O herbicida etilclorimuron, exemplar da família das sulfonilureias, apresentou relativa mobilidade. Os resultados das análises de caracterização dos sedimentos mostraram que o teor de matéria orgânica foi o fator que implicou em maior retenção no ambiente. $A$ classe textural foi outro fator que apresentou significante efeito na mobilidade do herbicida. Amostras com partícula com menor granulometria apresentaram maior retenção. Dentre as amostras analisadas, os sedimentos da Zona Pecuária apresentaram maior quantidade de herbicida adsorvida em um menor intervalo de tempo (via estudo sortivo por isotermas e cinética de adsorção), enquanto que as amostras Zona Agrícola e Estação Ecológica não apresentaram diferenças significativas.

Finalizadas as atividades propostas neste trabalho, considera-se concluído o que aqui se objetivou. Feito isso, refere-se a esta produção como um fruto do esforço e dedicação às atividades científicas e acadêmicas daqueles envolvidos no desenvolvimento deste mestrado. Todos os resultados aqui reportados serão de grande valia para projetos futuros na área de química analítica ambiental, contribuindo para novas pesquisas relacionadas ao estudo da dinâmica dos hebicidas sulfonilureia no ambiente. 


\section{REFERENCIAS BIBLIOGRÁFICAS}

1. LANDGRAF, M. D.; MESSIAS, R. A.; REZENDE, M. O. O. A importância ambiental da vermicompostagem: vantagens e aplicações. São Carlos: RiMa, 2005. 106 p.

2. TAN, K. H. Principles of soil chemistry. New York: Marcel Dekker, 1998. 521 p.

3. CARVALHO, N. O. Hidrossedimentologia prática. Rio de Janeiro: CPRM, 1994. 372 p.

4. SPOSITO, G. The chemistry of soils. New York: Oxford University Press, 1989. 329 p.

5. RESENDE, M.; CURI, N.; REZENDE, S. B.; CORRÊA, G. F. Pedologia: base para distinção de ambientes. Viçosa: NEPUT, 1995. 304 p.

6. ESSINGTON, M. E. Soil and water chemistry: an integrative approach. Boca Raton: CRC Press, 2004. $534 \mathrm{p}$.

7. PÉREZ, D. V.; CAMPOS, R. C. Solução do solo: importância e extração por centrifugação. Rio de Janeiro: Embrapa Solos, 2003. 36 p.

8. TAN, K. H. Environmental soil science. New York: Marcel-Dekker, 1994. 304 p.

9. STEVENSON, F. J.; FITCH, A. Chemistry of complexation of metal ions with soil solution organics. In: HUANG, P. M.; SCHNITZER, M. Interactions of soil minerals with natural organics and microbes. Madison: SSSA, 1986. p. 29-58.

10. PRATA, F.; LAVORENTI, A. comportamento de herbicidas no solo: influência da matéria orgânica. Revista Biociências, v. 6, n. 2, p. 17-22, 2000.

11. ZBYTNIEWSKI, R.; BUSZEWSKI, B. Characterization of natural organic matter (NOM) derived from sew age sludge compost. Part 1: chemical and spectroscopic properties. Bioresource Technology, v. 96, n. 4, p. 479-484, 2005.

12. SÁNCHEZ-MONEDERO, M. A.; CEGARRA, J.; GARCÍA, D.; ROIG, A. Chemical and structural evolution of humic acids during organic waste composting. Biodegradation, v. 13, n. 6, p. 361371, 2002.

13. ROCHA, J. C.; ROSA, A. H. Substâncias húmicas aquáticas: interação com espécies metálicas. São Paulo: Editora UNESP, 2003. 120 p. 
14. STEVENSON, J. F. Humus chemistry: genesis, composition, reactions. New York: John Wiley, 1994. 512 p.

15. SCHNITZER, M.; KHAN, S. U. Humic substances chemistry and reactions: soil organic matter. New York: Elsevier, 1978. 319 p.

16. SCHULTEN, H. R.; SCHNITZER, M. A state of the art structural concept for humic substances. Naturwissenschaften, v. 80, n. 1, p. 29-30, 1993.

17. BURDON, J. Are the traditional concepts of the structures of humic substances realistic? Soil Science, v. 166, n. 11, p. 752-769, 2001.

18. MACCARTHY, P. The principles of humic substances. Soil Science, v. 166, n. 11, p. 738-751, 2001.

19. PICCOLO, A. The supramolecular structure of humic substances. Soil Science, v. 166, n. 11, p. 810-832, 2001.

20. SEIN JR., L. T.; VARNUM, J. M.; JARSEN, S. A. Conformational modeling of a new building block of humic acid: approaches to the lowest energy conformer. Environmental Science $\&$ Technology, v. 33, n. 4, p. 546-552, 1999.

21. BAIRD, C. Química ambiental. Porto Alegre: Bookman, 2008. 622 p.

22. PRESS, F.; SIEVER, R.; GROTZINGER, J.; JORDAN, T. H. Para entender a Terra. Porto Alegre: Bookman, 2006. 656 p.

23. DROPPO, I. G.; JASKOT, C. Impact of river transport characteristics on contaminant sampling error and design. Environmental Science \& Technology, v. 29, n. 1, p. 161-170, 1995.

24. SOARES, H. M. V. M.; BOAVENTURA, R. A. R.; MACHADO, A. A. S. C.; SILVA, J. C. G. E. Sediments as monitors of heavy metal contamination in the Ave River Basin (Portugal): multivariate analysis of data. Experimental Pollution, v. 105, n. 3, p. 311-323, 1999.

25. FÖRSTNER, U.; WITTMANN, G. T. W. Metal pollution in the aquatic environment. Berlim: Springer-Verlag, 1981. $486 \mathrm{p}$.

26. ENVIRONMENTAL PROTECTION AGENCY (EPA). What is a pesticide?. Washington, 2012. Disponivel em: <http://www.epa.gov/pesticides/about/index.htm>. Acesso em: 25 jan. 2012.

27. CARRIER, M.; GUILLARD, C.; BESSON, M.; BORDES, C.; CHERMETTE, H. Photocatalytic degradation of diuron: experimental analyses and simulation of $\mathrm{HO}^{\circ}$ radical attacks by density functional theory calculations. Journal Physical Chemistry, v. 113, p. 6365-6374, 2009.

28. LUCENA, M. Entenda por que o Brasil é o maior consumidor de agrotóxico do mundo. Revista Galileu. Rio de Janeiro, 2011. Disponivel em: <http://revistagalileu.globo.com/Revista/Common/0,EMI150920-17770,00ENTENDA+POR+QUE+O+BRASIL+E+O+MAIOR+CONSUMIDOR+DE+AGROTOXICOS+DO+MUNDO.ht ml>. Acesso em: 09 dez. 2011. 
29. OLIVEIRA JUNIOR, R. S. Mecanismos de ação de herbicidas. In: OLIVEIRA JUNIOR, R. S.; CONSTANTIN, J.; INOUE, M. H. Biologia e manejo de plantas daninhas. Curitiba: Omnipax, 2011. p. 141-192.

30. GREEN, R. E.; KARICKHOFF, S. W. Sorption estimates for modeling. In: CHENG, H. H. Pesticides in the soil environment: processes, impacts, and modeling. Madison: Soil Science Society of America, 1990. p. 79-101.

31. SARMAH, A. K.; MULLER, K.; AHMAD, R. Fate and behaviour of pesticides in the agroecosystem: a review with a New Zealand perspective. Australian Journal of Soil Research, v. 42, p. 125-154, 2004.

32. BERTRAND, C.; WITCZAK-LEGRAND, A.; ABADIE, J.; COOPER, J. F. Flazasulfuron alcoholysis, chemical hydrolysis, and degradation on various minerals. Journal of Agricultural and Food Chemistry, v. 51, n. 26, p. 7717-7721, 2003.

33. HARTWING, I.; BERTAN, I.; GALON, L.; NOLDIN, J. A.; CONCENÇO, G.; SILVA, A. F.; ASPIAZÚ, I.; FERREIRA, E. A. Tolerância de trigo (Triticum aestivum) e aveia (Avena sp.) a herbicidas inibidores da enzima acetolactato sintase (ALS). Planta Daninha, v. 26, n. 2, p. 361-368, 2008.

34. BRASIL. Ministério da Saúde. ANVISA. Monografias técnicas do ministério da saúde sobre substâncias com ação tóxica sobre animais ou plantas, Portaria 9 10/85 - SNVS Anexo I. Diário Oficial da União, Brasília, 22 de julho de 1987. Seção 1, p. 28.

35. CORNELL UNIVERSITY. Chlorimuron ethyl (DPX F6025) Herbicide Profile 4/86. Ithaca, 1986. Disponivel em: <http://pmep.cce.cornell.edu/profiles/herb-growthreg/cacodyliccymoxanil/chlorimuron-ethyl/herb-prof-chlorim-ethyl.html>. Acesso em: 27 mar. 2012.

36. ENVIRONMENTAL PROTECTION AGENCY (EPA). Chlorimuron-ethyl Quickview. Washington, 2011. Disponivel em:

<http://cfpub.epa.gov/ncea/iris/index.cfm?fuseaction=iris.showQuickView\&substance_nmbr=04 06>. Acesso em: 27 mar. 2012.

37. CLORIMURON MASTER NORTOX. Rondonópolis: Nortox, 1997. Bula de herbicida.

38. SPADOTTO, C. A. Comportamento e destino ambiental de herbicidas. Londrina: SBCPD, 2002. 4 p. Disponivel em: <www.cnpma.embrapa.br/herbicidas/download/comport.pdf $>$. Acesso em: 14 mar. 2012.

39. MANCUSO, M. A. C.; NEGRISOLI, E.; PERIM, L. Residual effect of herbicides in soil (carryover). Revista Brasileira de Herbicidas, v. 10, n. 2, p. 151-164, 2011.

40. VIEIRA, E. M.; PRADO, A. G. S.; LANDGRAF, M. D.; REZENDE, M. O. O. Estudo da adsorção/dessorção do ácido 2,4 diclorofenoxiacético $(2,4 \mathrm{~d})$ em solo na ausência e presença de matéria orgânica. Química Nova, v. 22, n. 3, p. 305-308, 1999.

41. RUTHVEN, D. M. Principles of adsorption and adsorption processes. New York: John Wiley, 1984. $464 \mathrm{p}$. 
42. CHEREMISINOFF, P. N.; ELLERBUSCH, F. Carbon adsorption handbook. Collingwood: Ann Arbor Science, 1978. $1054 \mathrm{p}$.

43. ATKINS, P. W.; PAULA, J. Físico-química. Rio de Janeiro: Livros Técnicos e Científicos, 2004. 620 p.

44. MARUNGREUNG, K. Removal of basic dye (Astrazon Blue FGRL) using macroalga Caulerpa lentillifera. Journal of Environmental Management, v. 78, n. 3, p. 268-274, 2006.

45. DABROWSKI, A. Adsorption: from theory to practice. Advances in Colloid and Interface Science, v. 93, n. 1, p. 135-224, 2001.

46. LANGMUIR, I. The constitution and fundamental properties of solids and liquids. Jounal of the American Chemical Society - Part I, v. 38, n. 11, p. 2221-2295, 1916.

47. CASTELLAN, G. W. Fundamentos de físico-química. Rio de Janeiro: Livros Técnicos e Científicos, 1986. 552 p.

48. BARROS, M. A. S. D.; ARROYO, P. A. Métodos de remoção de cromo de águas residuais: métodos de adsorção. In: BARROS, M. A. S. D.; ARROYO, P. A.; SOUSA-AGUIAR, E. F.; GARCÍA, P. A. Problemas ambientais com soluções catalíticas. Madri: CYTED, 2001. p. 76-84.

49. FREUNDLICH, H. M. F. Über die adsorption in lösungen. Zeitschrift für Physikalische Chemie, v. 57 , n. 1, p. 385-470, 1906.

50. GILES, C. H.; MACEWAN, T. H.; NAKHWA, S. N.; SMITH, D. Studies in adsorption - Part XI: a system of classification of solution adsorption isotherms, and its use in diagnosis of adsorption mechanisms and in measurement of specific surface areas of solids. Journal of the Chemical Society, v. 1, n. 1, p. 3973-3993, 1960.

51. FALONE, S. Z.; VIEIRA, E. M. Adsorção/dessorção do explosivo tetril em turfa e em argissolo vermelho amarelo. Química Nova, v. 27, n. 6, p. 849-854, 2004.

52. LAGERGREN, S. Zur theorie der sogenannten adsorption geloster. Kungliga Svenska Vetenskapsakademiens, v. 24, n. 4, p. 1-39, 1898.

53. HO, Y. S. Citation review of Lagergren kinetic rate equation on adsorption reactions. Sientometrics, v. 59, n. 1, p. 171-177, 2004.

54. ZANELLA, R.; PRIMEL, E. G.; GONÇALVES, F. F.; KURZ, M. H. S.; MISTURA, C. M. Development and validation of a high-performance liquid chromatographic procedure for the determination of herbicide residues in surface and agriculture waters. Journal of Separation Science, v. 26, n. 9, p. 935-938, 2003.

55. PENA, M.; AMARAL, E.; VON SPERLING, E.; CRUZ, I. Método para determinação de resíduos de clorpirifós em alface por cromatografia a líquido de alta eficiência. Pesticidas: Revista de Ecotoxicologia e Meio Ambiente, v. 13, n. 1, p. 33-74, 2003.

56. LEITE, F. Validação em análise química. Campinas: Átomo, 2008. 357 p. 
57. LANÇAS, F. M. Validação de métodos cromatográficos de análise. São Carlos: RiMa, 2004. $46 \mathrm{p}$.

58. INSTITUTO BRASILEIRO DE METROLOGIA, NORMATIZAÇÃO E QUALIDADE INSDUSTRIAL (INMETRO). Orientação sobre validação de métodos analíticos: DOC CGCRE-008 (Revisão 4). Brasília, 2011. 19 p.

59. RIBANI, M.; BOTTOLI, C. B. G.; COLLINS, C. H.; JARDIM, I. C. S. F.; MELO, L. F. C. Validation for chromatographic and electrophoretic methods. Química Nova, v. 27, n. 5, p. 771-780, 2004.

60. BRASIL. Ministério da Saúde. ANVISA. Guia para validação de métodos analíticos e bioanalíticos, Resolução RE no 899. Diário Oficial da União, Brasília, 02 de junho de 2003. Seção 1, p. 56.

61. INSTITUTO BRASILEIRO DE METROLOGIA, NORMATIZAÇÃO E QUALIDADE INSDUSTRIAL (INMETRO). Orientação sobre validação de métodos analíticos: DOC CGCRE-008 (Revisão 1). Brasília, 2003. 36 p.

62. INTERNATIONAL ORGANIZATION FOR STANDARDIZATION (ISO). ISO 17025: General requirements for the competence of testing and calibration laboratories. Genebra, 1999. $21 \mathrm{p}$.

63. JOHNSON, R. A.; BHATTACHARYYA, G. K. Statistics principle and methods. New York: John Wiley and Sons, 2001. 723 p.

64. CAMARGO, O. A.; MONIZ, A. C.; JORGE, J. A.; VALADARES, J. M. A. S. Métodos de analise química, mineralógica e física de solos do Instituto Agronômico de Campinas. Campinas: IAC, 2009. $77 \mathrm{p}$.

65. NOGUEIRA, A. R. A.; SOUZA, G. B. Manual de laboratórios: solo, água, nutrição vegetal, nutrição animal e alimentos. São Carlos: EMBRAPA Pecuária Sudeste, 2005. 334 p.

66. ASSOCIAÇÃO BRASILEIRA DE NORMAS TÉCNICAS. NBR 7181: solo - análise granulométrica. Rio de Janeiro, 1984. $13 \mathrm{p}$.

67. SWIFT, R. S. Molecular weight, size, shape, and charge characteristics of humic substances: some basic considerations. In: HAYES, M. H. B.; MACCARTHY, P.; MALCOLM, R. L.; SWIFT, R. S. Humic substances II: in search of structure. New York: John Wiley, 1989. p. 449-466.

68. MC PHIE, P. Enzime purification and related techniques: dialysis. In: JACOBY, W. B. Methods in enzymology. New York: Academic Press, 1971. p. 25-175.

69. MILORI, D. M. B. P.; MARTIN-NETO, L.; BAYER, C.; MILNICZUK, J.; BAGNATO, V. S. Humification degree of soil humic acid determination by fluorescence spectroscopy. Soil Science, v. 167, n. 11, p. 739-749, 2002.

70. KALBITZ, K.; GEYER, W.; GEYER, S. Spectroscopic properties of dissolved humic substances: a reflection of land use history in a fen area. Biogeochemistry, v. 47, n. 2, p. 219-238, 1999. 
71. ALCARDE, J. C.; GUIDOLIN, J. A.; LOPES, A. S. Os adubos e a eficiência das adubações. São Paulo: ANDA, 1991. 35 p.

72. REZENDE, E. I. P.; PERALTA-ZAMORA, P. G.; ABATE, G. Estudo de sorção de herbicidas pelos argilominerais vermiculita e montmorilonita. Química Nova, v. 34, n. 1, p. 21-27, 2011.

73. CARROLL, D. Ion exchange in clays and other minerals. Geological Society of America Bulletin, v. 70, n. 6, p. 749-780, 1959.

74. TOGNON, A. A.; DEMATTÊ, J. L. I.; DEMATTÊ, J. A. M. Teor e distribuição da matéria orgânica em latossolos das regiões da floresta amazônica e dos cerrados do brasil central. Scientia Agricola, v. 55, n. 3, p. 343-354, 1998.

75. BLOOM, P. R.; LEENHEER, J. A. Vibrational, eletronic, and high-energy spectroscopic methods for characterizing humic substances. In: HAYES, M. H. B.; MACCARTHY, P.; MALCOLM, R. L.; SWIFT, R. S. Humic substances II: in search of structure. New York: John Wiley, 1989. p. 410-446.

76. NAKANISHI, K. Infrared absorption spectroscopy. Tokyo: Nankondo, 1962. 233 p.

77. POLAK, J.; SULKOWSKI, W. W.; BARTOSZEK, M.; PAPIEZ, W. Spectroscopic studies of the progress of humification process in humic acid extracted from sewage sludge. Journal of Molecular Structures, v. 744-747, n. 3, p. 983-989, 2005.

78. CANELLAS, L. P.; SANTOS, G. A.; RUMJANEK, V. M.; MORAES, A. A.; GURIDI, F. Distribuição da matéria orgânica e caracterização de ácidos húmicos em solos com adição de resíduos de origem urbana. Pesquisa Agropecuária Brasileira, v. 36, n. 12, p. 1529-1538, 2001.

79. SILVERSTEIN, R. M.; BASSLER, G.; MORRIL, T. C. Identificação espectroscópica de compostos orgânicos. Rio de Janeiro: Guanabara-Koogan, 1994. 387 p.

80. STEVENSON, J. F. Humus chemistry: genesis, composition, reactions. New York: John Wiley, 1994. $512 \mathrm{p}$.

81. CANELLAS, L. P. Humosfera: tratado preliminar sobre a química das substâncias húmicas. Seropédica: CCTA - UENF, 2005. 309 p.

82. LAKOWICZ, J. R. Principles of fluorescence spectroscopy. New York: Springer, 2004. 954 p.

83. UNIÃO EUROPÉIA. Quality of water intend for human consumption. Bruxelas, 1998. Disponivel em: <http://eurlex.europa.eu/LexUriServ/LexUriServ.do?uri=OJ:L:1998:330:0032:0054:EN:PDF>. Acesso em: 17 fev. 2012.

84. BRASIL. Ministério da Saúde. Portaria no 2914 de 12 de dezembro e 2011. Diário Oficial da União. Brasília, 04 de janeiro de 2012. Seção 1, p. 43.

85. NETO, M. L. F.; SARCINELLI, P. N. Pesticides in drinking water: a risk assessment approach and contribution to the Brazilian legislation updating process. Engenharia Sanitária Ambiental, v. 14 , n. 1, p. 69-78, 2009. 
86. ENVIRONMENTAL PROTECTION AGENCY (EPA). Report of the Food Quality Protection Act (FQPA) Tolerance Reassessment Progress and Risk Management Decision (TRED) for

Chlorimuron Ethyl. Washington: Office of Prevention, Pesticides and Toxic Substances, 2004. 5 p. Disponivel em: <http://www.epa.gov/oppsrrd1/REDs/chlorimuronethyl_tred.pdf>. Acesso em: 13 maio 2012.

87. ALLEN, S. J.; GAN, Q.; MATTHEWS, R.; JOHNSON, P. A. Comparison of optimised isotherm models for basic dye adsorption by Kudzu. Bioresource Technology, v. 88, n. 2, p. 143-152, 2003.

88. PIERANGELI, M. A. P.; GUILHERME, L. R. G.; OLIVEIRA, L. R.; CURI, N.; SILVA, M. L. N. Efeito da força iônica da solução de equilíbrio na adsorção de cádmio em Latossolos brasileiros. Pesquisa Agropecuária Brasileira, v. 38, n. 6, p. 737-745, 2003.

89. LI, Y.; DI, Z.; DING, J.; WU, D.; LUAN, Z.; Y., Z. Adsorption thermodymanic, kinetic and desorptiom studies of Pb2+ on carbon nanotubes. Water Research, v. 39, n. 4, p. 605-609, 2005.

90. ÖZCAN, A. S.; ÖZCAN, A. Adsorption of acid dyes from aqueous solutions onto acid-activated bentonite. Journal of Colloid and Interface Science, v. 276, n. 1, p. 39-46, 2004.

91. WALKER, G. M.; WEATHERLEY, L. R. Adsorption of dyes from aqueous solution: the effect of adsorbent pore size distribuition and dye aggregation. Chemical Engineering Journal, v. 83, n. 3, p. 201-206, 2001.

92. ORTIZ, N.; SUSCA, C.; R., O. K. M.; BRESSIANI, J. C. Estudo da estabilidade química da magnetita utilizada como adsorvedor naremoção de compostos orgânicos de soluções. Cerâmica, v. 49 , n. 1, p. 216-222, 2003.

93. CHAVES, T. F.; QUEIROZ, Z. F.; SOUSA, D. N. R.; GIRÃO, J. H.; RODRIGUES, E. A. Uso da cinza da casca do arroz (cca) obtida da geração de energia térmica como adsorvente de Zn(II) em soluções aquosas. Química Nova, v. 32, n. 6, p. 1378-1383, 2009.

94. TAGLIAfERRO, G. V.; PEREIRA, P. H. F.; RODRIGUES, L. A.; SILVA, M. L. C. P. Adsorção de chumbo, cádmio e prata em óxido de Nióbio (V) hidratado preparado pelo método da precipitação em solução homogênea. Química Nova, v. 34, n. 1, p. 101-105, 2011.

95. ALCÂNTARA, M. A. K.; CAMARGO, O. A. Isoterma de adsorção de Freundlich para o cromo (III) em latossolos. Scientia Agricola, v. 58, n. 3, p. 567-572, 2001. 


\section{ANEXOS}

Coordenadas geográficas dos pontos de coleta dos sedimentos (graus decimais)

\begin{tabular}{|c|c|c|c|c|c|c|c|c|}
\hline \multicolumn{3}{|c|}{ Zona Agrícola } & \multicolumn{3}{|c|}{ Zona Pecuária } & \multicolumn{3}{|c|}{ Estação Ecológica } \\
\hline $\begin{array}{c}\text { Código } \\
\text { (ZA) }\end{array}$ & $\begin{array}{l}\text { Longitude } \\
\text { (W) }\end{array}$ & $\begin{array}{l}\text { Latitude } \\
\text { (S) }\end{array}$ & $\begin{array}{c}\text { Código } \\
\text { (ZP) }\end{array}$ & $\begin{array}{l}\text { Longitude } \\
\text { (W) }\end{array}$ & $\begin{array}{l}\text { Latitude } \\
\text { (S) }\end{array}$ & $\begin{array}{c}\text { Código } \\
\text { (EE) }\end{array}$ & $\begin{array}{l}\text { Longitude } \\
\text { (W) }\end{array}$ & $\begin{array}{l}\text { Latitude } \\
\text { (S) }\end{array}$ \\
\hline ZA 01 & $47.884270^{\circ}$ & $21.430345^{\circ}$ & ZP 01 & $47.704635^{\circ}$ & $21.580573^{\circ}$ & EE 01 & $47.725872^{\circ}$ & $21.566445^{\circ}$ \\
\hline ZA 02 & $47.872611^{\circ}$ & $21.423846^{\circ}$ & ZP 02 & $47.708856^{\circ}$ & $21.557893^{\circ}$ & EE 02 & $47.798976^{\circ}$ & $21.606046^{\circ}$ \\
\hline ZA 03 & $47.886733^{\circ}$ & $21.481525^{\circ}$ & ZP 03 & $47.709501^{\circ}$ & $21.557600^{\circ}$ & EE 03 & $47.837420^{\circ}$ & $21.590820^{\circ}$ \\
\hline ZA 04 & $47.895754^{\circ}$ & $21.531594^{\circ}$ & ZP 04 & $47.708574^{\circ}$ & $21.556650^{\circ}$ & EE 04 & $47.797385^{\circ}$ & $21.588410^{\circ}$ \\
\hline ZA 05 & $47.890052^{\circ}$ & $21.530588^{\circ}$ & ZP 05 & $47.708121^{\circ}$ & $21.556178^{\circ}$ & EE 05 & $47.812046^{\circ}$ & $21.613003^{\circ}$ \\
\hline ZA 06 & $47.883704^{\circ}$ & $21.526952^{\circ}$ & ZP 06 & $47.709681^{\circ}$ & $21.558486^{\circ}$ & EE 06 & $47.813500^{\circ}$ & $21.614635^{\circ}$ \\
\hline ZA 07 & $47.882448^{\circ}$ & $21.525077^{\circ}$ & ZP 07 & $47.709037^{\circ}$ & $21.557163^{\circ}$ & EE 07 & $47.821635^{\circ}$ & $21.607467^{\circ}$ \\
\hline ZA 08 & $47.867896^{\circ}$ & $21.503064^{\circ}$ & ZP 08 & $47.707950^{\circ}$ & $21.556828^{\circ}$ & EE 08 & $47.786504^{\circ}$ & $21.579206^{\circ}$ \\
\hline ZA 09 & $47.868524^{\circ}$ & $21.533229^{\circ}$ & ZP 09 & $47.707903^{\circ}$ & $21.561867^{\circ}$ & EE 09 & $47.776636^{\circ}$ & $21.566589^{\circ}$ \\
\hline ZA 10 & $47.827475^{\circ}$ & $21.514455^{\circ}$ & ZP 10 & $47.713356^{\circ}$ & $21.560443^{\circ}$ & EE 10 & $47.788938^{\circ}$ & $21.570111^{\circ}$ \\
\hline ZA 11 & $47.836825^{\circ}$ & $21.550952^{\circ}$ & ZP 11 & $47.707705^{\circ}$ & $21.556519^{\circ}$ & EE 11 & $47.808549^{\circ}$ & $21.623290^{\circ}$ \\
\hline ZA 12 & $47.872804^{\circ}$ & $21.563584^{\circ}$ & ZP 12 & $47.707611^{\circ}$ & $21.556110^{\circ}$ & EE 12 & $47.822203^{\circ}$ & $21.609149^{\circ}$ \\
\hline ZA 13 & $47.880148^{\circ}$ & $21.582218^{\circ}$ & ZP 13 & $47.711745^{\circ}$ & $21.559070^{\circ}$ & EE 13 & $47.835708^{\circ}$ & $21.564686^{\circ}$ \\
\hline ZA 14 & $47.763464^{\circ}$ & $21.524422^{\circ}$ & ZP 14 & $47.711961^{\circ}$ & $21.559353^{\circ}$ & EE 14 & $47.835281^{\circ}$ & $21.561157^{\circ}$ \\
\hline ZA 15 & $47.832797^{\circ}$ & $21.514348^{\circ}$ & ZP 15 & $47.712209^{\circ}$ & $21.559927^{\circ}$ & EE 15 & $47.828191^{\circ}$ & $21.596787^{\circ}$ \\
\hline ZA 16 & $47.867322^{\circ}$ & $21.533817^{\circ}$ & ZP 16 & $47.709274^{\circ}$ & $21.558389^{\circ}$ & EE 16 & $47.831071^{\circ}$ & $21.594304^{\circ}$ \\
\hline ZA 17 & $47.898499^{\circ}$ & $21.568730^{\circ}$ & ZP 17 & $47.708541^{\circ}$ & $21.558125^{\circ}$ & EE 17 & $47.837045^{\circ}$ & $21.570111^{\circ}$ \\
\hline ZA 18 & $47.896456^{\circ}$ & $21.568362^{\circ}$ & ZP 18 & $47.710599^{\circ}$ & $21.559482^{\circ}$ & & & \\
\hline ZA 19 & $47.884198^{\circ}$ & $21.565608^{\circ}$ & ZP 19 & $47.710098^{\circ}$ & $21.559118^{\circ}$ & & & \\
\hline ZA 20 & $47.857193^{\circ}$ & $21.559498^{\circ}$ & ZP 20 & $47.703285^{\circ}$ & $21.559604^{\circ}$ & & & \\
\hline ZA 21 & $47.854156^{\circ}$ & $21.558188^{\circ}$ & & & & & & \\
\hline ZA 22 & $47.850773^{\circ}$ & $21.556930^{\circ}$ & & & & & & \\
\hline ZA 23 & $47.849819^{\circ}$ & $21.556531^{\circ}$ & & & & & & \\
\hline
\end{tabular}




\begin{tabular}{|c|c|c|}
\hline ZA 24 & $47.848476^{\circ}$ & $21.555856^{\circ}$ \\
\hline ZA 25 & $47.846951^{\circ}$ & $21.555396^{\circ}$ \\
\hline A 26 & $47.845558^{\circ}$ & $21.554855^{\circ}$ \\
\hline A 27 & $47.828179^{\circ}$ & $21.547820^{\circ}$ \\
\hline A 28 & $47.830152^{\circ}$ & $21.548762^{\circ}$ \\
\hline A 29 & $47.844055^{\circ}$ & $21.554842^{\circ}$ \\
\hline ZA 30 & $47.841746^{\circ}$ & $21.554223^{\circ}$ \\
\hline A 31 & $47.841335^{\circ}$ & $21.552460^{\circ}$ \\
\hline A 32 & $47.842591^{\circ}$ & $21.552919^{\circ}$ \\
\hline A 33 & $47.857500^{\circ}$ & $21.559180^{\circ}$ \\
\hline A 34 & $47.856654^{\circ}$ & $21.550700^{\circ}$ \\
\hline A 35 & $47.856708^{\circ}$ & $21.549658^{\circ}$ \\
\hline ZA 36 & $47.856451^{\circ}$ & $21.548518^{\circ}$ \\
\hline ZA 37 & $47.843843^{\circ}$ & $21.537750^{\circ}$ \\
\hline ZA 38 & $47.843033^{\circ}$ & $21.537903^{\circ}$ \\
\hline ZA 39 & $47.844813^{\circ}$ & $21.513544^{\circ}$ \\
\hline ZA 40 & $47.839296^{\circ}$ & $21.524136^{\circ}$ \\
\hline ZA 41 & $47.850773^{\circ}$ & $21.556930^{\circ}$ \\
\hline ZA 42 & $47.839790^{\circ}$ & $21.523793^{\circ}$ \\
\hline ZA 43 & $47.846385^{\circ}$ & $21.541244^{\circ}$ \\
\hline ZA 44 & $47.867178^{\circ}$ & $21.505431^{\circ}$ \\
\hline ZA 45 & $47.848359^{\circ}$ & $21.533459^{\circ}$ \\
\hline A 40 & $47.877835^{\circ}$ & $21.521017^{\circ}$ \\
\hline A 47 & $47.858611^{\circ}$ & $21.537866^{\circ}$ \\
\hline
\end{tabular}


Imagens de satélite dos pontos de coleta (As imagens não representam o momento exato da amostragem)

Fonte: Google Earth Image @ 2012 GeoEye
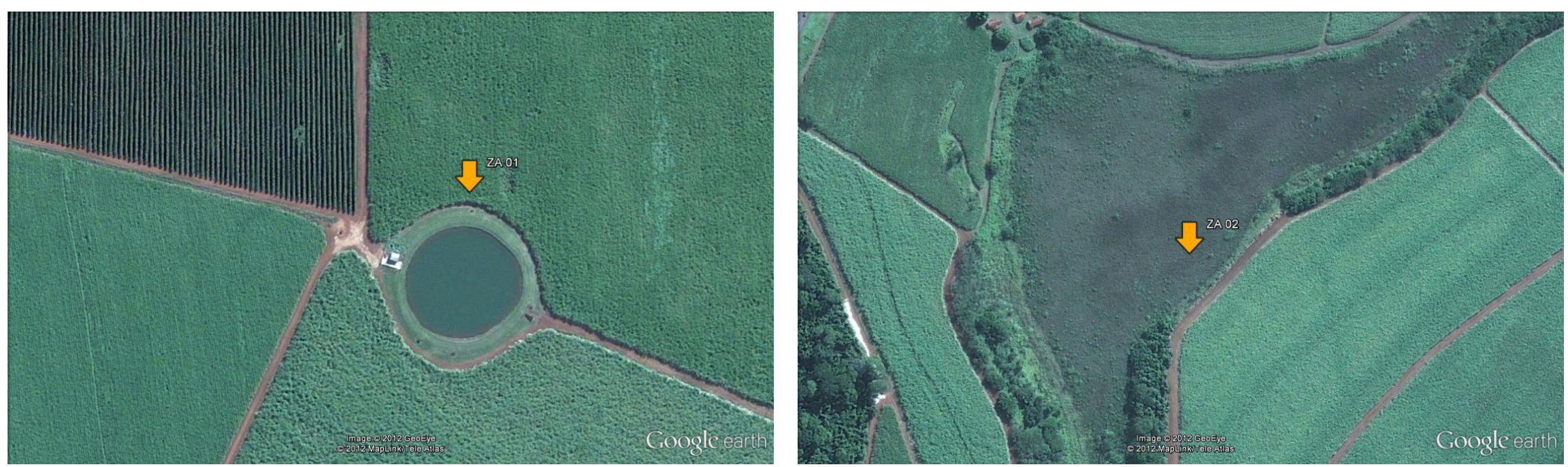

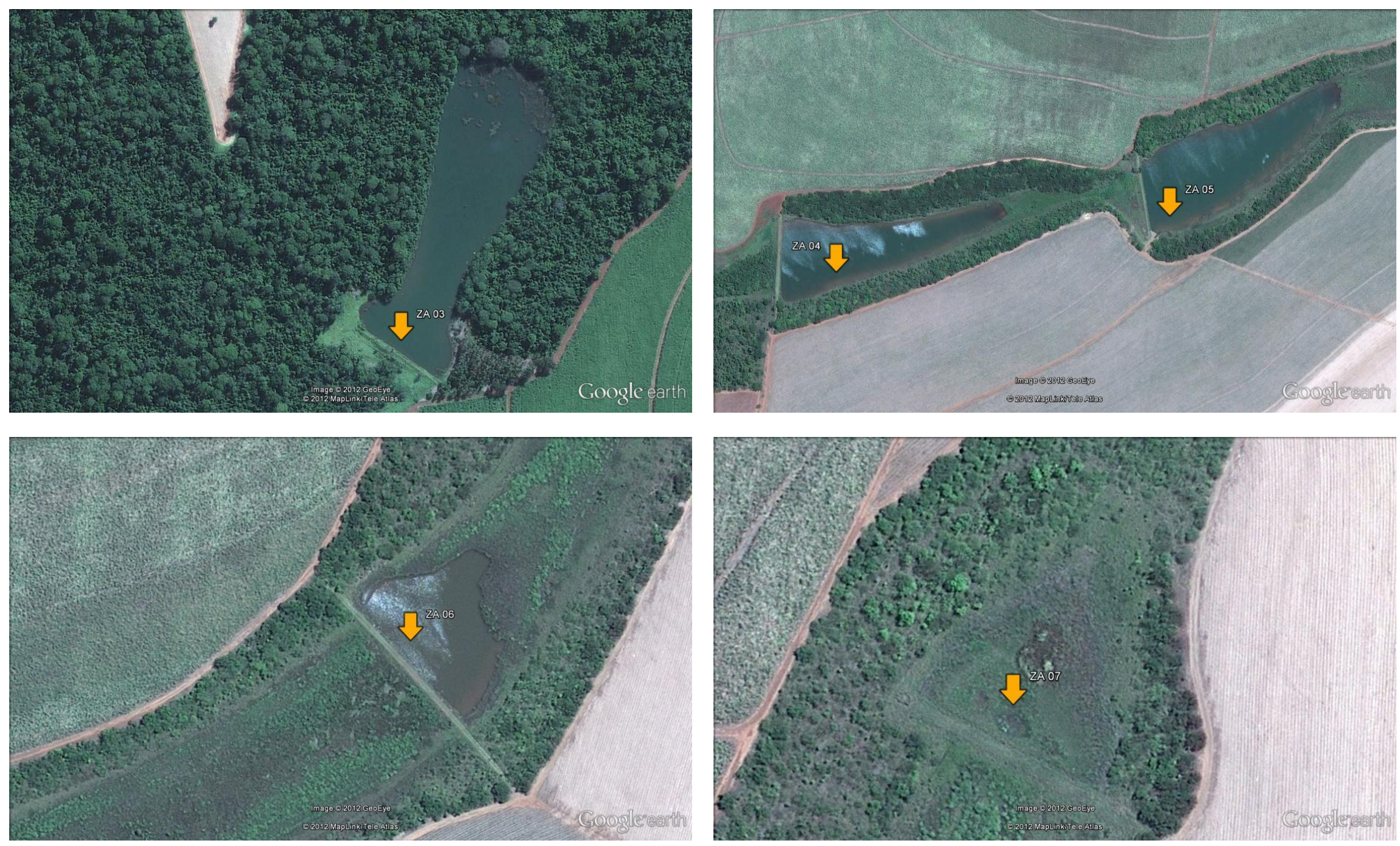

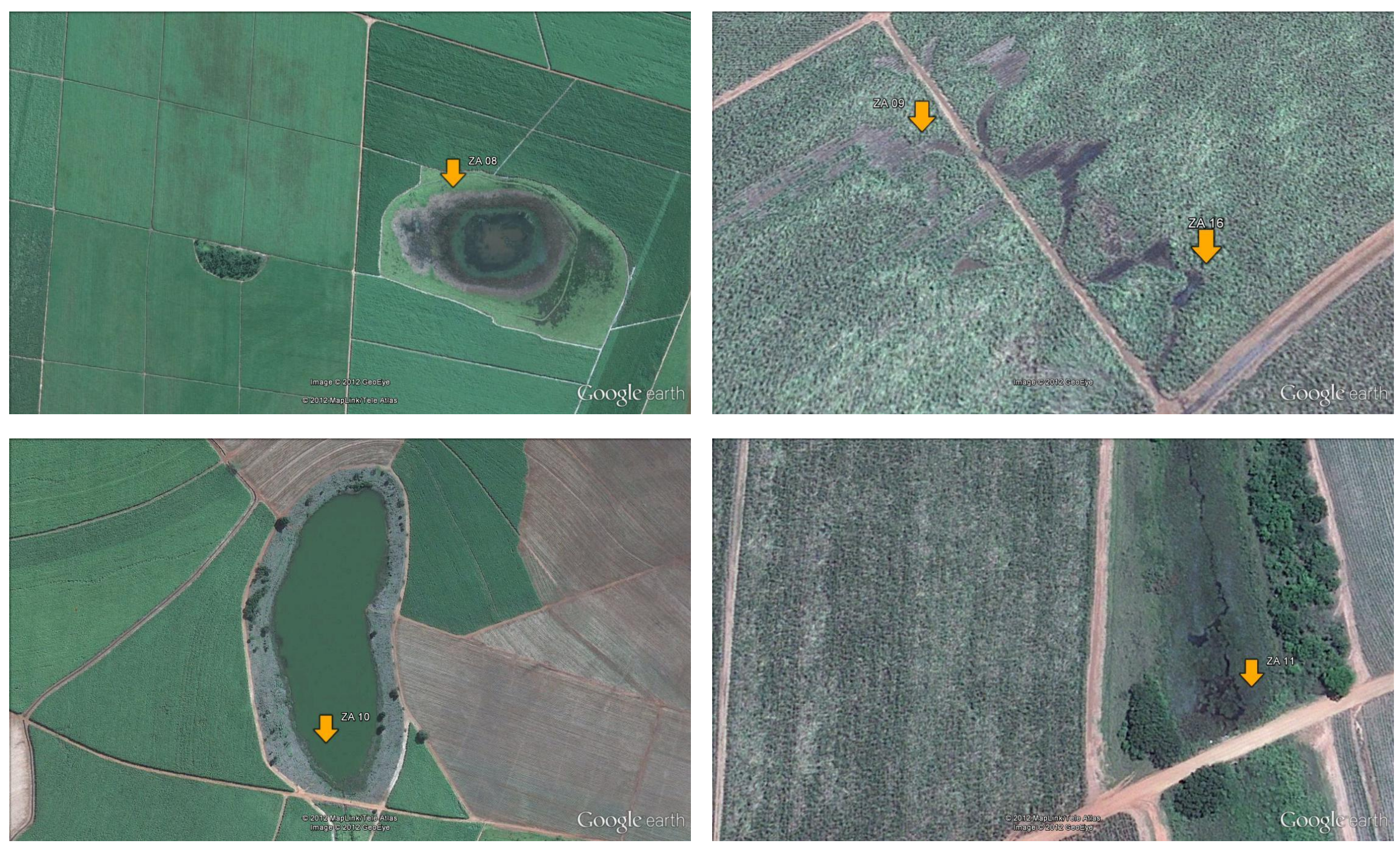

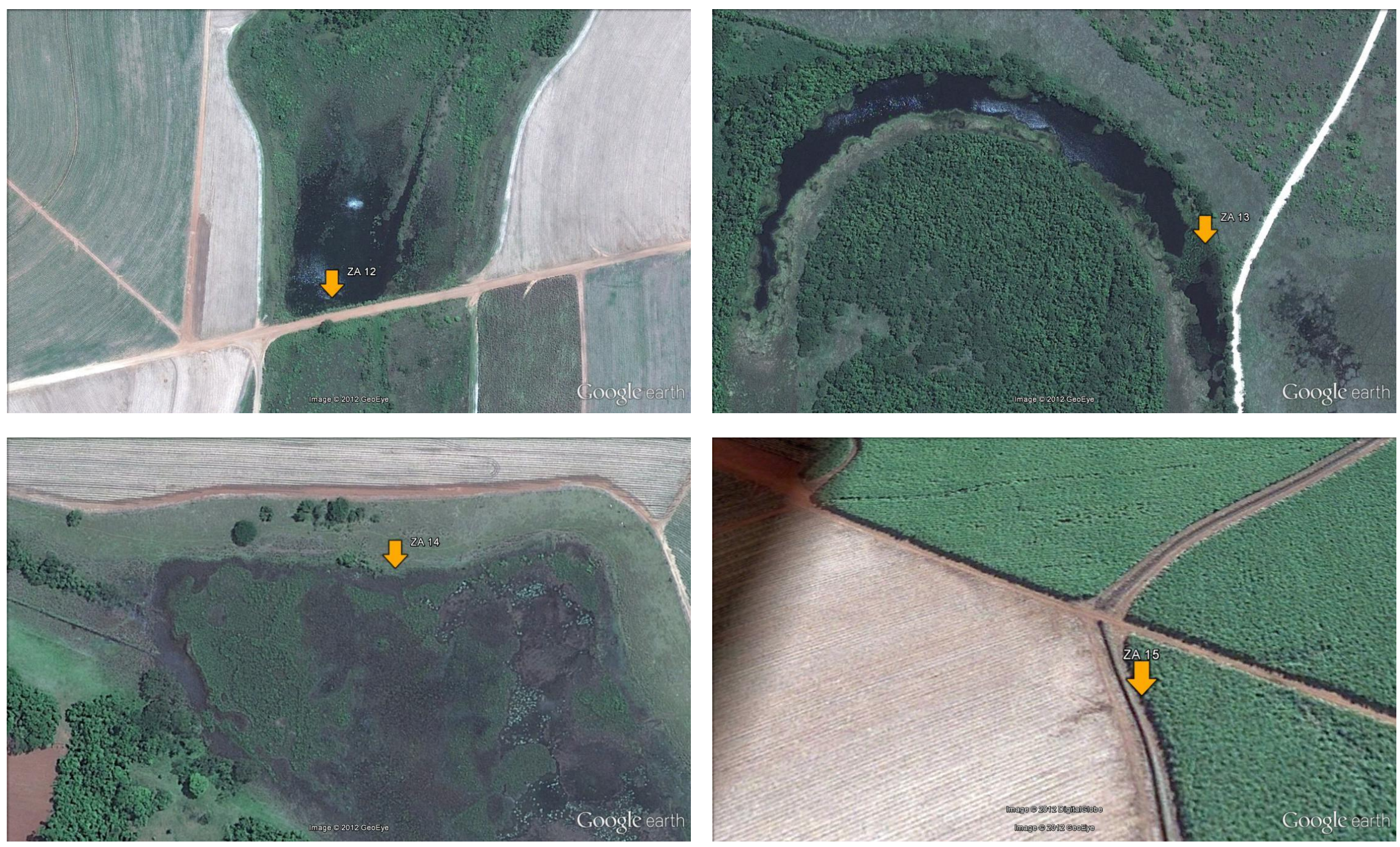

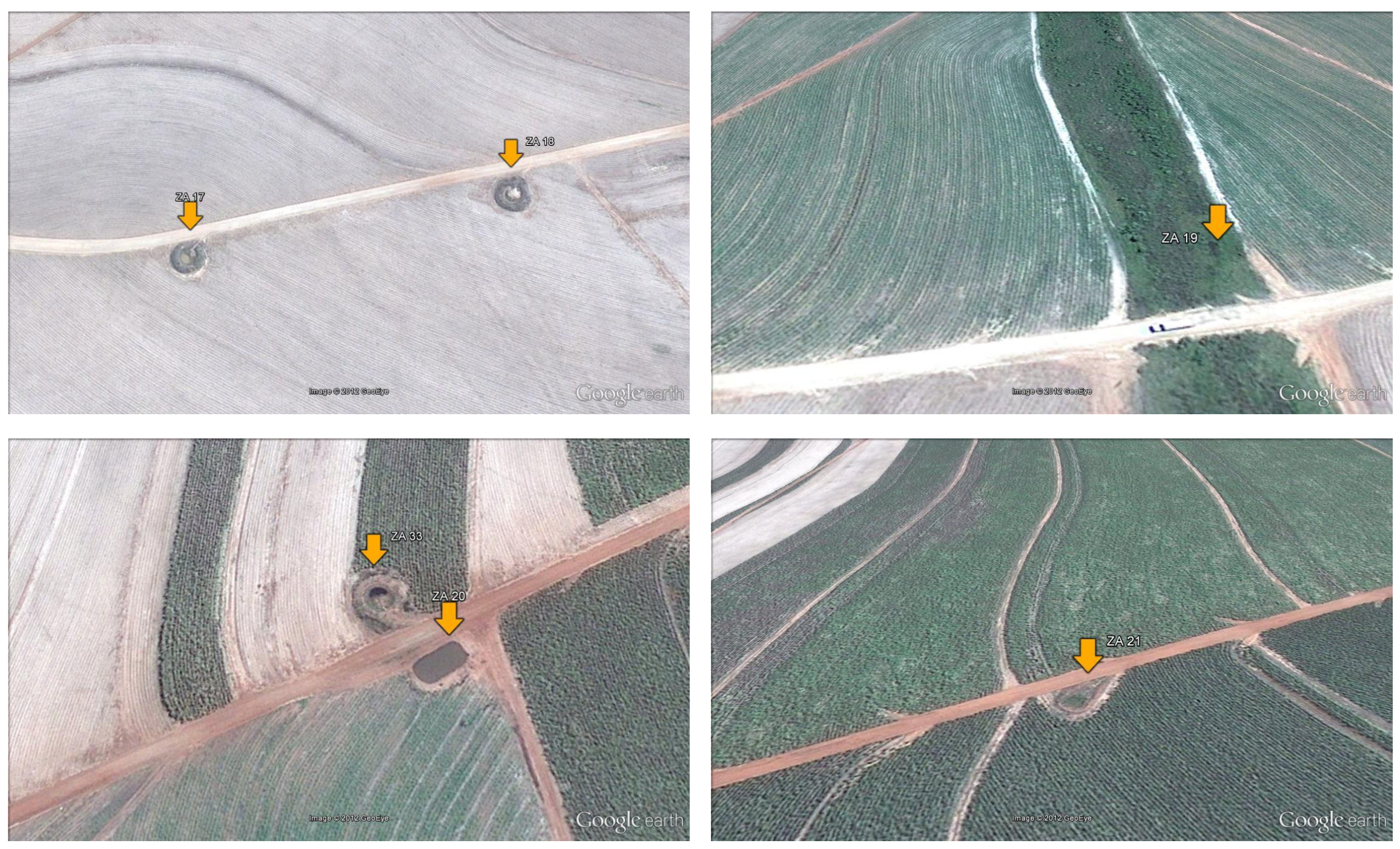

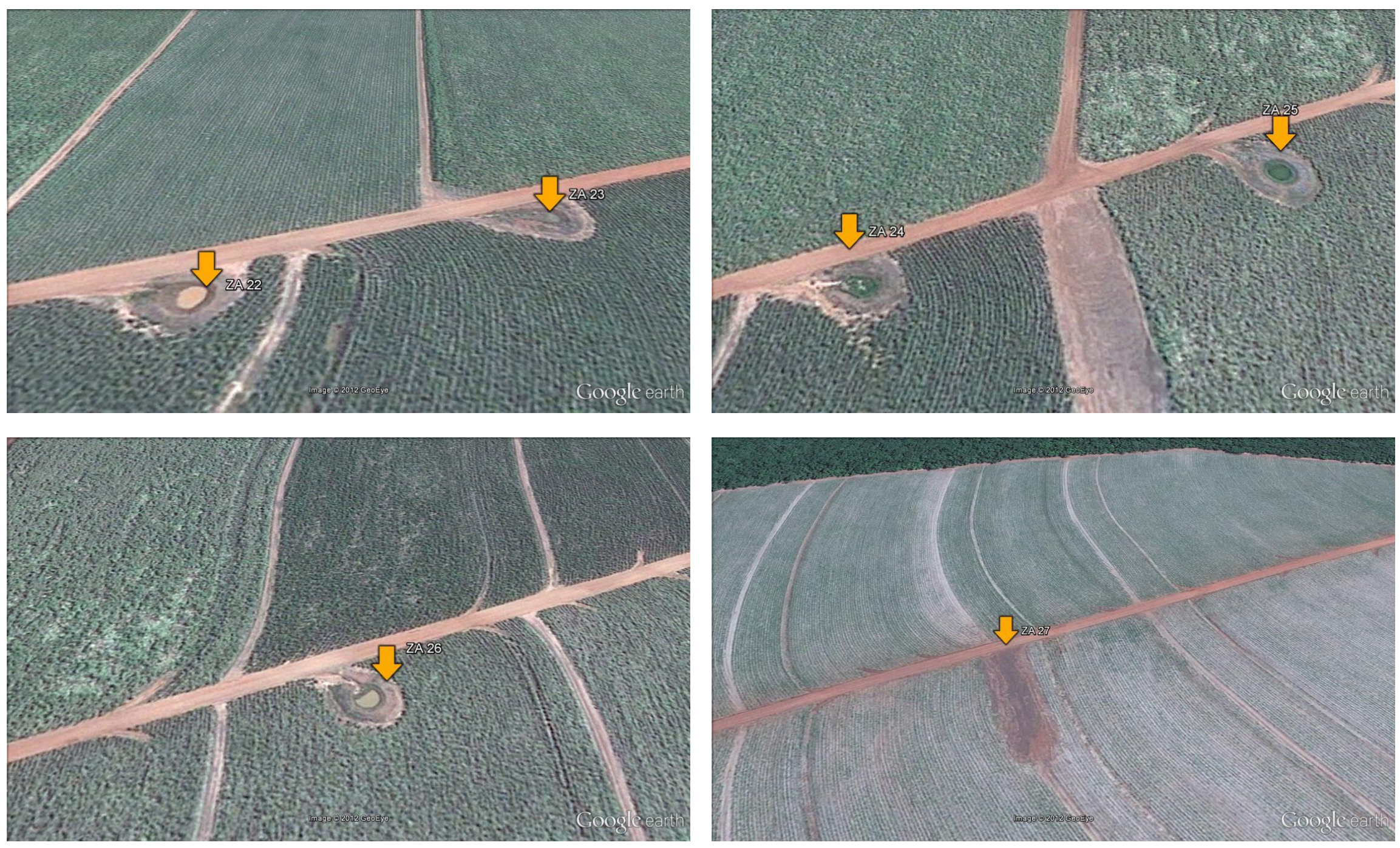

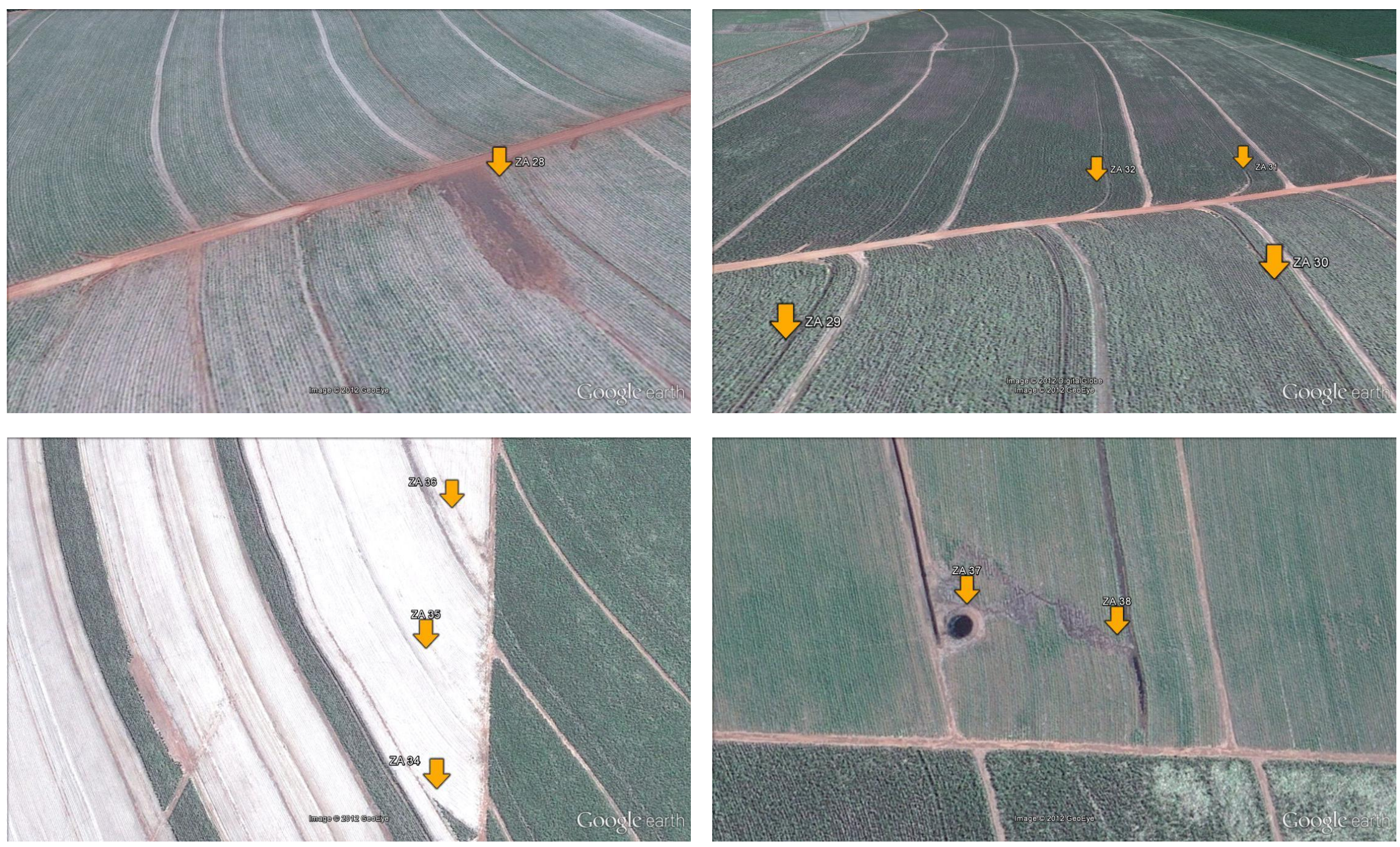

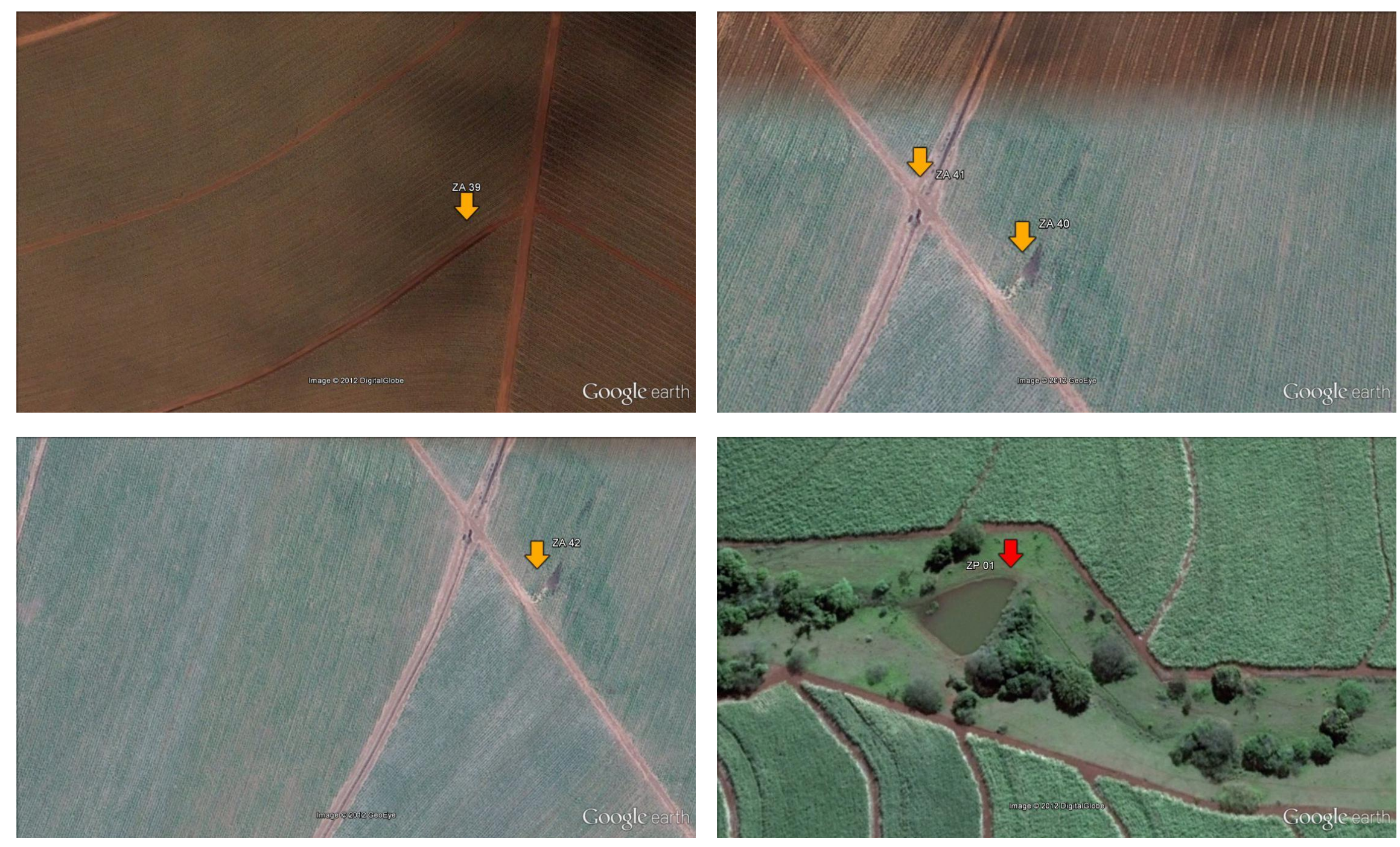

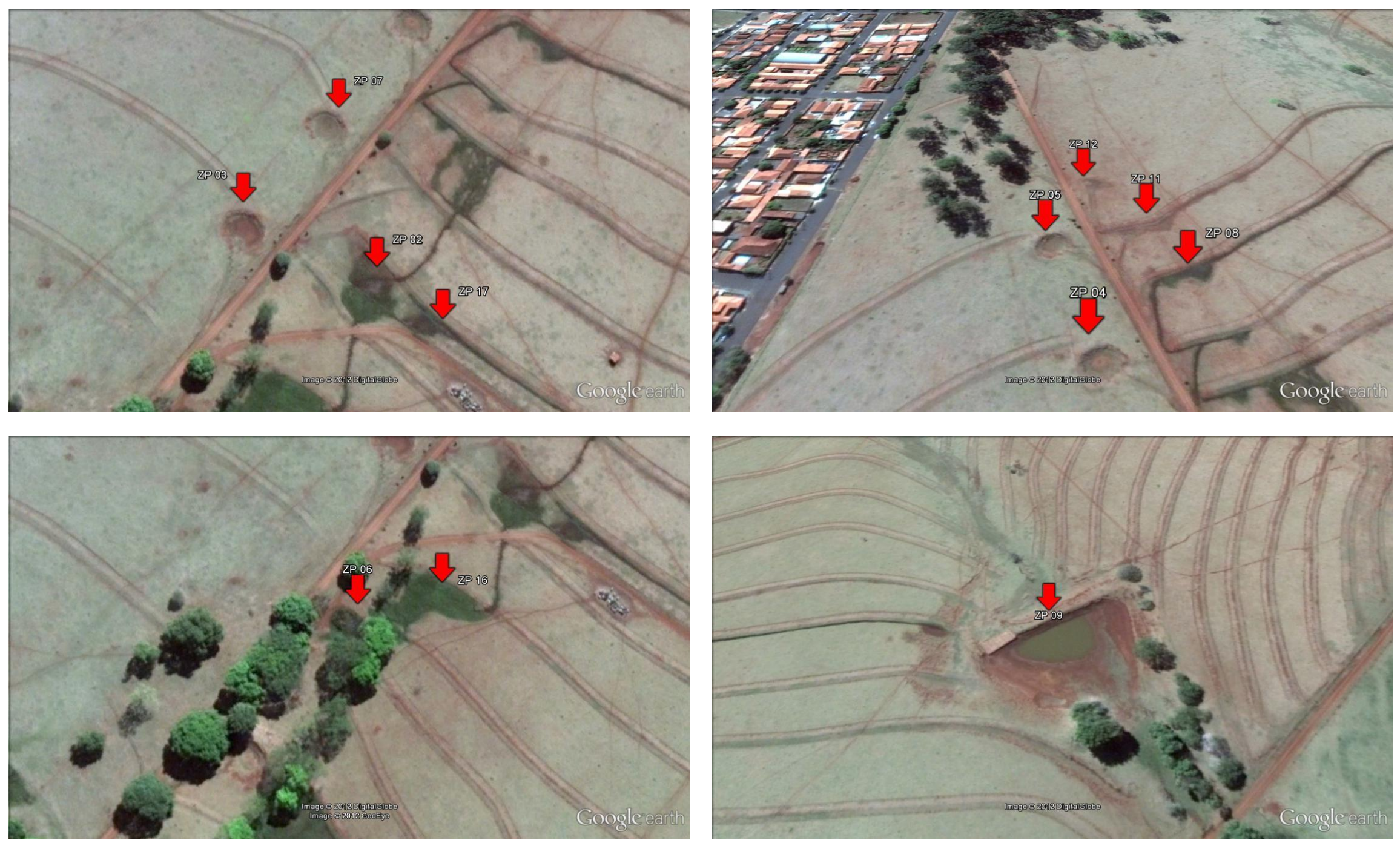

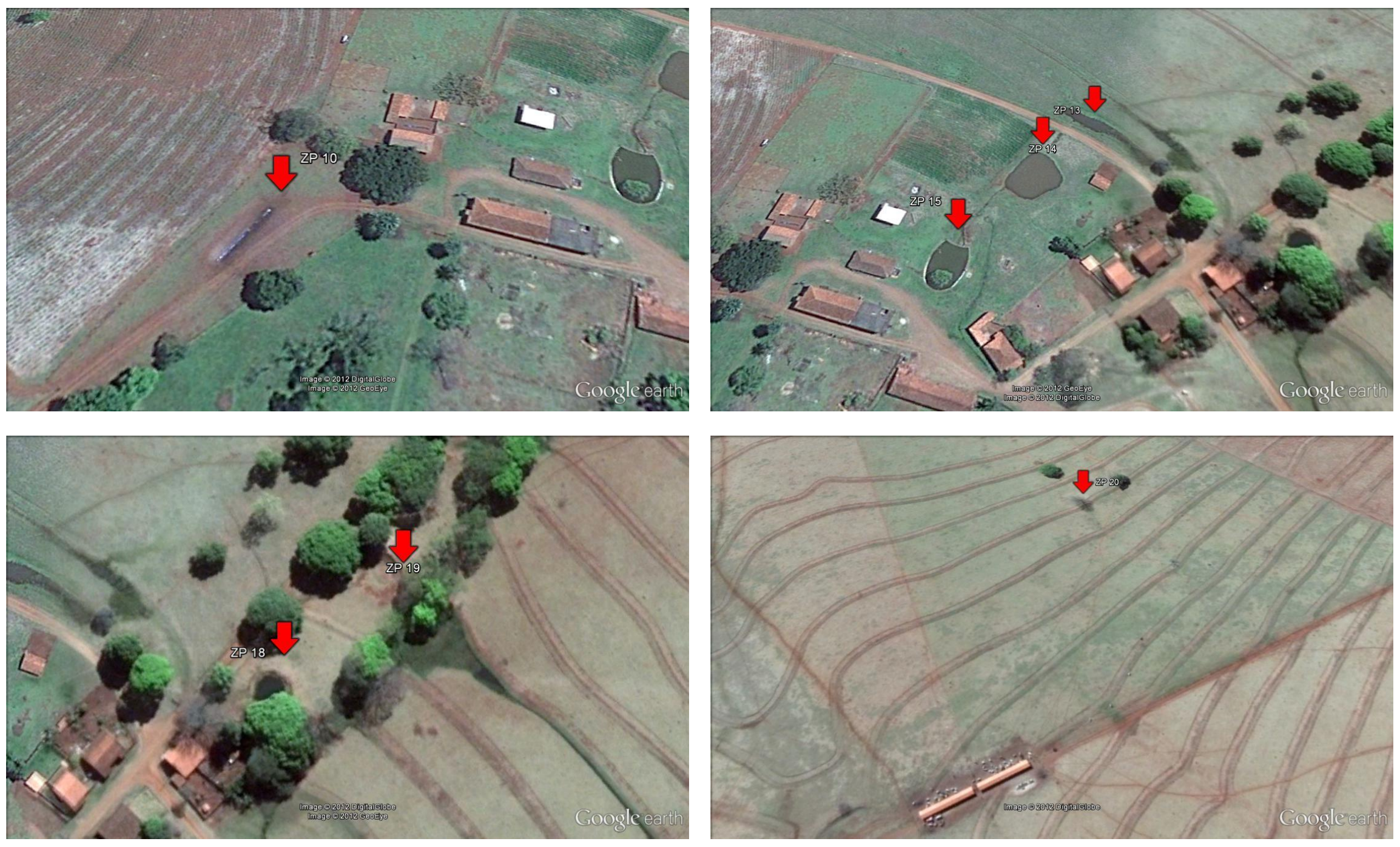

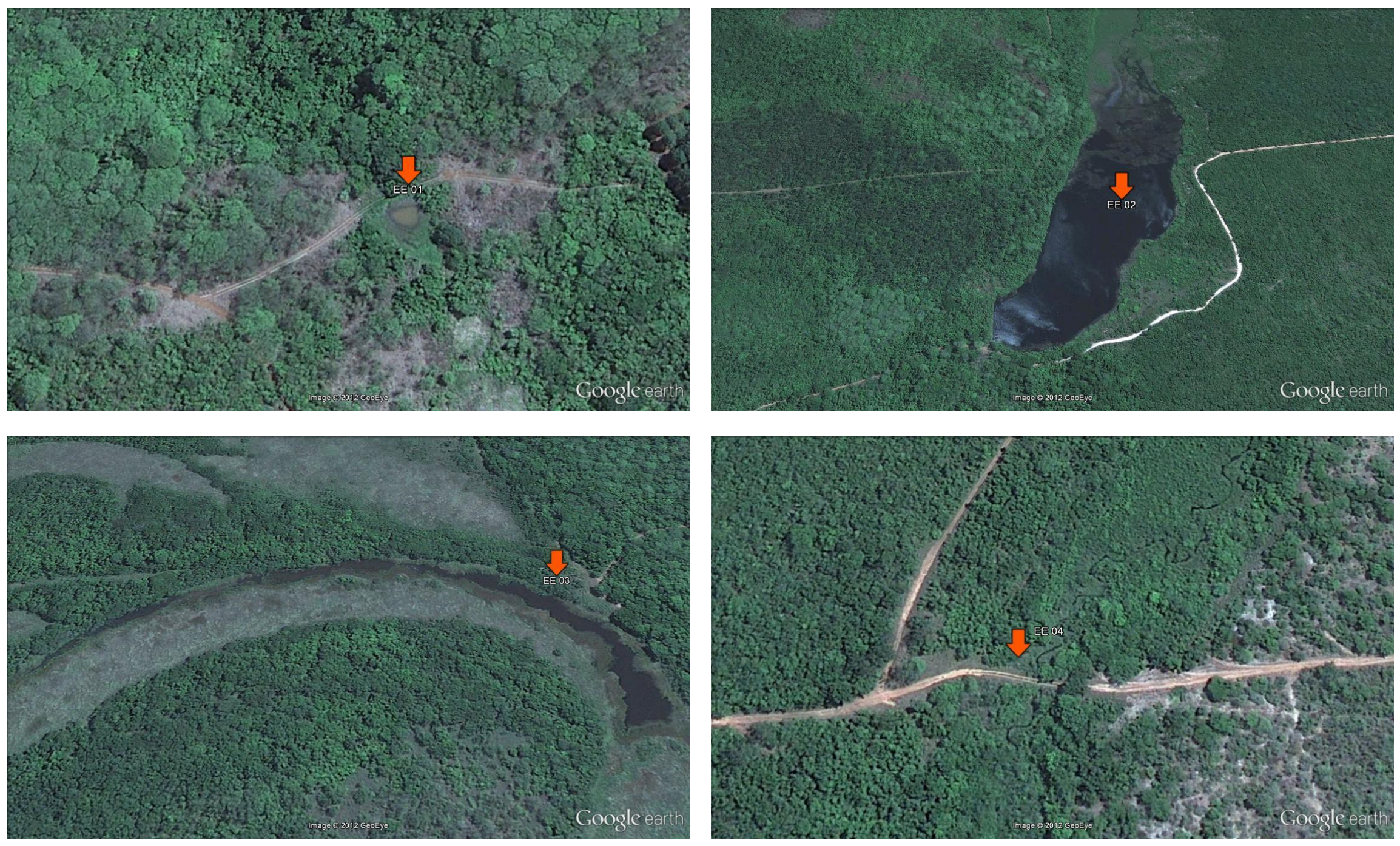

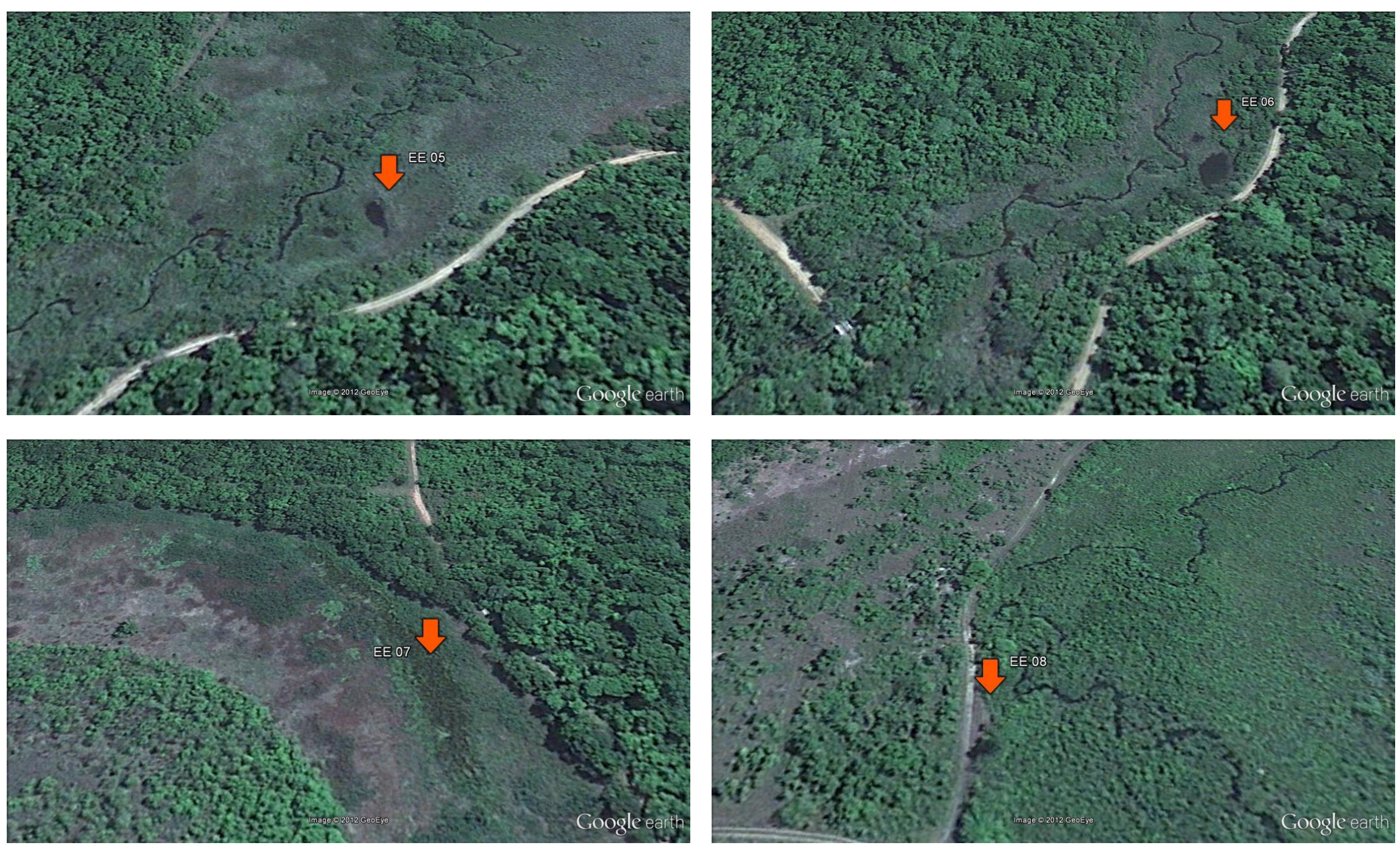

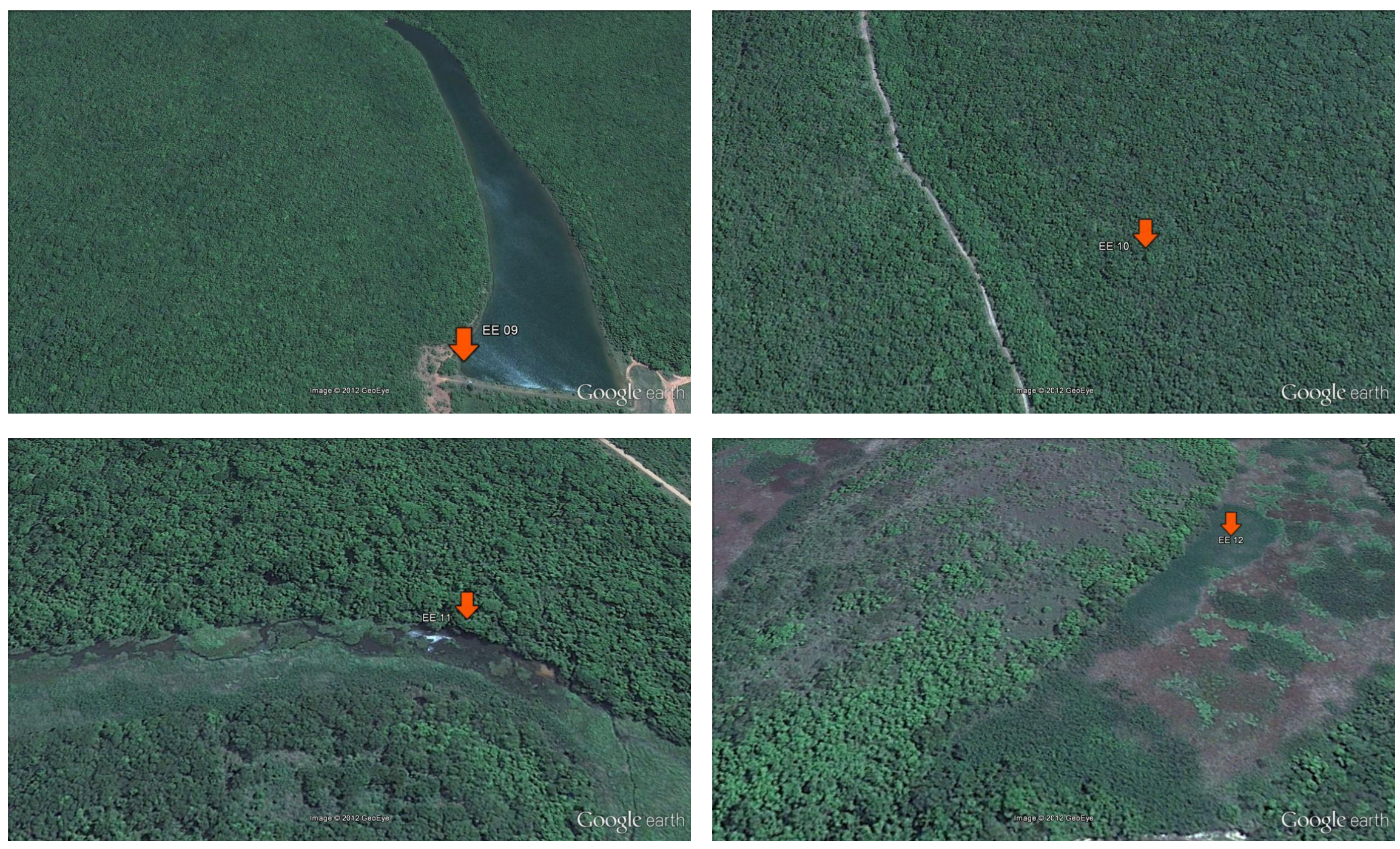

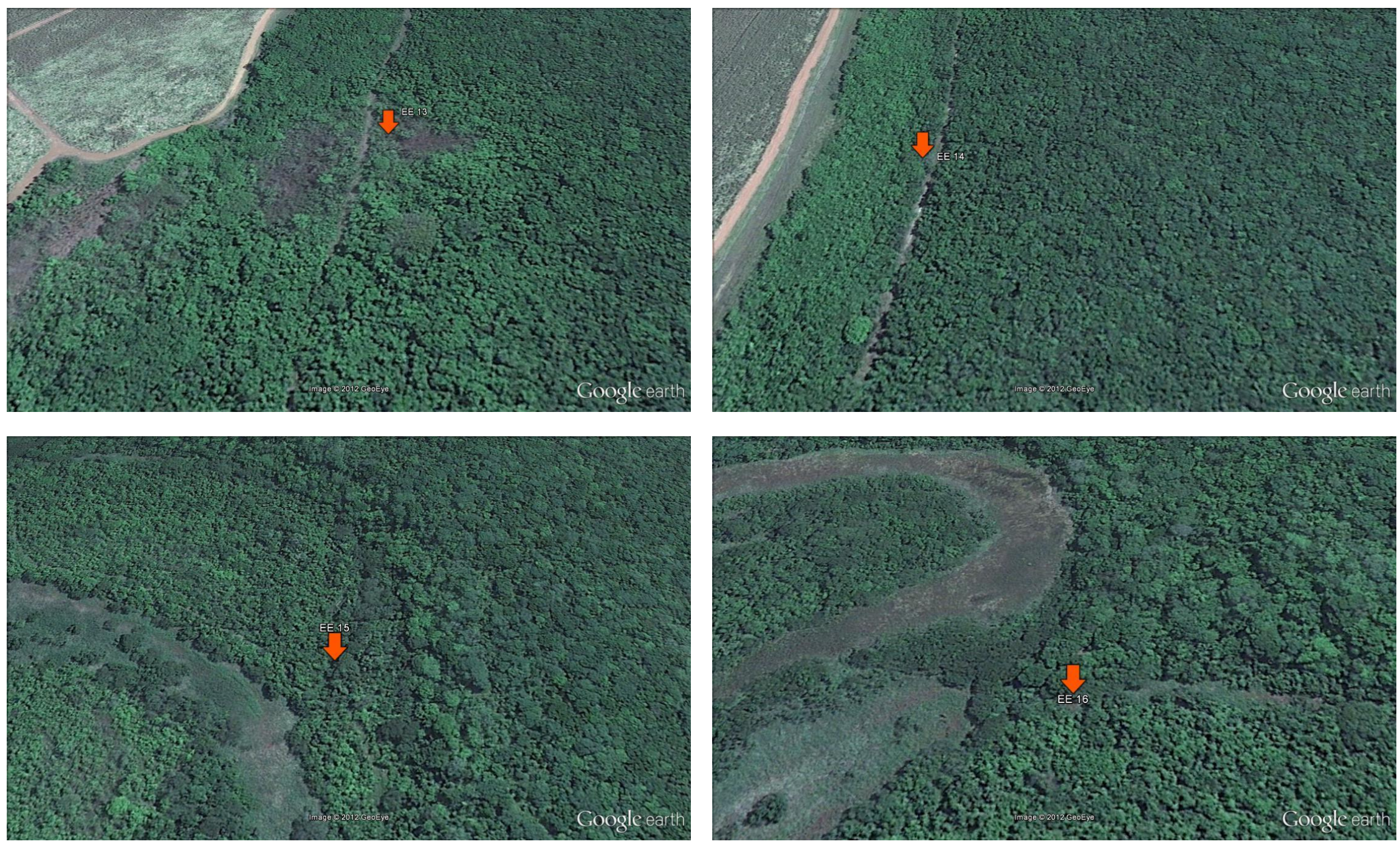

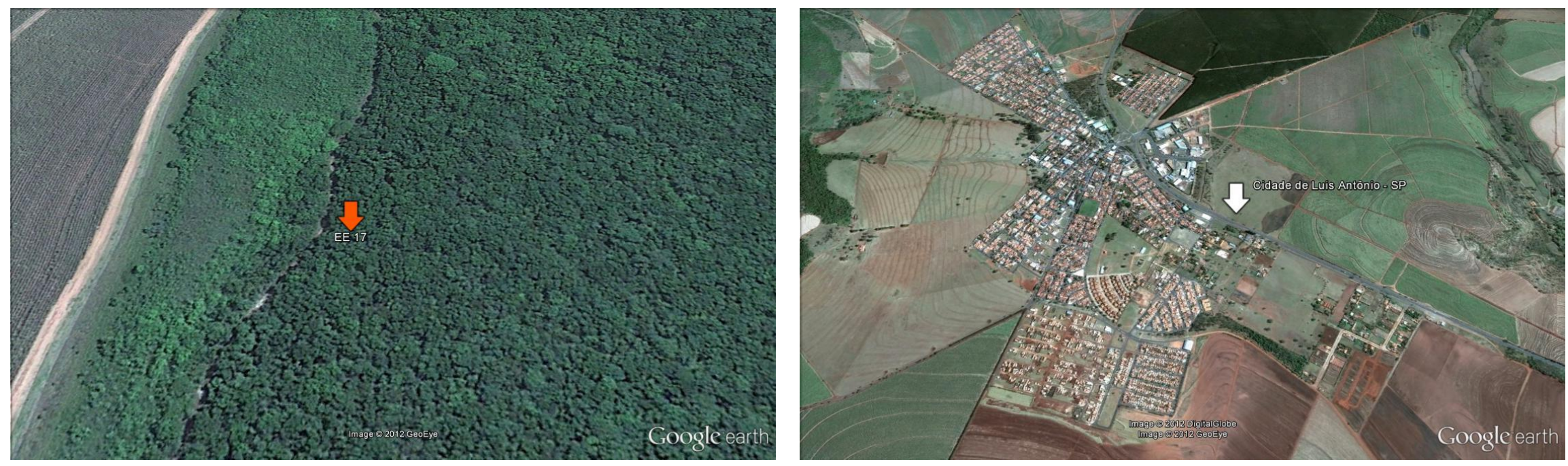


\section{Deus Seja Louvado}

